\title{
Cellulose-based fiber spinning processes using ionic liquids
}

\author{
Bahareh Azimi • Homa Maleki • Vito Gigante • Roohollah Bagherzadeh • \\ Andrea Mezzetta $\cdot$ Mario Milazzo $\cdot$ Lorenzo Guazzelli $\cdot$ Patrizia Cinelli $\cdot$ \\ Andrea Lazzeri $\cdot$ Serena Danti $($ i)
}

Received: 22 October 2021 / Accepted: 7 February 2022 / Published online: 7 March 2022

(C) The Author(s) 2022, corrected publication 2022

\begin{abstract}
Cellulose, a natural, renewable, and environment friendly biopolymer, has been considered as a sustainable feedstock in the near future. However, only $0.3 \%$ of cellulose is today processed since it is not soluble in conventional solvents due to the strong hydrogen bonding network and highly ordered structure. Hence, the search of effective and eco-friendly solvents for cellulose dissolution has been a key pillar for decades. In the recent years, ionic liquids (ILs) have been proposed as green solvents for cellulose and have been applied for the production of cellulose-based fibers. This review aims to focus the
\end{abstract}

B. Azimi · V. Gigante · M. Milazzo · P. Cinelli ·

A. Lazzeri $\cdot$ S. Danti $(\bowtie)$

Department of Civil and Industrial Engineering, University of Pisa, Largo Lucio Lazzarino 2, 56122 Pisa, Italy

e-mail: serena.danti@unipi.it

H. Maleki

Department of Carpet, University of Birjand,

Birjand 9717434765, Iran

R. Bagherzadeh

Institute for Advanced Textile Materials and Technologies (ATMT), Amirkabir University of Technology,

Tehran 1591634311, Iran

A. Mezzetta · L. Guazzelli

Department of Pharmacy, University of Pisa, Via Bonanno

6, 56126 Pisa, Italy

M. Milazzo $\cdot$ S. Danti

The BioRobotics Institute, Scuola Superiore Sant'Anna, Viale Rinaldo Piaggio 34, 56025 Pontedera (PI), Italy attention toward fiber spinning methods of cellulose based on ILs, as well as recent progress in cellulose dissolution using ILs. Moreover, the development of cellulosic fibers blended with other biopolymers, and cellulose composites are presented. Finally, different applications of cellulose fibers and composites are summarized and discussed.

Keywords Cellulose $\cdot$ Ionic liquid $\cdot$ Wet-spinning · Dry-jet-wet spinning $\cdot$ Electrospinning

\section{Introduction}

Environmental issues related to the use of fossil-fuelbased materials, such as green gas emissions, human health impacts, among others, have encouraged researchers to replace petroleum-derived products with sustainable nature-friendly materials. In view of this, cellulose is one of the most abundant natural resources on earth, harvested from plants, animals, and bacteria, which can be easily processed and fairly functionalized. Nearly one trillion tons of the world annual biomass production is based on cellulose fibers or derivatives and, to date, cellulose has played a relevant role in the growth of numerous eco-friendly materials, which can affect (bio) economy in the future. Cellulose is considered as an infinite source of feedstock for the growing demand for environmentally friendly materials since it is regularly regenerated by nature in relatively short periods 
of time (Brinchi et al. 2013). As a polysaccharide, cellulose has several desired features for (bio)engineering applications, such as hydrophilicity, biocompatibility, biodegradability, and proper mechanical properties (tensile strength $\sim 120 \mathrm{MPa}$ and Young's modulus $\sim 2 \mathrm{GPa}$ ). Cellulose fibrils include crystalline and amorphous segments. Cellulose nanocrystals (CNC) and cellulose nanofibers (CNF) can be generated using chemical treatments and mechanical processes, respectively, which can be considered as two main categories of plant-derived nano-cellulose (NC) (Moon et al. 2011). Aiming at developing new functionalities and to attaining a variety of environmental and social goals, there has been a relevant interest in producing continuous fibers from bio-based materials (Fig. 1).

Hence, considerable attempts have been made to investigate the spinning of continuous fibers from cellulose to nano-cellulose. Cellulose fibers have been produced from cellulose solutions for more than hundred years (Woodings 2001). Although they have been applied in textiles traditionally, the interest in using them as polymeric reinforcements has also increased (Adusumali et al. 2006; Ganster and Fink 2006). These fibers are more attractive than other natural fibers (e.g., flax), due to their lower variability in fiber length, morphology and biochemical composition of the plant. Man-made cellulose fibers are produced by pursuing different methods that include a first dissolution followed by the actual process. Although the production of pure cellulose fibers is still challenging, wet-, dry-, dry-jet-wet and electrospinning techniques have been successfully used as procedures to produce continuous cellulose fibers in micro- and nano-dimensions. In fact, cellulose is scarcely soluble in common solvents due to the extensive inter- and/or intra-molecular hydrogen bonding. In addition to its low solubility, cellulose is also not meltable and, thus, it is impossible to use the meltspinning technique. Therefore, cellulose processing has required either a chemical derivatization or a physical dissolution in appropriate solvents.

Viscose and Lyocell procedures are currently the only two technologies that have been industrially developed for the generation of manmade cellulosic fibers. Nevertheless, they show issues related to the applied solvents within the cellulose dissolution stage. For example, during the viscose procedure, the use of highly toxic chemicals and the formation of gases can be harmful for workers and the environment. Hence, environmental pollution and safety costs have become a serious concern. For the $\mathrm{N}$-methyl morpholine-N-oxide (NMMO monohydrate)-based Lyocell process that is now
Fig. 1 Schematic illustration of the topics presented in this review article: cellulose from different sources as a sustainable naturefriendly material

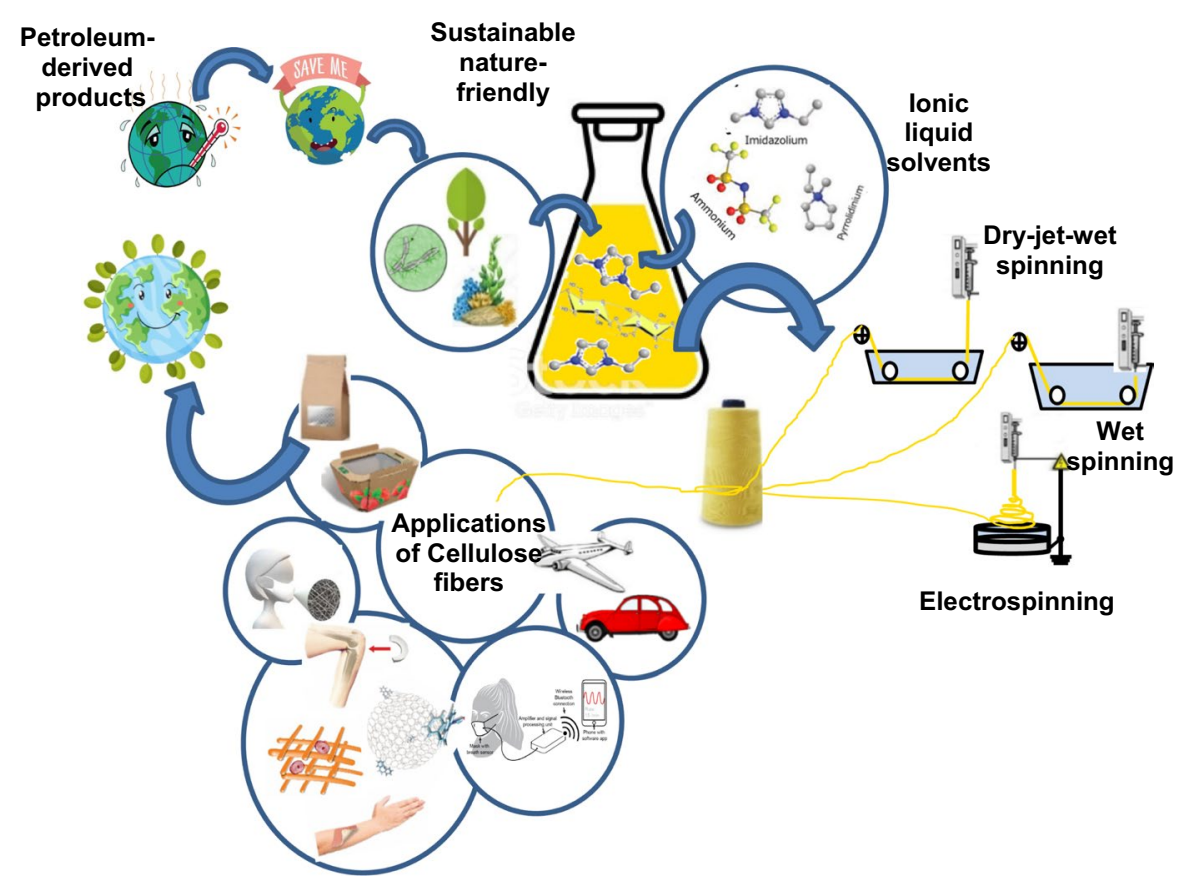


the only commercialized alternative to the spinning process of Viscose, there are also several limitations, such as poor thermal stability of the solvent, degradation of both the solvent and the cellulose due to the formation of by-products which require a large amount of stabilizers, high safety costs, complex dissolving techniques, serious solvent recovery procedures, and low productivity due to the low solubility of cellulose in the solvent (Rosenau et al. 2002, 1999, 2001). Owing to high-market demand for bio-based textiles and sustainable fashion products, the development of green spinning technologies is essential for the production of man-made cellulosic fibers. Practically, this requires the finding of green solvents that can dissolve raw celluloses effectively (Meksi and Moussa 2017).

Recently, room-temperature ionic liquids (ILs) have emerged as interesting green solvents that can efficiently dissolve and process biopolymers, such as silk (Goujon et al. 2012), wool (Zheng et al. 2015), chitin (Shamshina 2019), chitosan (Xie et al. 2006), lignocelluloses (Asim et al. 2019), wood, and cellulose (Morais et al. 2020). By virtue of their advantages, such as high dissolving ability, based on disruption of the hydrogen bond pattern present in the native polysaccharide (Pinkert et al. 2009), low vapor pressure (Welton 2018), chemical (Wang et al. 2017) and thermal stability (Maton et al. 2013), non-flammability, recyclability, and limitless number of possible structures (Singh and Savoy 2020), these new solvents have gained attention for cellulose processing, and have been used to produce a number of regenerated cellulose materials (Berga et al. 2020; Mezzetta et al. 2019a) and cellulose derivatives (Becherini et al. 2019; Ferreira et al. 2019).

This review encompasses the description of the basic concepts of ILs, their use to fabricate macro/ nano cellulose fibers, including the specifications for dissolving cellulose, the rheological features of cellulose-IL solutions in view of different manufacturing methods (i.e., wet-spinning, dry-jet-wet spinning, and electrospinning). Moreover, we review the development of new cellulose-based materials (e.g., composites or blend with other biopolymers), and we conclude with a perspective in the field. This comprehensive overview of the current knowledge on cellulose/IL systems and spinning technologies aims at encouraging further research towards the development of fully green products for the textile market.

\section{Ionic liquids}

ILs are organic salts characterized by a melting point lower than $100{ }^{\circ} \mathrm{C}$. Asymmetrical organic cations in combination with either organic or inorganic anions generally destabilize the crystal lattice packing thus favoring the liquid state of the system in terms of enthalpy and entropy. The most intriguing peculiarity of these liquid salts is the possibility to modify their chemical and physical properties (e.g., viscosity, conductivity, hydrophilicity, hydrophobicity, polarity, hydrogen bond forming ability) by an appropriate selection of cation and anion, or by the introduction of specific functional groups in the chemical structure (Branco et al. 2011; Rabideau et al. 2020). Figure 2a shows some common IL cations and anions.

Within the last twenty years, ILs and the so-called room temperature ILs (RTILs), namely ILs which are liquid at room temperature, have gained attention for their potential application in several chemical fields including their use as solvents and catalysts for chemical syntheses (Clarke et al. 2018; Keaveney et al. 2017), separation technologies, or electrochemistry (Pereira et al. 2018). Noteworthy, ILs show unique properties such as high chemical and thermal stability (Maton et al. 2013; Mezzetta et al. 2019b), low vapor pressure, and no flammability (Singh and Savoy 2020; Welton 2018). Furthermore, the structural features of these ionic media provide unique chemical environments, which ultimately allow for the dissolution of several organic and inorganic species via specific interactions (Hayes et al. 2015).

For these reasons, ILs possess a superior dissolving capability even towards biopolymers, such as keratin (Idris et al. 2013) or cellulose that are difficult to dissolve in conventional solvents (Pinkert et al. 2009; Zhang et al. 2017a). Therefore, the interest for processing biopolymers with ILs has grown significantly in recent years. The high variability of ILs, due to the possibility of a combination of different cations and anions, leads to the development of new solvents endowed with specific properties that enable the dissolution of almost any specific substrate (Forsyth et al. 2004; Izgorodina et al. 2007).

However, the selection of a proper IL for biopolymer dissolution cannot be based only on the dissolution capability: other parameters like eco-toxicity and recyclability of the solvent, rheological properties of IL-biopolymer solutions, and characteristics of the 
a<smiles>[2H]N1CCCC1</smiles>

Pyrrolidinium<smiles>[2H]c1sc([2H])[n+]([B])c1[2H]</smiles>

Thiazolium<smiles></smiles>

Imidazolium<smiles></smiles>

Pyridinium<smiles>[2H]B([B])[B]</smiles>

Sulfonium<smiles>[2H][N+]([2H])([2H])[13CH][13CH]</smiles><smiles></smiles>

Pyrazolium<smiles>[B][Pb]1CCCCC1</smiles>

Piperidinium<smiles>[2H]P([2H])([2H])([2H])[2H]</smiles>

Phosphonium

$$
R_{1}, R_{2}, R_{3}=H \text { or alkyl }
$$
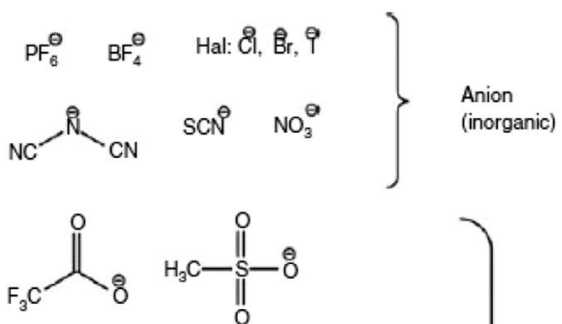

cation<smiles>O=S(=O)([O-])C(F)(F)F</smiles>

[DTf-<smiles>Cc1ccc(S(=O)(=O)Cl)cc1</smiles>

$\left[\mathrm{p}-\mathrm{Ph}-\mathrm{SO}_{3}\right]^{-}$

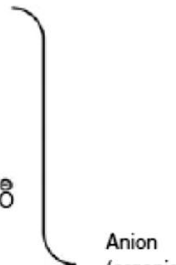

b
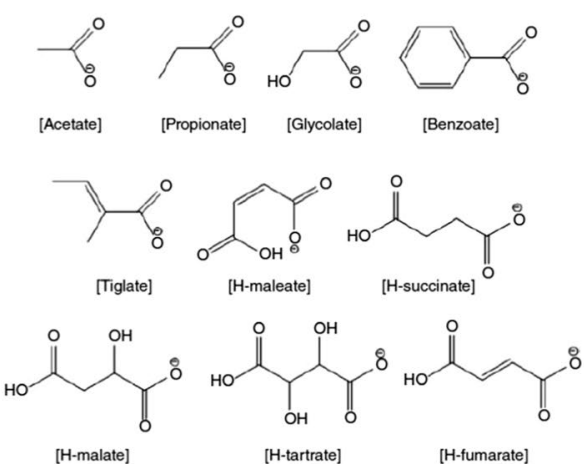<smiles>CC(=O)CCC(=O)[O-]</smiles>

Fig. 2 a Examples of common IL cations and anions, b Chemical structure of nontoxic anions (Pereira et al. 2018)

regenerated biopolymer, must be considered in the process. In fact, ILs are not always innocent media towards dissolving biopolymers. For example, Nie and Zang (2017b) investigated how the structure of different ILs impacted keratin microstructure and the disulfide cross-linking network in regenerated keratin, while Shamshina and Berton (2020) reviewed the use of ILs in the depolymerization and deacetylation of chitin. The effect of ILs on the microstructure of cellulose after dissolution was analyzed in detail compared to other biopolymers. For instance, it is well known that the solubilization of cellulose in ILs leads to a variation of the degree of crystallinity, and this variation depends on the working conditions and ILs nature (Ling et al. 2017). Furthermore, reactions of solvated cellulose in ILs have been extensively reported and discussed in the literature: ILs have been used as solvents and catalysts for homogeneous functionalization of cellulose (Hanabusa et al. 2018) and for its transformation into low molecular weight molecules (Asim et al. 2019). Beyond these reactions, also undesired side reactions between cellulose and ILs have been observed. New chemical species can affect the properties of reprocessed cellulose material and the recyclability of ILs.

For example, for the first time Enber et al. (2008) described the reaction between C-2 of imidazoliumbased ILs and cellulose. Clough et al. (2015) also reported that imidazolium carboxylate ILs react with cellulose through the reactive $\mathrm{C} 2$ position of the imidazolium ring to generate a series of intermediates.

Liebert and Heinze considered three paths for side reactions of imidazolium salts including the fairly high reactivity of the anion as a nucleophile, the 
abstraction of the C-2 proton of the 1,3-alkylimidazolium moiety, and ring-opening reactions (Liebert and Heinze 2008). They indicated that using C-2 alkyl substituted imidazolium ILs for the etherification of cellulose can decrease side reactions.

Other works (Gazit and Katz 2012; Michud et al. 2015a) reported the depolymerization of cellulose when imidazolium cations are used in combination with different anions. The Laborie groups (Abushammala et al. 2017; Zweckmair et al. 2015) analyzed the mechanism of the unwanted acetylation of cellulose by 1,3-dialkylimidazolium acetate ILs.

However, the in-depth study of many IL/cellulose systems allows for tuning different interactions of ILs with cellulose (Bodachivskyi et al. 2020; Clough et al. 2015). Therefore, the appropriate selection of processing conditions (e.g., type of cellulose, solvent, temperature, time, and even addition of co-solvent or additives) and the knowledge of IL characteristics permit the suppressing of side reactions while enabling the selective production of desirable cellulosederived materials.

\section{Cellulose dissolution issues and role of ILs}

The crystal structure of cellulose has a complex hydrogen bond (H-bond) network between the hydroxyl groups of glucose units of the same chain/ of different chains (Lindman et al. 2017). The intermolecular and intramolecular hydrogen bonds not only provide affordable strength and toughness of cellulose crystals and excellent mechanical properties, but also render cellulose insoluble in water and in most organic solvents, thus limiting its reactivity and processability for utilization. The issue of cellulose dissolution, to make this biopolymer usable in disparate processing and spinning operations, has always been on the agenda of scientific research in the last few years (Berga et al. 2020; Medronho and Lindman 2015). Before the introduction of ILs, alternative cellulose solvents and their limitations have been investigated.

In 1934, a combination of $N$-ethyl pyridinium chloride and nitrogen-containing bases was reported to dissolve cellulose (Graenacher 1934). In 1985, an improvement of cellulose solubility was observed by exploiting $\mathrm{N}, \mathrm{N}$-dimethylacetamide (DMAc)/ lithium chloride $(\mathrm{LiCl})$ and also with $N$-methyl pyrrolidone
(NMP)/LiCl (McCormick et al. 1985). However, solvent systems such as (DMAc)/LiCl, sodium hydroxide $(\mathrm{NaOH}) /$ urea, dimethyl sulfoxide (DMDO) (DMSO)/tetrabutylammonium fluoride (TBAF), have shown severe limitations including complex dissolving procedures, low solubility, hard solvent recovery processes, relevant energy costs, volatility, toxicity, gas pollution, and polymer degradation, thus limiting their large-scale use in industrial processes ( $\mathrm{Li}$ et al. 2018). Due to the economic and environmental drawbacks of cellulose dissolution and processing, more efficient and environmentally friendly solvents have thus become a subject of intensive research.

In 2002, ILs have been explored for the processing of cellulose to replace conventional noxious solvents. They can be considered as the new generation of solvents for a more sustainable industrial development (Swatloski 2002). The dissolution of cellulose using ILs can construct a new platform for "green" cellulose usage and can also provide, a "green" possibility of nanocellulose preparation (Zhu et al. 2006). The main advantage of this procedure is that cellulose can be easily regenerated by the addition of a non-solvent (e.g., water). NMMO monohydrate-based Lyocell process is so far the benchmark spinning process. In fact, NMMO monohydrate has one major advantage over ILs, since a considerable amount of water can be left in the system during its recovery. The increased water sensitivity of ILs requires energy-intensive evaporation of water down to a low weight percentage and is a cost factor to be considered.

In addition to cellulose fiber production, IL-technology also provides new opportunities to construct composites and also allows the in situ chemical modification of cellulose during the spinning process (Hermanutz et al. 2019).

Heinze et al. (Kostag et al. 2018) presented a comprehensive review about the dissolution process of cellulose in ILs. Several research works have shown that cellulose solubility in ILs is strongly dependent on (i) process parameters like time required for dissolution, temperature, or heating method, (ii) cellulose parameters like degree of polymerization or crystallinity, and (iii) ILs parameters like, purity, water content or ILs structure (Schlufter et al. 2006; Swatloski 2002). The efficiency of the ILs in the dissolution process depends on the polarity and the hydrogenbonding ability between IL components and cellulose chains (Figueiredo et al. 2015). It is generally 
believed that $\mathrm{H}$-bond formation between anions and the hydroxyl groups of cellulose is the main driving force for cellulose dissolution in ILs (Fig. 3b). Indeed, the high ionic strength of the ILs allows for disrupting the inter-and intramolecular hydrogen-bondingbased interactions present in pristine cellulose chains (Kostag et al. 2018; Vitz et al. 2009). Specifically, the intermolecular anhydro glucose units (AGUs) of cellulose are bonded by H-bonds between the equatorial $\mathrm{OH}$ of $\mathrm{C} 3$ and the oxygen of $\mathrm{C} 6$ of an adjacent chain. In this way, cellulose molecules are linked in a layer, and the hydrophobic interactions, due to the axial $\mathrm{CH}$ of $\mathrm{AGU}$, hold together the layers forming the conformation of native cellulose (cellulose I) and of other allomorphs (cellulose II, IIII and IV, etc.) (El Seoud et al. 2020; Nishiyama et al. 2002). Physical dissolution of cellulose requires the disruption of the intramolecular H-bonds between the hydroxyl groups of the AGUs, as well as the hydrophobic interactions present between the layers.

Starting from the pioneering work of Swatloski et al. (2002) cellulose dissolution mechanism in
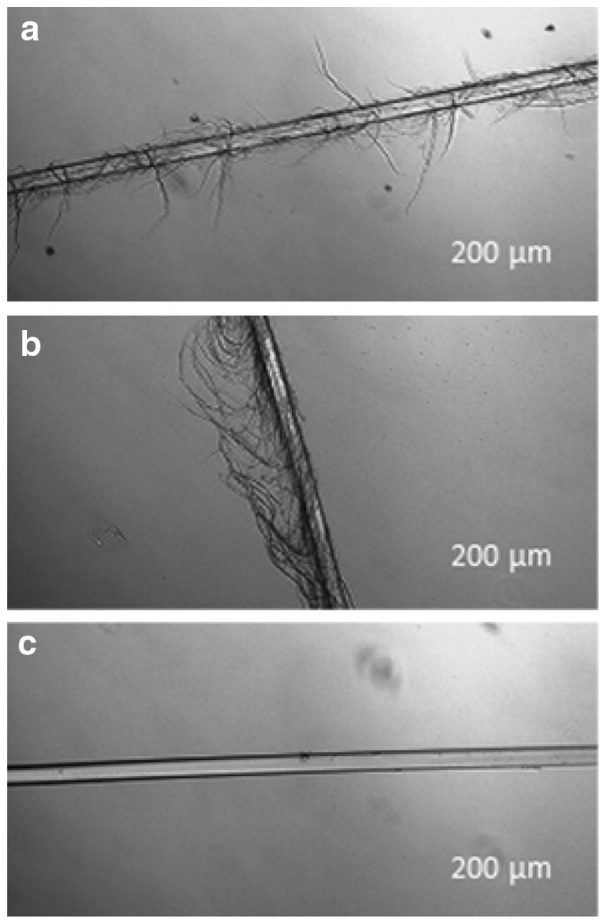

Fig. 3 Micrograph of the dry-wet-spun fiber samples from a [Emim]OAc, b NMMO_H ${ }_{2} \mathrm{O}$ and $\mathbf{c}[$ Emim $]\left[(\mathrm{EtO})_{2} \mathrm{PO}_{2}\right]$ (Ingildeev et al. 2013)
ILs has been widely studied. Firstly, the role of the anion in the dissolution process has been analyzed: ILs with anions like nitrate $\left(\mathrm{NO}_{3}\right)$, triflate $\left(\mathrm{F}_{3} \mathrm{CSO}_{3}\right)$, ethyl sulfate $\left(\mathrm{EtSO}_{4}\right)$, tetrafluoroborate $\left(\mathrm{BF}_{4}\right)$, hexafluorophosphate $\left(\mathrm{PF}_{6}\right)$, exhibit low cellulose solubility, while acetate, phosphate and formate anions have a higher ability to play as hydrogen bond acceptors: therefore, they are better choices for cellulose dissolution (Medronho et al. 2012; Swatloski 2002; Wang et al. 2012). However, the structure of the cation also affects the solubility process (Lu et al. 2014; Zhang et al. 2016). In fact, the cation can increase substantially the solubility by forming hydrogen bonds with hydroxyl groups and acetal oxygens of cellulose ( $\mathrm{Lu}$ et al. 2014). Imidazolium, phosphonium, ammonium, or pyridinium cations favor cellulose dissolution: increasing the alkyl chain length in the (imidazolium) cation reduces cellulose solubility. Moreover, it has been shown that cations with even numbered alkyl side chains display higher cellulose solubility than those with odd numbers in the $\mathrm{C} 2-\mathrm{C} 10$ series, and this effect may partly be related to the IL viscosity (Vitz et al. 2009). In summary, several different structural features of the ion components of an IL, such as acidic $\mathrm{H}$-atom and allyl groups, length of the alkyl chains and/or presence of functional groups, compete to determine the ease or the difficulty of cellulose dissolution in these media. Some general trends have been reported and structural effects of cellulose dissolution ability are known (for instance saturated alkyls and bulky groups in anion/cation have detrimental effects), while other aspects are still a matter of investigation (Xu et al. 2018a).

The chemical structure of the IL is not the only feature that should be evaluated for designing a good dissolution process giving that many parameters such as the viscosity of ILs and of the IL- cellulose solution, the IL water content, the heating mode (classic or microwave), and the thermal stability of ILs play also significant roles. (Lindman et al. 2010; Ruan et al. 2004a, 2004b; Zhu et al. 2006). For example, Pinker et al. (Pinkert et al. 2009) reported that dissolution times longer than $12 \mathrm{~h}$ do not lead to good results, and high temperatures cause the risk of partial degradation. In general, the working temperature depends on the degree of polymerization and on the cellulosic source. In fact, cellulose with a high degree of polymerization results in a very viscous solution in ILs and, by varying the temperature, it is possible to 
adjust the viscosity of the solution (Druel et al. 2018; Zheng et al. 2019). In general, to increase the solubility percentage, impressive results have been obtained when microwave (MW) pulses of 3-5 s are applied instead of conventional thermal heating. MW heating is characterized by an internal heating process due to the direct absorption of energy which is responsible for the more effective breakage of the H-bonds present (Feng and Chen 2008). It is worth stressing that low-temperature processes have to be preferred since higher reaction temperature, as well as longer reaction times and strong agitation are harsh conditions for processing cellulose in ILs that, in turns, could ultimately change the structure of the biopolymer (Sun et al. 2015a).

Nowadays, several ILs are known as cellulose solvents, but only a restricted number of them has been reported to date for the fabrication of cellulosic fibers (Table 1). These so-called first-generation spinning ILs typically comprise an imidazolium cation with chloride as the anion. As already mentioned above, the work of Swatloski et al. has opened new possibilities to process cellulose (Swatloski 2002). They reported that cellulose can be dissolved in 1-butyl3-methylimidazolium ([Bmim])-based ILs such as 1-butyl-3-methylimidazolium chloride $([\mathrm{Bmim}][\mathrm{Cl}])$ in rather high concentration (up to 15-20\%) within a short time (1-12 h) and without any pretreatment and derivatization. Zhang et al. (2005) employed 1-allyl-3-methylimidazolium chloride ([Amim][Cl]) to produce solutions containing up to $5 \mathrm{w} \%$ of nanocellulose. The presence of chloride atoms in imidazolium-based ILs is highly effective in breaking the hydrogen-bonding network in cellulose, while the presence of water in ILs reduces the solubility (Swatloski et al. 2004, 2002). However, some drawbacks such as the high melting point of imidazolium chloride and the corrosive character of halides toward metal processing equipment led to the exploration of alternative anions, such as acetate and dialkylphosphates. The use of 1-ethyl-3-methylimidazolium acetate $[\mathrm{Emim}][\mathrm{Ac}]$ at room temperature showed some side reactions like cellulose acetylation, which limits its use for cellulose dissolution (Köhler et al. 2007).

Analyzing the data summarized in Table 1, one of the best ILs to dissolve cellulose is 1-butyl-3-methylimidazolium acetate ([Bmim]OAc), which showed $23 \mathrm{~g} / \mathrm{mol}$ solubility at $40{ }^{\circ} \mathrm{C}$. However, at the same temperature, changing the cationic structure to 1-methoxyethyl-3-methylimidazolium resulted in a significant decrease to $8 \mathrm{~g} / \mathrm{mol}$ solubility ( $\mathrm{Lu}$ et al. 2014). Other important values of cellulose solubility were found to be around $15 \mathrm{w} \%$ for [Amim] $\mathrm{Cl}$ at $80{ }^{\circ} \mathrm{C}$ that can be increased up to $20-25$ wt. $\%$ with microwave heating (Kosan et al. 2008). Medronho et al. (2012) hypothesized that cellulose would be soluble in ILs and $N$-methylmorpholine- $N$-oxide because of their ability to weaken also the hydrophobic interactions. Some 1,3-dialkylimidazolium forms displayed substantial dissolution capacity of up to 22 w\% (Fukaya et al. 2006).

Another class of ILs capable of dissolving cellulose is that of protic ILs (PILs). This class of ionic solvents is particularly attractive from both the synthetic and the cost perspectives. In fact, PILs are simply prepared by the addition of a Brønsted acid to a Brønsted base, thus reducing to the minimum the synthetic steps required, the use of solvents, and the workup procedure. Typically, superbases such as 1,8-diazabicyclo[5.4.0] undec-7-ene (DBU), 1,5-diazabicyclo[4.3.0]non-5-ene (DBN), 7-methyl-1,5,7-triazabicyclo[4.4.0]dec-5-ene (mTBD) or 1,1,3,3-tetramethylguanidin (TMG), are employed in the preparation of PILs since their high basicity provides complete conversion even with weak carboxylic acids. PILs composed of a weak acid and a superbase with a low boiling point are called distillable ILs (DILs). In fact, by exploiting the acid-base equilibrium, the volatile precursors can be distilled thus making the ionic liquid distillable. King et al. reported the first examples of DILs composed by 1,1,3,3-tetramethylguanidine (TMG) with different carboxylic acids (formic, acetic, and propionic acids) and these systems were able to rapidly dissolve cellulose. The cellulose solubility depends on the alkyl chain length of the carboxylate anion while all tested PILs were recyclable by distillation with recoveries and purities higher than 99\% (King et al. 2011). Based on these structures, cellulose solvating capability of structurally related DILs with different carboxylate anions and a range of bases and superbases of varying basicity has been recently investigated (Parviainen et al. 2013; Olga Kuzmina et al. 2017). The maximum amounts of cellulose dissolved in carboxylate DILs are reported in Table 1. Cellulose solubility does not seem to strictly correlate with the difference in acidity between acid and base $\left(\Delta \mathrm{p} K_{\mathrm{a}}\right)$. Indeed, several PILs exhibit disparate cellulose solubilities, despite very similar $\Delta \mathrm{p} K_{\mathrm{a}}$ 
Table 1 Dissolution capability of different ILs for cellulose obtained by different sources

\begin{tabular}{|c|c|c|c|c|}
\hline Ionic liquid & Cellulose type & Temperature $\left({ }^{\circ} \mathrm{C}\right)$ & Solubility (\%) & References \\
\hline \multirow{2}{*}{$\begin{array}{l}\text { 1-allyl-3-methylimidazolium } \\
\text { chloride }([\mathrm{Amim}] \mathrm{Cl})\end{array}$} & Pulp cotton linter & $100-130$ & $5.0-14.5$ & Zhang et al. (2005) \\
\hline & Eucalyptus pulp & 80 with microwave heating & $20-25$ & Kosan et al. (2008) \\
\hline $\begin{array}{l}\text { 1-allyl-2,3-dimethylimidazo- } \\
\text { lium bromide ([ADmim] } \\
\mathrm{Br} \text { ) }\end{array}$ & Avicel & 80 & 12 & Barthel and Heinze (2006) \\
\hline $\begin{array}{l}\text { 1-allyl-3-methylimidazolium } \\
\text { formate ([Amim]HCOO) }\end{array}$ & MCC (DP:250) & 85 & 22 & Fukaya et al. (2006) \\
\hline $\begin{array}{l}\text { 1-butyl-3-methylimida- } \\
\text { zolium aminoethanoate } \\
\left([\mathrm{Bmim}]\left[\mathrm{H}_{2} \mathrm{NCH}_{2} \mathrm{COO}\right]\right)\end{array}$ & $\mathrm{MCC}$ & 70 & 12 & Xu et al. (2010) \\
\hline $\begin{array}{l}\text { 1-butyl-3-methylimidazo- } \\
\text { lium benzoate ([Bmim }] \\
\left.\left[\mathrm{PhCO}_{2}\right]\right)\end{array}$ & MCC & 70 & 12 & Xu et al. (2010) \\
\hline \multirow{7}{*}{$\begin{array}{l}\text { 1-butyl-3-methylimidazo- } \\
\text { lium chloride }([\mathrm{Bmim}] \mathrm{Cl})\end{array}$} & MCC (DP:250) & 100 & 20 & Ohno et al. (2004) \\
\hline & MCC Avicel & 100 & 20 & Vitz et al. (2009) \\
\hline & MCC Avicel & 83 & 18 & Heinze et al. (2005) \\
\hline & Suprice sulfite pulp & 83 & 13 & Heinze et al. (2005) \\
\hline & Cotton linters & 83 & 10 & Heinze et al. (2005) \\
\hline & MCC Avicel & 110 & 10 & Zhao et al. (2008) \\
\hline & Dissolving pulp & 100 & 10 & Swatloski (2002) \\
\hline $\begin{array}{l}\text { 1-butyl-3-methylimidazo- } \\
\text { lium formate ([Bmim] } \\
\text { [HCOO }])\end{array}$ & MCC Avicel & 110 & 8 & Zhao et al. (2008) \\
\hline $\begin{array}{l}\text { 1-butyl-3-methylimidazo- } \\
\text { lium acetate([Bmim]OAc) }\end{array}$ & & 40 & $23(\mathrm{~g} / \mathrm{mol})$ & Lu et al. (2014) \\
\hline \multirow{4}{*}{$\begin{array}{l}\text { 1-ethyl-3-methylimidazo- } \\
\text { lium acetate ([Emim]OAc) }\end{array}$} & MCC (DP:250) & 100 & 10 & Ohno et al. (2004) \\
\hline & MCC Avicel & 90 & 16 & Zavrel et al. (2009) \\
\hline & MCC Avicel & 110 & 15 & Zhao et al. (2008) \\
\hline & Eucalyptus pulp & 85 & 13.5 & Kosan et al. (2008) \\
\hline $\begin{array}{l}\text { 1-ethyl-3-methylimidazo- } \\
\text { lium methylphosphonate } \\
{[\text { Emim }]\left[(\mathrm{MeO})(\mathrm{H}) \mathrm{PO}_{2}\right]}\end{array}$ & & 45 & 10 & Fukaya et al. (2008) \\
\hline $\begin{array}{l}\text { 1-ethyl-3-methylimidazo- } \\
\text { lium diethylphosphate } \\
\left.\text { ([Emim] }\left[\mathrm{Et}_{2} \mathrm{PO}\right]\right)\end{array}$ & Avicel & 100 & $12-14$ & Vitz et al. (2009) \\
\hline $\begin{array}{l}\text { N,N-dimethyl-2-methoxy- } \\
\text { ethylammonium acetate } \\
\left(\left[(\mathrm{Me})_{2}(\mathrm{MeOEt}) \mathrm{NH}\right] \mathrm{OAc}\right)\end{array}$ & MCC Avicel & 110 & 12 & Zhao et al. (2008) \\
\hline $\begin{array}{l}\text { Triethyl-2-(2-methoxy- } \\
\text { ethoxy)ethanammonium } \\
\text { acetate }\left(\left[\mathrm{Me}(\mathrm{OEt})_{3}-\mathrm{Et}_{3} \mathrm{~N}\right]\right. \\
\text { OAc) }\end{array}$ & MCC Avicel & 110 & 10 & Zhao et al. (2008) \\
\hline $\begin{array}{l}\text { 3-methyl-N-butylpyridinium } \\
\text { chloride }\left(\left[\mathrm{C}_{1} \mathrm{NC}_{4} \mathrm{Py}\right] \mathrm{Cl}\right)\end{array}$ & MCC Avicel & 105 & 12 & Heinze et al. (2005) \\
\hline $\begin{array}{l}\text { 1-ethyl-3-methylimidazo- } \\
\text { lium Levulinate ([Emim] } \\
\text { Lev) }\end{array}$ & $\mathrm{MCC}$ & 100 & 38 & Becherini et al. (2019) \\
\hline
\end{tabular}


Table 1 (continued)

\begin{tabular}{|c|c|c|c|c|}
\hline Ionic liquid & Cellulose type & Temperature $\left({ }^{\circ} \mathrm{C}\right)$ & Solubility (\%) & References \\
\hline $\begin{array}{l}\text { 1-butil-3-methylimidazolium } \\
\text { Levulinate ([Bmim]Lev) }\end{array}$ & $\mathrm{MCC}$ & 100 & 34 & Becherini et al. (2019) \\
\hline $\begin{array}{l}\text { 1,5-diazabicyclo[4.3.0]non- } \\
\text { 5-ene acetate [DBNH]OAc }\end{array}$ & $\begin{array}{l}\text { (Eucalyptus urograndis) } \\
\text { prehydrolysis kraft pulp }\end{array}$ & 70 & 13 & Michud et al. (2016b) \\
\hline $\begin{array}{l}\text { 1,5-diazabicyclo[4.3.0]non- } \\
\text { 5-ene propionate }[\mathrm{DBNH}] \\
{\left[\mathrm{CO}_{2} \mathrm{Et}\right]}\end{array}$ & $\begin{array}{l}\text { Eucalyptus urograndis) pre- } \\
\text { hydrolysis kraft pulp }\end{array}$ & 100 & 16 & Parviainen et al. (2013) \\
\hline $\begin{array}{l}\text { 1,8-diazabicyclo[5.4.0] } \\
\text { undec-7-ene propionate } \\
{[\mathrm{DBUH}]\left[\mathrm{CO}_{2} \mathrm{Et}\right]}\end{array}$ & $\begin{array}{l}\text { Eucalyptus urograndis) pre- } \\
\text { hydrolysis kraft pulp }\end{array}$ & 100 & 16 & Parviainen et al. (2013) \\
\hline $\begin{array}{l}\text { 1,1,3,3-tetramethylguanidine } \\
\text { propionate:1-ethyl-3-meth- } \\
\text { ylimidazolium acetate } 1: 1 \\
{[\mathrm{TMGH}]\left[\mathrm{CO}_{2} \mathrm{Et}\right]:[\text { Emim }]} \\
\text { OAc }\end{array}$ & $\begin{array}{l}\text { Eucalyptus urograndis) pre- } \\
\text { hydrolysis kraft pulp }\end{array}$ & 100 & 18 & Parviainen et al. (2013) \\
\hline $\begin{array}{l}\text { 1,1,3,3-tetramethylguanidine } \\
\text { acetate [TMG]OAc }\end{array}$ & $\begin{array}{l}\text { Eucalyptus urograndis) pre- } \\
\text { hydrolysis kraft pulp }\end{array}$ & 100 & 7 & Parviainen et al. (2013) \\
\hline $\begin{array}{l}\text { 1,1,3,3-tetramethylguanidine } \\
\text { propionate }[\mathrm{TMG}]\left[\mathrm{CO}_{2} \mathrm{Et}\right]\end{array}$ & $\begin{array}{l}\text { Eucalyptus urograndis) pre- } \\
\text { hydrolysis kraft pulp }\end{array}$ & 100 & 15 & Parviainen et al. (2013) \\
\hline $\begin{array}{l}\text { 1,1,3,3-tetramethylguanidine } \\
\text { acetate [TMG]OAc }\end{array}$ & MCC & 110 & 5.1 & Olga Kuzmina (2017) \\
\hline $\begin{array}{l}\text { 1,8-diazabicyclo[ } 5.4 .0] \\
\text { undec-7-ene acetate } \\
\text { [DBUH]OAc }\end{array}$ & Cellulose & 100 & 28 & Hideki Hanabusa (2019) \\
\hline $\begin{array}{l}\text { 1,8-diazabicyclo[ } 5.4 .0] \\
\text { undec-7-ene propionate } \\
{[\mathrm{DBUH}]\left[\mathrm{CO}_{2} \mathrm{Et}\right]}\end{array}$ & Cellulose & 100 & 27 & Hideki Hanabusa (2019) \\
\hline $\begin{array}{l}\text { 1,8-diazabicyclo[ } 5.4 .0] \\
\text { undec-7-ene butanoate } \\
{[\mathrm{DBUH}]\left[\mathrm{CO}_{2} \mathrm{Pr}\right]}\end{array}$ & Cellulose & 100 & 27 & Hideki Hanabusa (2019) \\
\hline $\begin{array}{l}\text { 1,8-diazabicyclo[ } 5.4 .0] \\
\text { undec-7-ene hexanoate } \\
{[\mathrm{DBUH}]\left[\mathrm{CO}_{2} \mathrm{Pen}\right]}\end{array}$ & Cellulose & 100 & 24 & Hideki Hanabusa (2019) \\
\hline $\begin{array}{l}\text { 1,8-diazabicyclo[ } 5.4 .0] \\
\text { undec-7-ene octanoate } \\
{[\mathrm{DBUH}]\left[\mathrm{CO}_{2} \text { Ept }\right]}\end{array}$ & Cellulose & 100 & 3 & Hideki Hanabusa(2019) \\
\hline $\begin{array}{l}\text { 1,8-diazabicyclo[ 5.4.0] } \\
\text { undec-7-ene acetate } \\
\text { [DBUH]OAc }\end{array}$ & $\mathrm{MCC}$ & 80 & 22.5 & Olga Kuzmina (2017) \\
\hline $\begin{array}{l}\text { 1,5-diazabicyclo[4.3.0]non- } \\
5 \text {-ene acetate [DBNH]OAc }\end{array}$ & $\mathrm{MCC}$ & 80 & 22 & Olga Kuzmina (2017) \\
\hline $\begin{array}{l}\text { 1,5-diazabicyclo[4.3.0]non- } \\
\text { 5-ene butanoate [DBNH] } \\
{\left[\mathrm{CO}_{2} \mathrm{Pr}\right]}\end{array}$ & $\mathrm{MCC}$ & 80 & 5.3 & Olga Kuzmina (2017) \\
\hline $\begin{array}{l}\text { 1,8-diazabicyclo[ } 5.4 .0] \\
\text { undec-7-ene propionate } \\
{[\mathrm{DBUH}]\left[\mathrm{CO}_{2} \mathrm{Et}\right]}\end{array}$ & $\mathrm{MCC}$ & 80 & 4.3 & Olga Kuzmina (2017) \\
\hline $\begin{array}{l}\text { 1,8-diazabicyclo[ 5.4.0] } \\
\text { undec-7-ene levulinate } \\
\text { [DBUH]Lev }\end{array}$ & $\mathrm{MCC}$ & 100 & 20 & Becherini et al. (2019) \\
\hline
\end{tabular}


Table 1 (continued)

\begin{tabular}{|c|c|c|c|c|}
\hline Ionic liquid & Cellulose type & Temperature $\left({ }^{\circ} \mathrm{C}\right)$ & Solubility (\%) & References \\
\hline $\begin{array}{l}\text { 1,8-diazabicyclo[ } 5.4 .0] \\
\text { undec-7-ene levulinate } \\
\text { [DBUH]Lev }\end{array}$ & MCC & 100 & 15 & Becherini et al. (2019) \\
\hline $\begin{array}{l}\text { tetrabutylammonium } \\
\text { acetate:dimethyl sul- } \\
\text { foxide [TBAA]:DMSO } \\
\left(\chi_{\mathrm{IL}}=0.15\right)\end{array}$ & MCC & 25 & 8.2 & Huang et al. (2016) \\
\hline $\begin{array}{l}\text { tetrabutylammonium } \\
\text { fluoride:dimethyl sul- } \\
\text { foxide [TBAF]:DMSO } \\
\left(\chi_{\mathrm{IL}}=0.10\right)\end{array}$ & $\mathrm{MCC}$ & 60 & 2 & Ciacco et al. (2003) \\
\hline $\begin{array}{l}\text { Trioctylmethylphosphonium } \\
\text { acetate: dimethyl sulfoxide } \\
{\left[\mathrm{P}_{8881}\right] \text { OAc:DMSO ( } 40 \%} \\
\text { w/w) }\end{array}$ & MCC & 60 & 19 & Holding et al. (2014) \\
\hline $\begin{array}{l}\text { Tetraoctylphosphonium } \\
\text { acetate:dimethyl sulfoxide } \\
{\left[\mathrm{P}_{8888}\right] \text { OAc:DMSO }(60 \%} \\
\text { w/w) }\end{array}$ & MCC & 60 & 8 & Holding et al. (2017) \\
\hline $\begin{array}{l}\text { Trioctyl(tetradecyl)phospho- } \\
\text { nium acetate:dimethyl sul- } \\
\text { foxide }\left[\mathrm{P}_{14888}\right] \mathrm{OAc}: \text { DMSO } \\
(60 \% \mathrm{w} / \mathrm{w})\end{array}$ & MCC & 60 & 3 & Holding et al. (2017) \\
\hline $\begin{array}{l}\text { Trioctylmethylphosphonium } \\
\text { levulinate: dimethyl sul- } \\
\text { foxide }\left[\mathrm{P}_{8881}\right] \text { Lev:DMSO } \\
(50 \% \mathrm{w} / \mathrm{w})\end{array}$ & MCC & 100 & 10 & Mezzetta et al. (2019a) \\
\hline $\begin{array}{l}\text { Trioctylmethylammonium } \\
\text { levulinate: dimethyl sul- } \\
\text { foxide }\left[\mathrm{N}_{8881}\right] \text { Lev:DMSO } \\
(50 \% \mathrm{w} / \mathrm{w})\end{array}$ & MCC & 10,012 & & Mezzetta et al. (2019a) \\
\hline
\end{tabular}

values. Although all DILs with carboxylate anion are distillable with high purity, it is worth mentioning that TMG- and DBU-based DILs are more viscous than DBN-based DILs, which makes these latter systems of interest for rapid cellulose dissolution. The carboxylate anions ability to disrupt the hydrogen bond network of cellulose is also predominant for the dissolution of cellulose in carboxylate-based PILs. However, the hydrophobic alkyl chains would prevent interactions between carboxylate ions and hydroxyl groups of cellulose, thus decreasing cellulose solubility with increasing alkyl chain length of the carboxylate ion (Hideki Hanabusa 2019). For this reason, [DBNH]OAc was the first non-imidazoliumbased ionic liquid that was used for spinning of cellulose solutions demonstrating extraordinary properties (Michud et al. 2016b). Furthermore, the low cost of PILs, compared to traditional aprotic ILs, prompted their use in biomass deconstruction processes ( $\mathrm{Tu}$ et al. 2020).

An intriguing potential of ILs as solvents for cellulose is also their use as components of organic electrolyte solutions, intended as mixtures of an ionic liquid and a neutral polar co-solvent such as dimethyl sulfoxide (DMSO) or $\gamma$-valerolactone. This class of cellulose solvents is attracting increasing attention because of the rapid or instantaneous dissolution ability, the decreased viscosity, the enhanced thermal stability, and the possibility to finely-tune their physicochemical properties. Starting from the pioneering work of Rinaldi (2011), several organic electrolyte systems based on ILs and polar solvents for cellulose dissolution were developed (Clough 2017). In 2011, Rinaldi reported (2011) how low molar fractions of $[\mathrm{Emim}] \mathrm{Cl}$ or $[\mathrm{Emim}] \mathrm{OAc}(\chi \mathrm{IL}=0.08-0.4)$ in different polar organic solvents, such as 
1,3-dimethyl-2-imidazolidinone (DMI), DMSO, sulfolane and $\gamma$-valerolactone were able to dissolve $10 \%$ $\mathrm{w} / \mathrm{w}$ of cellulose within seconds or few minutes. The co-solvent has been shown to improve the solubility of cellulose, even with ILs that in their pure form are not able to do so. In the form of organic electrolyte solutions, ILs such as tetra(n-butyl)ammonium acetate (Huang et al. 2016), tetra(n-butyl) ammonium fluoride, (Ciacco et al. 2003) tetraoctylphosphonium acetate, trioctyl(tetradecyl)phosphonium acetate, (Holding et al. 2017) and tri(n-octyl)methylphosphonium acetate (Holding et al. 2014) were able to solubilize up to $19 \% \mathrm{w} / \mathrm{w}$ of cellulose. A valuable example of organic electrolyte solution for cellulose solubilization was reported by King et al. (Holding et al. 2014, 2017) who analyzed different mixtures of acetate amphiphilic phosphonium ILs and DMSO in several ratios. One of the major advantages of these systems is that the hydrophobic IL can be easily recovered by phase separation at the end of the dissolution procedure when water was added.

As reported, a wide portfolio of systems capable of dissolving, purifying, modify and spinning cellulose is currently available. Therefore, the choice of the best system has to be made on the basis of the starting cellulosic material and the characteristics of the material to obtain.

Despite the advantages of IL-based solvents for the dissolution of cellulose, it is worth stressing that they have intrinsic drawbacks (Heinze et al. 2005). Toxicity of ILs is for instance one of the major concerns that must be addressed especially for biomedical applications in which cellulose-based materials may end up in the body. Even if the biomaterial is purified before implantation, there may still be IL effects in the material. It is important to stress that IL-based cellulose products will never reach to the market if IL impurities can affect the health of a patient. In the recent past, the topic of IL toxicity has gained much attention. The classification of the harmfulness of ILs was collected for different IL-types by Pham et al. (2010).

Owning to the demand for nontoxic ILs, several research groups have developed alternative ILs with the same favorable characteristics (i.e., low melting points, low viscosities) but without toxic components or degradable products. Quaternary ammonium, imidazolium and phosphonium cations (Kagimoto et al. 2006) have been combined with anions like acetate, tartrate, or amino acids. The resulting ILs are still characterized by a relatively low melting temperature and high solubilizing power for different chemicals (Anderson et al. 2007; Xue et al. 2006). Figure 2b shows the chemical structure of nontoxic anions. In the recent years, the trend of replacing petroleumderived constituent of ILs with natural or bio-based ions has emerged. In this regard, the components of ILs for cellulose treatment have also undergone variations in their structure aimed at the introduction of bio-based ions. In this scenario, Guazzelli et al. reported a series of novel ammonium, phosphonium and imidazolium ILs based on levulinic acid (LA) as the anion. Levulinic acid can be prepared, via an acidcatalyzed reaction, from cellulose and can be used for preparing cellulose-derived ILs, which in turn display a surprising high ability to dissolve their parent polysaccharide. In fact, the imidazolium ILs were able to dissolve a considerable amount of cellulose (up to $38 \mathrm{w} \%$ ), while the hydrophobic ILs, used in electrolyte solutions, reached $12 \%$ wt for $\left[\mathrm{N}_{8881}\right]$ Lev:DMSO and $10 \mathrm{w} \%$ for $\left[\mathrm{P}_{8881}\right]$ Lev:DMSO (Mezzetta et al. 2019a). In a previous work, Guazzelli et al. also reported the preparation of protic levulinate ILs (Lev PILs) carried out by adding equimolar amount of levulinic acid to DBU or DBN, and tested them as cellulose dissolution and functionalization media. The solubilization performance of levulinate based ILs are summarized in Table 1 (Becherini et al. 2019).

As a conclusion of this section, it is important to stress that although ILs hold great promise as media for cellulose dissolution, specific criteria need to be met for further process development: in particular, the IL has to be easy to synthesize, recyclable at least at $99.5 \%$, with the lowest possible toxicity, no vapor pressure, and high dissolution capability towards different pulp sources (Hermanutz et al. 2019).

Although the recyclability of ILs is promising, due to the current market scale and the relatively high cost of ILs, no industrial technology is yet available for IL recycling with the goal of reuse, and several challenges must be still addressed before IL pretreatment technology can become commercially viable (Abu-Eishah 2011). Most of the published works on IL recycle, rely upon extracting a solute from a mixture via suitable ILs, then recovering them for further reuse. The number of trial cycles in most cases was low (3 to 5 cycles) (Shamshina et al. 2021). One of the most important challenges is the affordable and 
scalable recovery and recycle of the IL itself (Sun et al. 2017). There are also some challenges when binary solvent systems containing IL and co-solvent are used, due to possible phase separation during recycling of the ternary system IL/co-solvent/antisolvent (Sun et al. 2017).

\section{Spinning of cellulose with ILs: advantages and limitations}

Various spinning techniques such as melt- or solution-spinning can be used to produce filaments, continuous fibers of indefinite length. Solution spinning methods can be categorized into dry-spinning, wetspinning and dry-jet-wet spinning. In any type of spinning method, a spinning dope is formed through melting or dissolving the polymer precursor that is then extruded through spinneret. Solidification of the dope can be obtained through cooling, solvent evaporation in a hot atmosphere or precipitation in a non-solvent. These techniques are referred to as melt-, dry- and wet-spinning, respectively (Stibal et al. 2000). High polymer chain alignment, which is key to high stiffness and strength, can be achieved by drawing the fiber immediately after the spinneret, or in a separate step, or by some combination of the two. Solution spinning techniques usually lead to greater mechanical performance by carefully controlling the amount of molecular entanglement (Clemons 2016).

Another widely reported method is electrospinning, in which a high voltage electrical field that is applied between the nozzle and a conductive collector leads to uniaxial elongation of the polymeric jet from a melt ink, solution, emulsion, or dispersion. The optimal spinning approach for a particular polymer is selected based on the polymer melting point, melt stability, or solubility in organic and/or inorganic solvents. The ability to form fibers of a particular polymer dope is often defined as spinnability. To evaluate the spinnability of a dope, several factors have to be considered, such as flow, rheology, melt flow index (for melt-spun polymers), crystallization, phase transition, solvent/solvent system behavior, and structure development (Lundahl et al. 2016).

The production of pure cellulose fibers is a challenging task since cellulose is scarcely soluble in conventional solvents due to notable inter- and/or intra-molecular hydrogen bonding (Quan et al. 2010).
In addition to its low solubility, cellulose is also difficult to be processed from the melt. Hence, processing of cellulose requires either chemical derivatization followed by regeneration or physical dissolution in non-derivatising solvent (e.g., $\mathrm{N}$-Methylmorpholine$\mathrm{N}$-oxide (NMMO), Cuoxam, ILs) and consequent regeneration (Quan et al. 2010; Röder et al. 2009).

\section{Solution-spinning}

The history of man-made cellulose fibers (MMCF) starts from the discovery of cellulose nitrate by KarlFriedrich Schönbein in 1846. The high flammability of nitrocellulose limited respective fibers for textile applications. Comte de Chardonnet was the founder of the MMCF industry in 1889. Even though the process was simple in principle, it faced some limitations including difficulties to scale up safely the production with a consequent limited economic potential.

In 1892, the foundation of the Viscose process changed the approach by involving the activation of cotton and wood cellulose in aqueous sodium hydroxide solution followed by reaction with $\mathrm{CS}_{2}$ to form a cellulose xanthate (Cross et al. 1892). After dissolution in alkaline solution, the cellulose xanthate is spun into a sulfuric acid bath. In this method, in addition to other auxiliaries (e.g., carbon disulfide, sodium hydroxide, sulfuric acid, zinc sulfate), a considerable volume of fresh water is required (Hermanutz et al. 2019). To overcome the problems related to the extensive use of $\mathrm{CS}_{2}$, it has been developed the so called second cellulose processing that is based on the dissolution of cellulose in aqueous systems using solvation-mediators. For example, in cupro process cellulose fibers produce via a spinning process using a copper-based complexing agent such as tetraaminecopper dihydroxide (Burchard et al. 1994; Zhang et al. 2018). Another class of aqueous cellulose solvents is based on alkaline systems in which cellulose should be activated in a pretreatment step. However, alkaline solutions can handle only low-DP cellulose, which results in fiber with low strength.

The third type of cellulose dissolution is based on the discovery of NMMO monohydrate as a nonaqueous, non-derivatizing solvent for cellulose. In this technique that is known as the Lyocell process, NMMO monohydrate dissolves cellulose directly and spin dope can be dry-jet wet spun into an aqueous coagulation bath (Fink et al. 2001). Isopropyl gallate 
usually is used to stabilize the spinning dope to prevent side reactions. By spinning through an air-gap, high stretch ratios can be applied, which lead to the formation of long and thin crystallites align along the fiber axis. Therefore, there is little lateral interaction between the macrofibrils, which results in a high tendency to fibrillation in the wet state (Hermanutz et al. 2019). A pronounced lateral orientation leads, instead, to high mechanical performance of Lyocelltype fibers (Gindl et al. 2008). Despite the benefits of Lyocell process, such as minimum pulp losses and quantitative recycling of the solvent, NMMO monohydrate suffers from some intrinsic shortcomings resulting from the redox-active $\mathrm{N}-\mathrm{O}$ moiety and the thermally labile cyclic ether structure. Therefore, from an environmental and economic point of view, the application of alternative direct cellulose solvents has gained interest in the scientific and industrial communities. Other direct solvent systems such as electrolyte solutions or phosphoric acids have been investigated but faced with some limitations including complex dissolving methods, cumbersome solvent recovery processes, and low solubility, which limit their large-scale use in industrial processes (Ahn et al. 2016; Rosenau et al. 2018).

As mentioned above, RTILs have emerged as desirable green solvents that can dissolve and process biopolymers such as silk (Gupta et al. 2007), wool (Xie et al. 2005a), chitin and chitosan (Wu et al. 2008; Xie et al. 2006), lignocelluloses (Kang et al. 2013), wood (Pu et al. 2007), and cellulose (Rahatekar et al. 2009 b) with promising properties. They have been studied intensively within the latest 15 years, since Rogers and his co-workers rediscovered the ability of selected ILs to dissolve cellulose in high concentrations (Swatloski et al. 2004; Swatloski 2002). Fiber spinning of cellulose using ILs offers advantage of a simple, single step dissolution process cellulose solution without derivation, and without the addition of stabilizers, ensuring the design of both fibrillating and nonfibrillating fibers (Rahatekar et al. 2009b). In particular, these IL-based spinning dopes can be either processed by wet spinning or by dry-jet-wet spinning, allowing for the modification of fiber characteristics according to the envisaged application. Solubility of cellulose in ILs also facilitates the electrospinning process of this material to produce fibers with tunable properties (Isik et al. 2014). Dialkylimidazoliumbased ILs, such as $[\mathrm{Amim}] \mathrm{Cl},[\mathrm{Bmim}] \mathrm{Cl}$, [Emim]
$\mathrm{Cl}$, [Emim]OAc, [Bmim]OAc, and 1-ethyl-3-methylimidazolium diethylphosphate ([Emim] $\left.\left[(\mathrm{EtO})_{2} \mathrm{PO}_{2}\right]\right)$, and ammonium-based ILs such as tetrabutylammonium acetate (TBAA)/ DMSO (Sun et al. 2015a) and [DBNH]OAc, have been used for cellulose spinning (Zhang et al. 2017a). In 2002, Swatloski et al. (Swatloski 2002) studied the possibility of producing fibers and films from cellulose-ILs solutions.

\section{Dry-jet-wet spinning}

The first attempts towards a technical conversion of the fiber processing were performed by Bentivoglio and co-workers (Bentivoglio et al. 2006; Laus et al. 2005), who reported the properties of fibers for textile applications. The stability and spinnability of various commercial dissolving pulps dissolved in $[\mathrm{Bmim}] \mathrm{Cl}$ and $[\mathrm{Amim}] \mathrm{Cl}$ were investigated as spinning solvent instead of NMMO monohydrate in NMMO monohydrate -based Lyocell technique (dry-jet-wet spinning). Fibers showed lower values of tenacity and elongation compared with conventional Lyocell fibers. In 2005, Zhang et al. studied the dry-jet-wet spinning of cellulose/[Amim]Cl solution on an industrial test scale. By optimizing the air gap and minimizing the degradation of cellulose, fibers with an average tensile strength of $675 \mathrm{MPa}$ which was comparable to that of Tencell $(\sim 600 \mathrm{MPa})$, were prepared from $5 \mathrm{wt} \%$ cellulose/[Amim][Cl] solution (Zhang et al. 2005). Later, properties of cellulose fibers spun from ILs solutions were investigated by the BASF Company, the Institute for Textile Chemistry and Chemical Fibres (ITCF) and the Institute of Textile and Plastics Research (TITK) using a pilot manufacturing plant (Hermanutz et al. 2008). Wet and dry-jetwet spinning have been successfully exploited using [Bmim] as the IL. In order to avoid corrosion, cellulose decomposition, and to handle the IL with its fairly high melting point $70{ }^{\circ} \mathrm{C}$, ([Emim]OAc) as noncorrosive ionic solvent was selected, and dry-jet-wet spinning process derived from the NMMO monohydrate process was developed and adapted to this IL solvent. Fibers achieved higher tenacities in comparison to conventional wet-spun fibers, which were comparable to Lyocell fibers.

In 2008, Kosan et al. produced cellulose fibers via a dry-jet-wet spinning process and compared 5 types of ILs with NMMO monohydrate, and found that depending on the type of solvent, cellulose exists in 
different solution states and the tensile strength of all fibers from the IL regeneration process was superior to the Lyceoll fiber (NMMO monohydrate process) (Kosan et al. 2008).

In a following study, they investigated the acetylation of cellulose in different ILs without using catalyst and the subsequent dry/wet spinning process. After the dissolution of cellulose in the IL (first step), and the homogeneous modification of cellulose to cellulose acetate (second step), cellulose acetate fibers with controlled degree of substitution (DS) values and properties were obtained (Kosan et al. 2010). Afterwards, the rheological behavior of the cellulose/ $([\mathrm{Bmim}] \mathrm{Cl})$ solution was investigated by Cai et al. (2010), and the fibers were spun with a dry-jet-wetspinning process. The obtained fibers had crystalline polymorph of Type-II similar to Lyocell fibers. Orientation, crystallinity, and consequently the mechanical properties of the fibers, were improved by increasing the draw ratio. To prepare the cellulose/([Bmim] $\mathrm{Cl})$ spinning dope with fewer particles, lower apparent viscosity, and higher uniformity, they developed a two-step dissolving process, in which cellulose was first swelled to its maximum volume in aqueous $[\mathrm{Bmim}] \mathrm{Cl}$ solution, and then dissolved by stirring under vacuum to remove excessive water. By using this new dissolving process, spinnability and mechanical properties of regenerated cellulose fibers improved when compared to the direct dissolving process (Cai et al. 2012). Jiang et al. (2012, 2011) produced regenerated cellulose fibers from bagasse and wood, and obtained fibers with the tensile strength of $630 \mathrm{MPa}$ via increasing the spinning speed. The regenerated bagasse fibers had higher crystallinity and tenacity than the regenerated wood fibers. Hong et al. (2013) prepared cellulose fibers using cellulose/ [Emim]OAc: dimethylformamide (DMF) solution under dry-jet-wet spinning conditions. The presence of DMF decreased the solution viscosity and improved spinnability and the fiber surface, but it led to a reduced crystallinity and tensile strength of the fibers. Ingildeev et al. (2013) compared the rheological behavior of the spinning dopes, the structures, and the physical properties of the regenerated cellulosic fibers using NMMO monohydrate, [Emim][Ac], and $[$ Emim $]\left[(\text { EtO })_{2} \mathrm{PO}_{2}\right]$ as ionic solvents. They demonstrated the considerable influence of anions in ILs on the spinning process and the properties of the fibers. The fibrillation behavior of prepared fibers, spun in
[Emim] OAc, [Emim] $\left[(\text { EtO })_{2} \mathrm{PO}_{2}\right]$, and $\mathrm{NMMO}_{-} \mathrm{H}_{2} \mathrm{O}$ was totally different. The fibrillation tendency was observed for fibers spun from NMMO_H $\mathrm{N}_{2} \mathrm{O}$ (Fig. 3).

Vinogradova and Chen (Vinogradova and Chen 2016) tested two types of ILs, [Bmim]Cl and [Emim] OAc as recyclable solvents for dissolving raw cellulose in order to spin micro- and nano-scale regenerated cellulose fibers. The comparison of the properties of the spun fibers in terms of tensile strength, crystallinity and thermal decomposition, demonstrated that [Emim]OAc is a better candidate for dissolving cellulose because it requires lower dissolving and spinning temperatures than those of $[\mathrm{Bmim}] \mathrm{Cl}$, and needs less energy for the fiber formation. Besides, [Emim]OAc residuals are not toxic and safe for both consumers and healthcare end-users. In the dry-wet spinning process, many parameters, such as influence of pulp source, degree of polymerization of cellulose, mass distribution, concentration of the spinning dope, type of solvent, drawing ratio in the air gap, spinneret diameter, extrusion velocity, draw ratio, and coagulation bath temperature impact the mechanical properties of fibers (Michud et al. 2016a; Wendler et al. 2009a, b).

Sixta et al. developed a novel regenerated cellulose fiber process of the Lyocell type, denoted Ioncell via using of powerful direct cellulose solvent, [DBNH] OAc in which airgap spinning can be conducted at higher cellulose concentration in the dope, and lower temperature is used during dissolution and spinning (Sixta et al. 2015). Cellulose is less degraded due to the generally mild process conditions, which result in both high fiber yield and strength properties. The effect of different cellulose concentrations and draw ratios on the fiber properties have been investigated in their work and the highest tenacity was achieved by spinning from $15 \mathrm{wt} \%$ to $17 \mathrm{wt} \%$ cellulose solutions. A very high initial modulus of up to $34 \mathrm{GPa}$ made the Ioncell fibers very interesting for technical applications. The effect of dope concentration and the stretching rate influence in Ioncell process on the fiber characteristics is also confirmed by Sun et al. (2015b).

In a series of studies of cellulose solution spinning with [DBNH]OAc, Michud et al. (2015b) demonstrated that the distribution of cellulose chains, the presence of a specific rheological matrix of zero-shear viscosity, and the dynamic modulus of the spinning dope have a considerable effect on the 
spinnability of cellulose/IL solution. They also indicated that the MMD of the cellulose chains contributed to the tensile strength. High-molecular weight cellulose chains combined with a low-fraction of the short-cellulose chain $(\mathrm{DP}<100)$ are desirable for obtaining high strength cellulosic fibers. By using cotton linters, spruce sulfite pulp (68.7:31.3\%) with an intrinsic viscosity of $433 \mathrm{ml} / \mathrm{g}$, cellulose fibers with the tensile strength of $70 \mathrm{cN}$ tex ${ }^{-1}$ approximately $1 \mathrm{GPa}$, according to the conversion proposed by Maenner et al. (2011) assuming fibers with a perfect round cross-section and a density of about $1.5 \mathrm{~g} / \mathrm{cm}^{3}$ was obtained.

Hauru et al. (2014) found that the increase of the temperature of the coagulation bath resulted in a decrease of the fiber tenacity. Olsson et al. (2014) demonstrated that application of N-methylimidazole (MIM) as a co-solvent with [Emim]OAc and $[\mathrm{Bmim}] \mathrm{Cl}$, provided better solubility of microcrystalline cellulose (MCC), higher dissolution rate and lower solution viscosity. The stable solution successfully converted to regenerated fibers with high crystallinity and good mechanical properties via both dry-jet-wet spinning and traditional wet spinning. Low molecular weight MCC, which is often used for low mechanical performance applications, was converted into highly aligned and stiff regenerated cellulose fibers (Young's modulus $\sim 22 \mathrm{GPa}$ ) using [Emim] $\left[(E t O)_{2} \mathrm{PO}_{2}\right]$ as ionic solvent, optimizing the solution concentration $(18 \mathrm{w} \%)$ and applying a high fiber extrusion/winding ratio during the dryjet-wet spinning process (Zhu et al. 2016). By using DMSO as a co-solvent with $\left[\right.$ Emim] $\left[(\mathrm{EtO})_{2} \mathrm{PO}_{2}\right]$, and increasing the concentration of cellulose (20.8 w\% and $23.6 \mathrm{w} \%$ ), considerable alignment of cellulose chains along the fiber axis and, consequently, cellulose fibers with exceptional mechanical properties (Young's modulus $\sim 4 \mathrm{GPa}$ ) were produced (Zhu et al. 2018). Ma et al. produced cellulose fibers with high tensile strength via dry-jet-wet spinning of cellulosic waste such as paper and cardboard using [DBNH]OAc) as ionic solvent (Ma et al. 2016). Most of the studies briefly summarized above are based on imidazolium halide or carboxylate ILs that produced filaments with diameters of about $100 \mu \mathrm{m}$. Depending on the spinning method, there are specific chemical and physical requirements to extrude continuous filaments on a commercial scale. Specifically, ILs should be thermally stable to keep the solute stable at the required processing temperatures since the extreme degradation of the IL and biopolymer may be an issue for solvent recovery and recycling. Therefore halide-based ILs has a substantial limitation for scaling-up the technology (Kosmulski et al. 2004). In contrast, carboxylate-based ILs could overcome this problem to some extent (Michud et al. 2015a). Besides the thermal and chemical stability of ILs, distinct viscoelastic properties of IL-polymer solutions have to be suitable for an industrially applicable spinning process. A key particularity of the dry-jet-wet spinning method is the draw of the fluid filament in the air gap that leads cellulose chains to align along the fiber axis and forms filaments with lower diameters and high mechanical properties (typical for Lyocelltype fibers). The filament breaks in the air gap if it is too thin at its exit point, so that the draw-ability of an initially thick filament is important to achieve thin and strong fibers. The archetypical IL, [Emim] [Ac], is a desirable cellulose solvent due to its low viscosity but, since the solution lacks the required elasticity, filaments cannot be extensively stretched.

Recently, a wet-type solution blow spinning mechanism with a water-mist coagulation chamber has been developed to produce fine regenerated cellulose fibers from the non-volatile IL solvent ([Emim] $\left.\left[\mathrm{Et}_{2} \mathrm{PO}_{4}\right]\right)$ (Fig. 4a). Within the optimum spinning condition, a non-woven fabric from fine fibers with an average diameter of $0.98 \pm 0.62 \mu \mathrm{m}$ was fabricated directly using a multi-nozzle spinneret (Fig. 4b). Drag force of the hot air and rapid coagulation in the water mist led to well-defined molecular orientation and high crystallinity (up to 67.6\%) (Zhang et al. 2019a).

Table 2 shows mechanical behavior of cellulose fibers produced with dry-jet-wet spinning methods from different cellulose sources. According to this table, the highest tensile strengths were $850 \mathrm{MPa}$ related to the cellulose fibers using Spr.NH4-S pulp source, with $\mathrm{DPw}=722$, dissolved in $[\mathrm{Bmim}] \mathrm{Cl}$, produced by a dry-jet-wet spinning technique collected in the water bath at $85{ }^{\circ} \mathrm{C}$ and $852 \mathrm{MPa}$ related to the cellulose fibers using Eucalyptus pulp (Eu-556) source with $\mathrm{DP}=556$, dissolved in [Bmim] OAc, produced by a dry-jet-wet spinning technique collected in the water bath. 

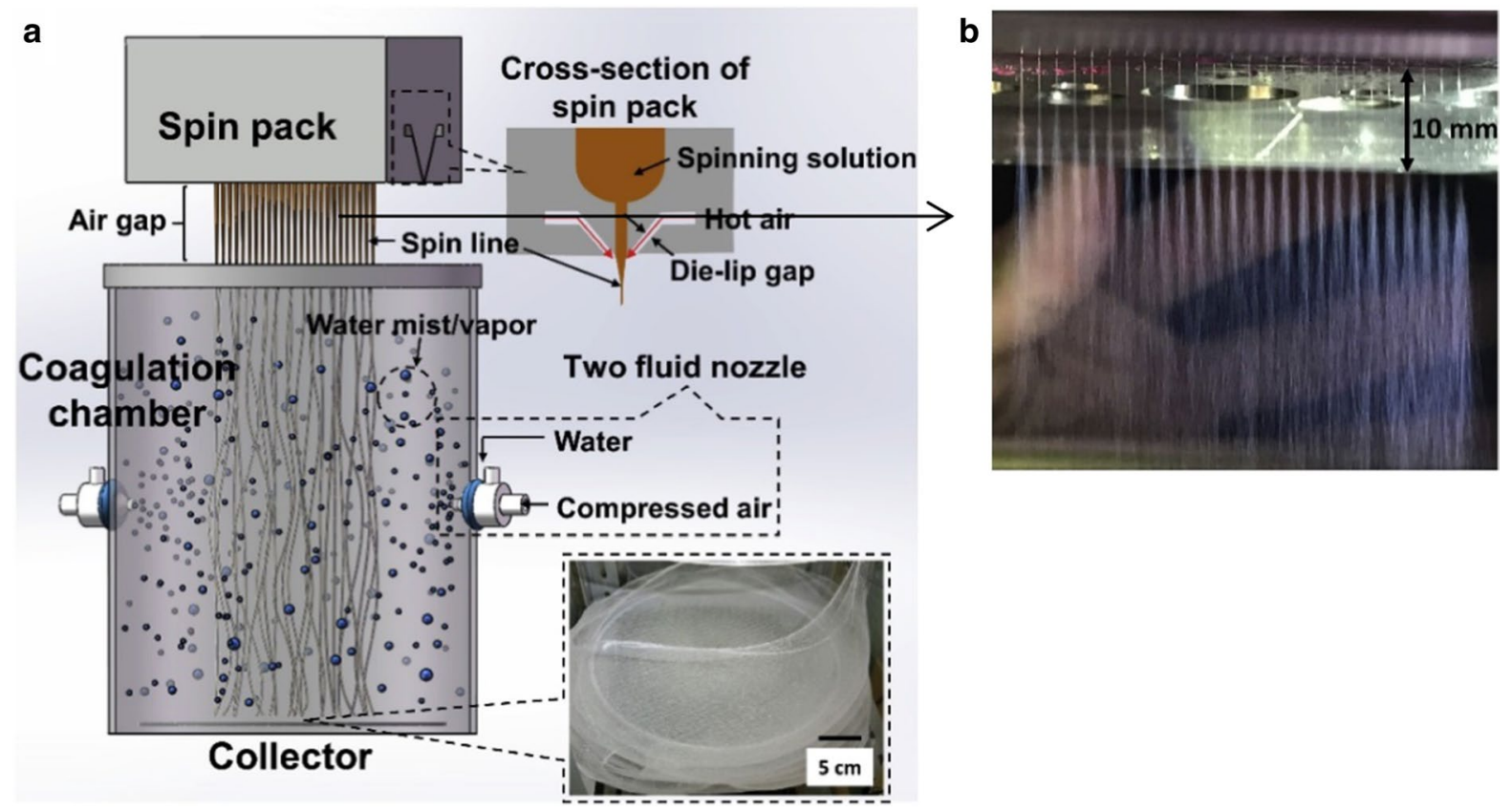

Fig. 4 Wet type solution blow-spinning mechanism. Inset at the bottom right represents an image of fine regenerated cellulose as non-woven fabric assembled on the collector (Zhang et al. 2019a)

\section{Wet spinning}

To fabricate cellulose fibers via wet-spinning process, the viscosity of cellulose solutions has to be decreased through an increasing spinning temperature (Kim and Jang 2013), reducing dope concentration (Ingildeev et al. 2013), and using co-solvents (Sun et al. 2015a). Smaller spin capillaries with a smaller diameter can be used in the wet spinning of IL-biopolymer solutions; subsequent draw forces are considerably smaller, which prevent filament breaks. However, the fibers fabricated with this process have low mechanical properties since polymer alignment is mostly confined to shear-induced orientation in the spin capillary, and stretching of the filament in the spin bath is also only possible within limits. Therefore, since dry-jet-wet spinning is the more promising method for processing of IL-biopolymer solutions, suitable viscoelastic properties of the solution are a mandatory requirement (Rosenau et al. 2018). De Silva et al. (2016a) investigated two imidazoliumbased ILs: [Amim] Cl and [Bmim]OAc for the development of regenerated cellulose fibers via wet spinning. They reported that the IL anion significantly affects the coagulation kinetics owning to its association with cellulose and deduced that imidazolium-based ILs containing halides or carboxylates are efficient cellulose solvents and have been adopted for cellulose spinning. However, depending on the substituent on the imidazolium ring and the chemical nature of the ionic liquid anion, they can degrade cellulose at high temperatures $\left(>90{ }^{\circ} \mathrm{C}\right.$ ) (Ebner et al. 2008). Sun et al. (2015a) introduced a new kind of environment-friendly wetspun cellulose fibers by using a new cellulose solvent, TBAA/DMSO. The cellulose/TBAA/DMSO solution is a typical shear-thinning fluid. Cellulose fibers with a smooth surface and compact structure with strength as high as $375 \mathrm{MPa}$ were obtained. This numerical value is similar to that of viscose fibers but lower than that of dry-jet-wet spinning fibers. Ingildeev et al. (2013), observed that the fibrillation of fibers that occurred during the dry-jet-wet spinning process was avoidable in the wet -spinning process of cellulose using [Emim] OAc as ionic solvent (Fig. 5). Wet-spinning process of four cellulosic materials (MCC, cotton linter pulp, bamboo pulp, and bleached softwood sulphite dissolving pulp) and six non-derivative solvents was investigated by Chen et al. (2015a) to find the combined effects of materials and solvents on the preparation, and on the structural and mechanical properties of regenerated cellulose fibers. The results showed that the dissolving 


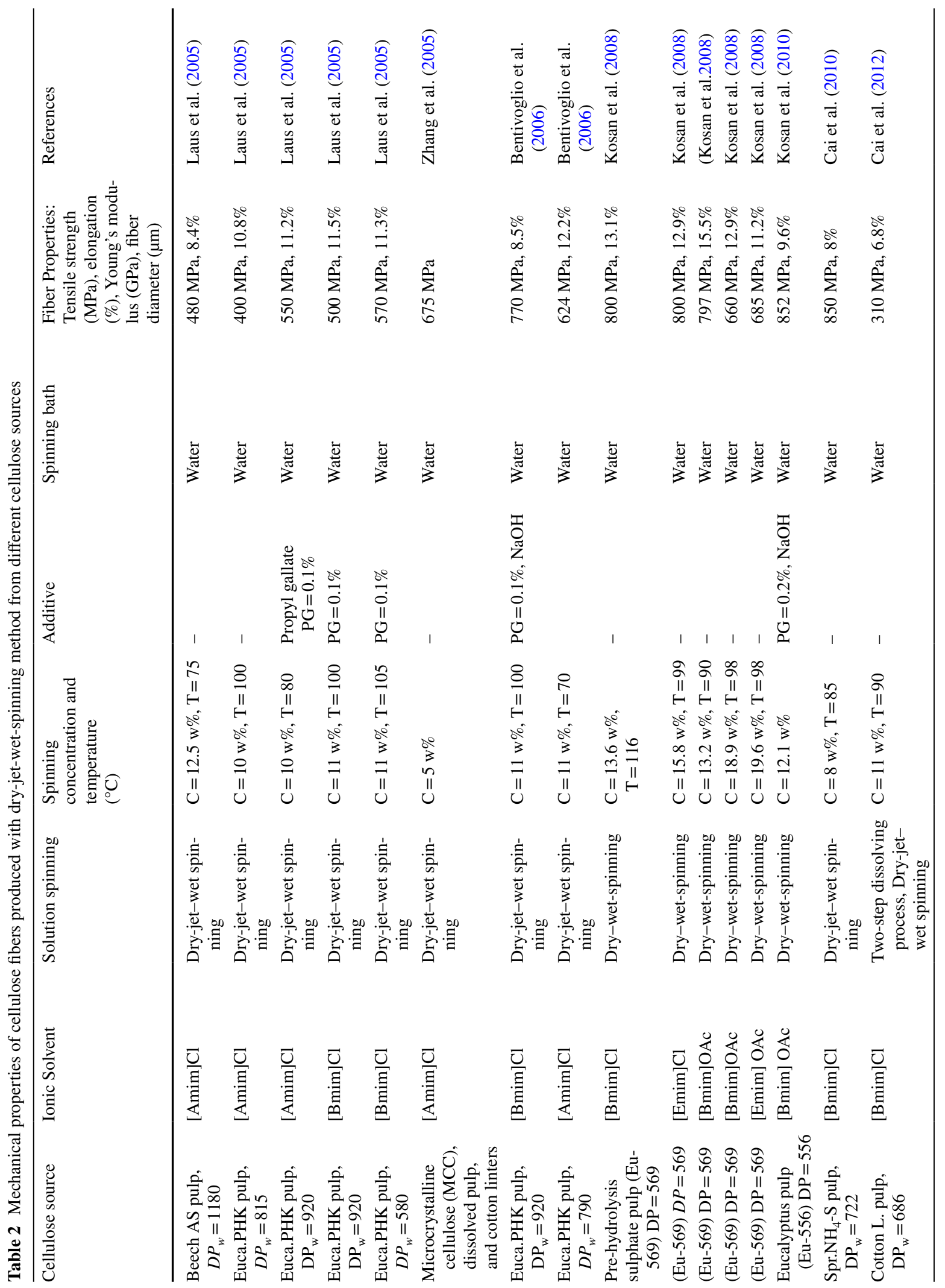




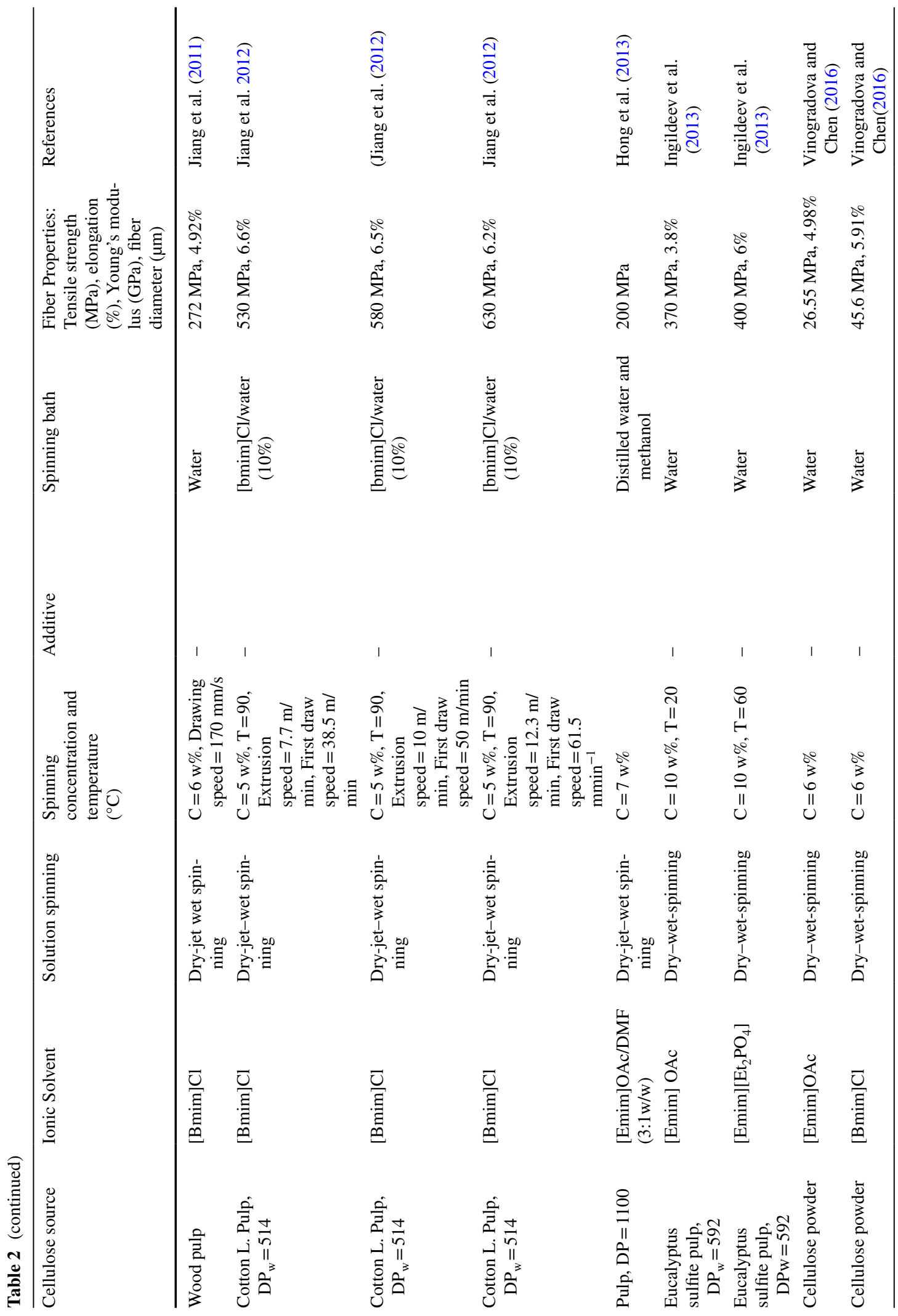




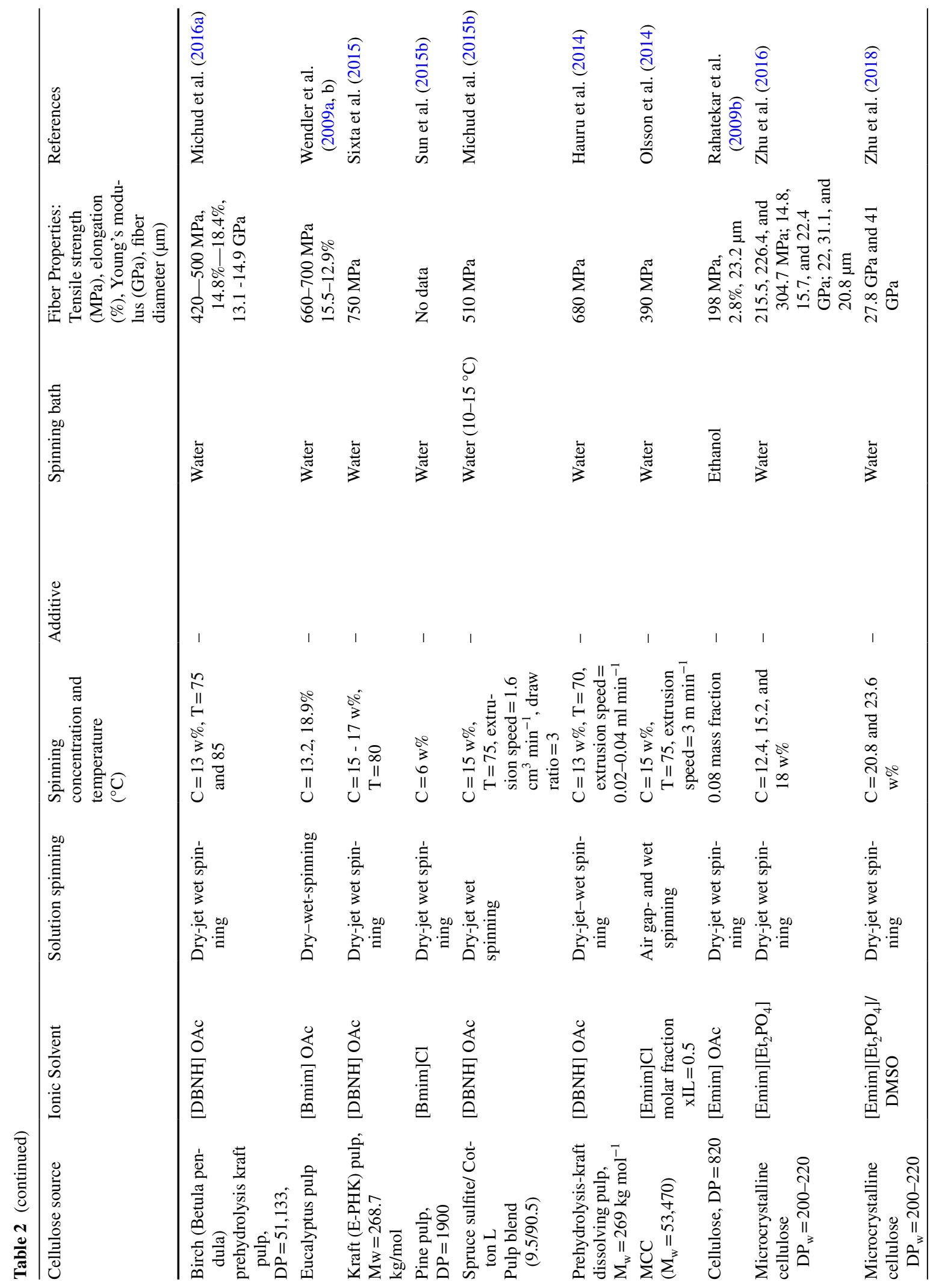




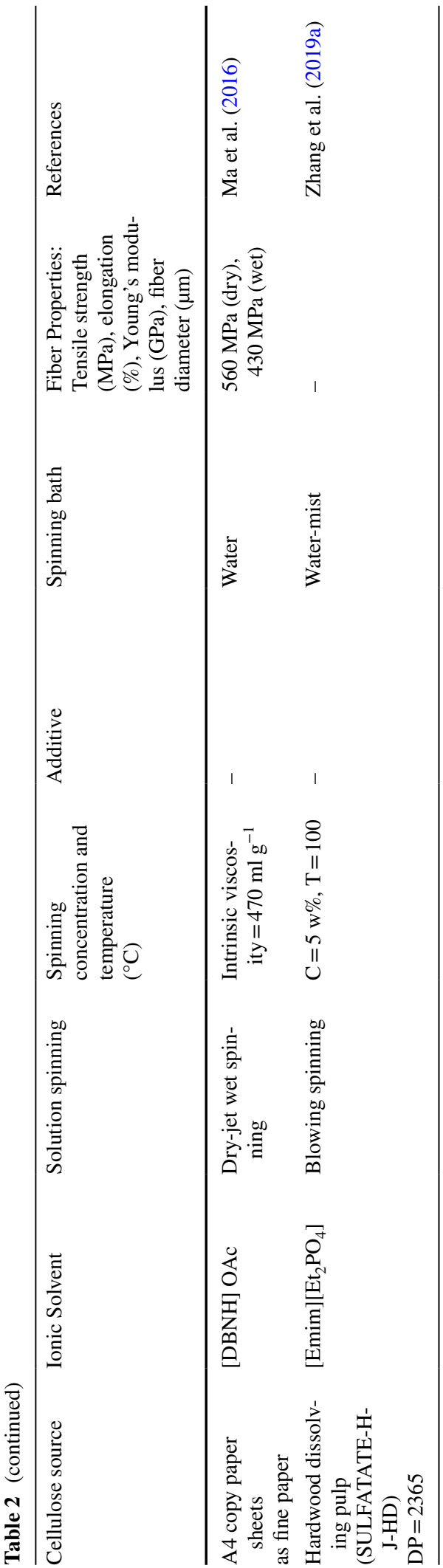

time was affected by the raw materials' properties (e.g., the molecular weight), but raw materials and solvents had no significant influence on the crystallinity and elongation at break of the fibers. The tensile strength of the fibers was directly dependent on the molecular weight of the raw materials, and varied with the type of solvents. The influence of degree of polymerization (DP) on the properties of spin dopes and wet-spun cellulose fibers from dopes of mixed cellulose sources has been investigated. A nonlinear relationship between DP and fiber features was observed and fibers composed of polymers with the highest DP showed the highest mechanical properties (Olsson and Westman 2013). Regarding the several controllable spinning parameters, Hermanutz et al. (2013) wet-spun cellulose filaments with a fineness down to 0.2 dtex. Cellulosic fibers were directly spun from IL to fibers below 0.5 dtex. The high surface area is a main advantage of super-microfibers smaller than $5 \mu \mathrm{m}$ in diameter, in comparison to standard microfibers produced in the 5-9 $\mu \mathrm{m}$ range. In recent work, wet spinning was used to produce cellulose fibers from cellulose/(IL)/co-solvent solutions. [Emim]OAc, DMF, DMSO, and water with various compositions were used as co-solvents. The solutions were stable and converted to regenerated fibers with desirable properties via the conventional wet-spinning process. The presence of co-solvent led to increase of dissolution rate, reduction of the complex viscosity and increase of fibers crystallinity as a result of interaction between cellulose chains. Additionally, the plasticization effect of the co-solvent led to the increase of the mobility of the cellulose chain and a slight increase in tensile strain (Fig. 5) (Lee et al. 2019).

Luo et al. (2008) proposed a technique to produce regenerated fibers from cellulose dissolved in [Emim] OAc solvent and extruded by the melt blowing process with the goal of fabricating bonded non-woven webs. Table 3 shows the mechanical behavior of cellulose fibers produced with wet-spinning methods from different cellulose sources.

Solution-spinning of composite fibers

\section{Dry-jet-wet spinning}

A comprehensive understanding on the recrystallization of cellulose in ILs is of a paramount importance towards the regeneration process for fibers, films and nonwovens (Ahn et al. 2014). Actually, one of 
Fig. 5 Schematic illustration of diffusion competition between solvent (IL or IL/cosolvent) and coagulant. And structural model of regenerated cellulose fiber (Lee et al. 2019)
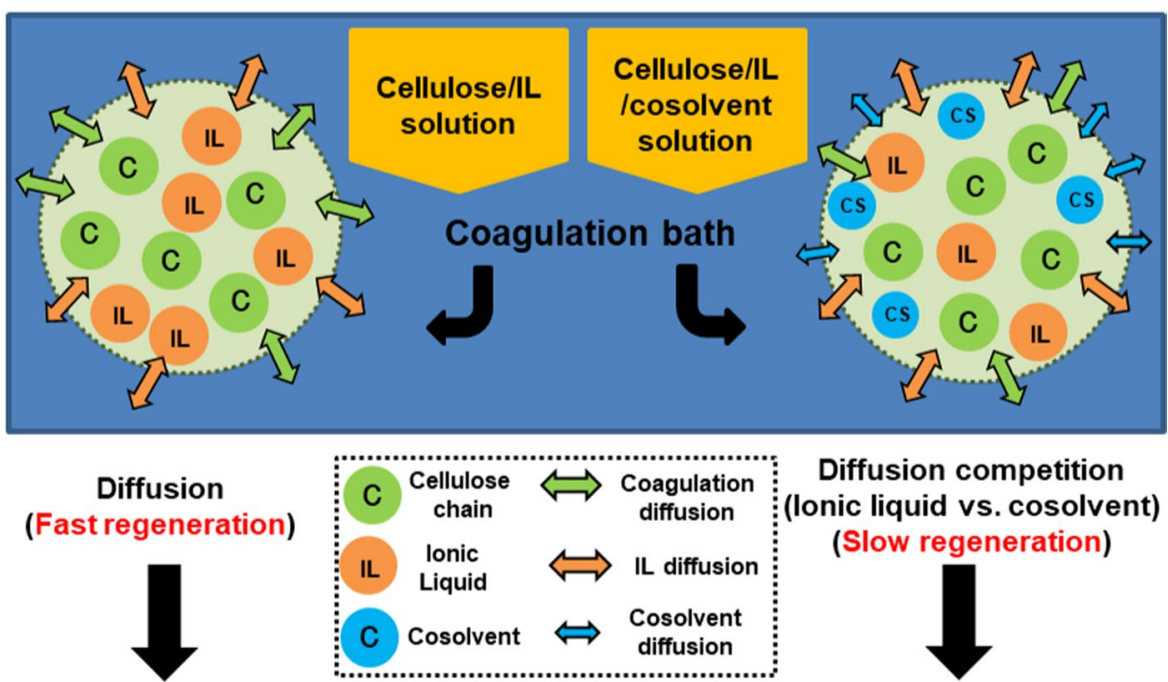

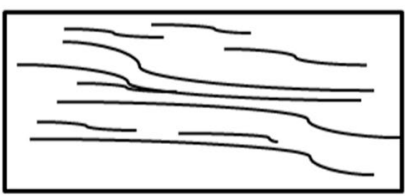

Structuralmodel

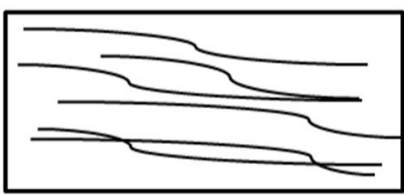

Structural model the main challenges for developing cellulosic materials from ILs is the understanding of crystallization, which affects the physical and chemical stability, and mechanical strength of the cellulose (Isogai et al. 2011; Wang et al. 2007). Several studies have reported quite low crystallinity of cellulose regenerated from ILs that may influence mechanical properties (Ahn et al. 2016). Native cellulose generally exhibits a polymorph structure of Type-I cellulose with the highest degree of intermolecular and intramolecular hydrogen bonding, while the crystalline polymorph of Type-II occurs when cellulose is processed with an IL (Salem 2018). The fast coagulation and regeneration of cellulose from the ionic solution might be an issue for the re-crystallization of cellulose chains. Indeed, when cellulose has been solubilized and regenerated, the transformation of cellulose type-I into type-II remains an irreversible process. This trend indicates that, during the dissolution process, IL molecules penetrate into the gap between hydrogen-bonded sheets in cellulose I and lead to a slight expansion of the lattice. Simultaneously, intermolecular hydrogen bonds are disturbed such that the long-range order within each sheet decreases (Cheng et al. 2012; Freire et al. 2011) (Fig. 6).
The addition of other microparticles or secondary (bio-) polymers, such as multi-walled carbon nanotubes (MWCNTs) (Rahatekar et al. 2009a; Zhang et al. 2007), modified MWCNTs (Liu et al. 2019; $\mathrm{Zhu}$ et al. 2014), graphene nanoplatelets (Härdelin and Hagström 2015), magnetite $\left(\mathrm{Fe}_{3} \mathrm{O}_{4}\right)$ powder (Maxim et al. 2012; Sun et al. 2008), rutile $\left(\mathrm{TiO}_{2}\right)$ (Maxim et al. 2010), nano-SiO 2 (Song et al. 2013), silver particles and charcoal (Wendler et al. 2009a, 2009b) (Chen et al. 2015b), has been also considered. Halloysite nanotubes (HNTs) (Luo et al. 2014) and nanolignin with cellulose solution using IL prior to the spinning process allow exploring the preparation of functional fibers with a specific physical, mechanical or biological properties. ILs are also ideal solvents since they can be used for the preparation of cellulose-polymer blends. In most cases, a small share of particles can also have a positive influence on the fiber strength until a certain threshold: once this limit is overcome, the tensile strength deteriorates with further addition of solids.

It is well recognized that the spinning process and fiber properties are strongly dependent on the rheological behavior of the applied cellulose/IL based solution. The shear rheological characterization 
Table 3 Mechanical properties of cellulose fibers produced with different wet-spinning method from different cellulose sources

\begin{tabular}{|c|c|c|c|c|c|c|c|}
\hline $\begin{array}{l}\text { Cellulose } \\
\text { source }\end{array}$ & Ionic Solvent & $\begin{array}{l}\text { Solution spin- } \\
\text { ning }\end{array}$ & $\begin{array}{l}\text { Spinning } \\
\text { concentration } \\
\text { and tempera- } \\
\text { ture } \\
\left({ }^{\circ} \mathrm{C}\right)\end{array}$ & Additive & Spinning bath & $\begin{array}{l}\text { Fiber proper- } \\
\text { ties: tensile } \\
\text { strength }(\mathrm{MPa}) \text {, } \\
\text { elongation }(\%)\end{array}$ & Reference \\
\hline $\begin{array}{l}\text { Soft wood pulp } \\
\mathrm{DP}=1050\end{array}$ & TBAA/DMSO & Wet-spinning & $\begin{array}{l}\mathrm{C}=4,6,8 \\
\text { and } 10 \mathrm{w} \%, \\
\mathrm{~T}=50\end{array}$ & - & Water $25^{\circ} \mathrm{C}$ & $\begin{array}{c}375 \mathrm{MPa} \\
9-11 \%\end{array}$ & $\begin{array}{r}\text { Sun et al. } \\
(2015 a)\end{array}$ \\
\hline $\begin{array}{l}\text { Eucalyptus } \\
\text { sulfite pulp, } \\
\text { DPw }=592\end{array}$ & [Emim] OAc & Wet-spinning & $\begin{array}{c}\mathrm{C}=6 \mathrm{w} \%, \\
\mathrm{~T}=90\end{array}$ & - & $\begin{array}{l}\text { Water/[emim] } \\
\text { Ac }\end{array}$ & $330 \mathrm{MPa}, 8 \%$ & $\begin{array}{l}\text { Ingildeev et al. } \\
\text { (2013) }\end{array}$ \\
\hline $\begin{array}{l}\mathrm{MCC} \\
\mathrm{DP}=1740\end{array}$ & {$[\mathrm{Amim}] \mathrm{Cl}$} & Wet-spinning & $\mathrm{C}=5 \mathrm{w} \%$ & - & Water & $170 \mathrm{MPa}, 1.5 \%$ & $\begin{array}{l}\text { Kim and Jang } \\
\text { (2013) }\end{array}$ \\
\hline $\begin{array}{l}100 \% \text { cotton } \\
\text { yarns, } \\
\mathrm{DP}=1260\end{array}$ & $\begin{array}{l}{[\mathrm{Amim}] \mathrm{Cl},} \\
{[\mathrm{Bmim}] \mathrm{OAc}}\end{array}$ & Wet-spinning & $\begin{array}{l}\mathrm{C}=10 \\
\mathrm{w} \%, \mathrm{~T}=40\end{array}$ & - & Water & $\begin{array}{c}141.32 \mathrm{MPa} \\
3.97 \%\end{array}$ & $\begin{array}{l}\text { De Silva et al. } \\
\text { (2016a) }\end{array}$ \\
\hline $\begin{array}{l}\text { Microcrystal- } \\
\text { line } \\
\text { Cellulose }\end{array}$ & {$[\mathrm{Amim}] \mathrm{Cl}$} & Wet-spinning & $\mathrm{C}=4 \mathrm{w} \%$ & - & Water, $80^{\circ} \mathrm{C}$ & $104 \mathrm{MPa}, 1.9 \%$ & $\begin{array}{c}\text { Chen et al. } \\
\text { (2015a) }\end{array}$ \\
\hline $\begin{array}{l}\mathrm{MCC} \\
\mathrm{DPw}=330\end{array}$ & [Emim] OAc & Wet- spinning & $\begin{array}{c}\mathrm{C}=10 \mathrm{w} \%, \\
\mathrm{~T}=70\end{array}$ & - & $\begin{array}{l}\text { Pure tap water, } \\
80^{\circ} \mathrm{C}\end{array}$ & $\begin{array}{l}105 \mathrm{MPa} \text { (dry), } \\
7 \%\end{array}$ & $\begin{array}{l}\text { Olsson and } \\
\text { Westman } \\
(2013)\end{array}$ \\
\hline $\begin{array}{l}\text { Bleached Kraft } \\
\text { dissolving } \\
\text { Pulp, } \\
\text { DPw }=1340\end{array}$ & [Emim] OAc & Wet -spinning & $\begin{array}{c}\mathrm{C}=10 \mathrm{w} \%, \\
\mathrm{~T}=70\end{array}$ & - & $\begin{array}{l}\text { Pure tap water, } \\
80^{\circ} \mathrm{C}\end{array}$ & $\begin{array}{l}240 \mathrm{MPa} \text { (dry), } \\
8 \%\end{array}$ & $\begin{array}{l}\text { Olsson and } \\
\text { Westman } \\
(2013)\end{array}$ \\
\hline $\begin{array}{l}\text { Cellulose } \\
\text { (Buck-eye) } \\
\text { DP }=850\end{array}$ & $\begin{array}{l}\text { [Emim]OAc as } \\
\text { solvent, DMF } \\
\text { and DMSO as } \\
\text { co-solvent }\end{array}$ & Wet- spinning & $\begin{array}{c}\mathrm{C}=7 \mathrm{w} \%, \\
\mathrm{~T}=70\end{array}$ & - & Water & $35 \mathrm{MPa}, 4.53 \%$ & Lee et al. (2019) \\
\hline Pulp sheets & [Emim] OAc & Wet -spinning & $\begin{array}{l}\mathrm{C}=12 \mathrm{w} \%, \\
\text { draw } \\
\text { ratio }=2.63\end{array}$ & - & Water & $41 \mathrm{MPa}$ & Li et al. (2014) \\
\hline
\end{tabular}
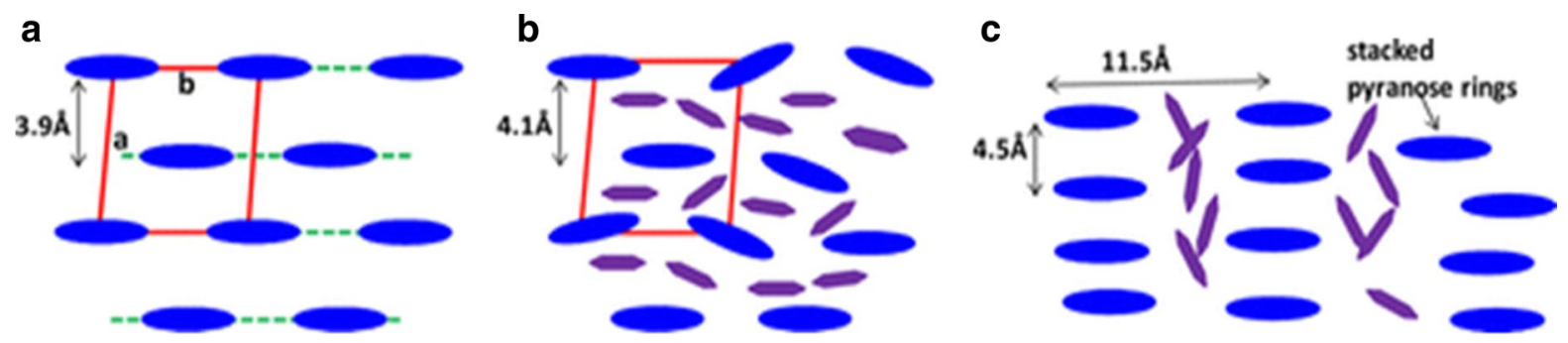

Fig. 6 a Schematic illustration of cellulose chain (blue) arrangement for the view parallel to the chain $\mathrm{c}$ axis and the unit cell for cellulose I $\beta$. The dotted lines along the $\mathrm{b}$ axis demonstrates the intermolecular hydrogen bonding that forms sheet structure. b The intermediate structure and the intercalation of [Emim]OAc molecules (purple) proposed here. c Proposed intermediate structure and the arrangement of intercalated [Emim]OAc molecules in ramie fibers from Samayam et al. (Cheng et al. 2012) 
and solution viscometry are essential for determining polymer solution properties to design processing strategies. Thus, the understanding of the concentration-dependent shear and extensional rheology of cellulose dissolved in ILs as well as the dynamics and thermodynamics of cellulose chains dispersed in ILs, are necessary steps toward realizing the potential of ILs as processing aids in fiber spinning (Haward et al. 2012; Song et al. 2010). Early studies on the macromolecular nature of cellulose and cellulose derivatives, as well in ILs, have established many of the fundamental concepts regarding the relationships between solution viscosity, polymer molecular weight, and polymer-solvent interactions (Haward et al. 2012; Klemm et al. 2005; Song et al. 2011, 2010; Zugenmaier 2009). However, for cellulose/ILs composites and blends, the situation is quite different. The presence of nanoparticles, CNT, polymers, or other additives strongly alters the rheology and viscoelastic behavior of the solution system. Table 4 shows fiber properties from different composite cellulose fibers produced with dry-jet-wet spinning method and from different cellulose sources.

Carbon nanotubes (CNTs) have been widely investigated owning to their excellent physicochemical and mechanical properties, and have an excellent potential as electrically conducting inclusions in textiles due to their great electrical conductivity and high aspect ratio (Xie et al. 2005b). They offer several advantages for polymeric composites, such as versatility as reinforcement in both thermoplastic and thermoset areas, extremely high tensile strength (150-180 GPa) and Young's modulus (640 GPa to $1 \mathrm{TPa}$ ), and their compatibility with other chemical compounds (Baur and Silverman 2007). Reinforcements with CNTs not only improve mechanical and thermal properties, but also provide additional functional properties. Preliminary studies have demonstrated the effect of multi-walled carbon nanotube (MWCNs) on thermal and mechanical properties of wet-spun cellulose fibers (Rahatekar et al. 2009b; Zhang et al. 2007). For the preparation of a polymer/CNT solution, a uniform CNT dispersion or a CNT solubilization in solvents is still challenging to achieve since CNTs have low surface energy, tend to form agglomerates, and are amphiphobic (repel common polar and nonpolar solvents) (Xie et al. 2005b). In 2007, Zhange et al. (2007) used AmimCl to fabricate regenerated cellulose fibers reinforced with different concentration of
MWCNs via dry-jet-wet-spinning process. In order to determine the degree of MWCNT dispersion in the $\mathrm{AmimCl}$, they considered the rheological properties of MWCNT/AmimCl mixtures (within 2-8 w\% of MWCNTs in AmimCl). In this study, the critical MWCNT concentration was between 2 w\% (liquidlike) and 4 w\% (gel-like).

Smooth round surfaces were obtained for both cellulose fibers and cellulose/MWCNT composite fibers (Fig. 7a). At 4 w\%, aligned MWCNs were well-dispersed within the cellulose matrix (Fig. $7 a_{\text {iii }}$ ). Higher CNT loadings resulted in aggregation of CNTs. The regenerated-cellulose/MWCNT composite fiber containing $4 \mathrm{w} \%$ MWCNTs exhibited improvement in mechanical properties.

MWCNs have been also successfully blended with cellulose using ethyl methylimidazolium acetate [Emim]OAc prior to the dry-jet-wet-spinning process. Rheological characterization of cellulose/ [Emim]OAc blends showed pseudoplastic shear thinning behavior. The $0.01,0.03,0.05,0.07$, and 0.1 MWCNT mass fraction solutions used for fiber spinning also exhibited a strong shear thinning behavior. Cellulose orientation and crystal size subsequently tensile strength and strain to failure of the fibers were significantly higher in the composite than in the control cellulose fiber while Young's Moduli essentially remained unchanged. A relative improvement (30\%) in the tensile strength of MWNT/cellulose composite fibers was obtained by adding up to 0.07 mass fractions MWNT. Moreover, the composite fibers exhibited lower thermal shrinkage than the control cellulose fibers (Rahatekar et al. 2009a; Rahatekar et al. 2009b). Besides, Zhu et al. (2014) improved the dispersion of carbon nanotubes in [Emim]OAc and in cellulose solution dope by non-covalently surface modification of CNTs using carboxymethyl cellulose (CMC) (Fig. 7b). The influence of fiber extrusion rate and fiber winding speed on the degree of alignment of the electrical conductivity of the cellulose/carbon nanotube composite fibers was investigated.

Sun et al. prepared functionalized cellulosic fibers by using magnetite particles and 1-ethyl-3-methylimidazolium chloride as the ionic solvent (Sun et al. 2008). The fiber texture was affected by cellulose concentration, molecular weight in the spinning solution and magnetite concentration. The enhanced degree of polymerization (DP) and/or cellulose concentration improved mechanical properties of the fibers while 
Table 4 Fiber properties of different composite cellulose fibers produced with dry-jet-wet- spinning method from different cellulose sources. MWCNT = multiwalled carbon nanotubes

\begin{tabular}{|c|c|c|c|c|c|c|c|}
\hline $\begin{array}{l}\text { Cellulose } \\
\text { source }\end{array}$ & Ionic solvent & $\begin{array}{l}\text { Solution } \\
\text { spinning }\end{array}$ & $\begin{array}{l}\text { Concentration \& } \\
\text { temperature }\left({ }^{\circ} \mathrm{C}\right)\end{array}$ & Additive & $\begin{array}{l}\text { Spinning } \\
\text { bath }\end{array}$ & Fiber properties & References \\
\hline $\begin{array}{l}\text { Cellulose, } \\
\mathrm{DP}=820\end{array}$ & $\begin{array}{c}{[\text { Emim }]} \\
\text { OAc }\end{array}$ & $\begin{array}{l}\text { Dry-jet wet } \\
\text { spinning }\end{array}$ & $\begin{array}{l}\text { From } 0.07 \text { to } 0.045 \\
\text { mass fraction }\end{array}$ & $\begin{array}{l}\text { MWCNT } \\
(0.01,0.05 \\
\text { and } 0.1 \\
\text { mass frac- } \\
\text { tion) }\end{array}$ & Ethanol & $\begin{array}{l}\text { Tensile strength } \\
244,253 \text {, } \\
179 \mathrm{MPa} \text {; elonga- } \\
\text { tion } \\
3.7 \%, 5.8 \%, 3.2 \% \text {; } \\
\text { fiber diameter } \\
16.6,17.4 \text { and } \\
29.6 \mu \mathrm{m}\end{array}$ & $\begin{array}{l}\text { Rahatekar } \\
\text { et al. } \\
(2009 a, b)\end{array}$ \\
\hline $\begin{array}{l}\text { Wood pulp } \\
(\alpha \text {-cellulose } \\
94.9 \%)\end{array}$ & {$[\mathrm{Amim}] \mathrm{Cl}$} & $\begin{array}{l}\text { Dry-jet wet } \\
\text { spinning }\end{array}$ & $\mathrm{C}=4 \mathrm{w} \%, \mathrm{~T}=100$ & $\begin{array}{l}\text { MWCNT } \\
(4 \mathrm{w} \%)\end{array}$ & & $\begin{array}{l}\text { Tensile strength } \\
335 \mathrm{MPa} \text {, Storage } \\
\text { modulus } 17.6 \\
\mathrm{GPa}\end{array}$ & $\begin{array}{l}\text { Zhang et al. } \\
\text { (2007) }\end{array}$ \\
\hline $\begin{array}{l}\text { Cellulose } \\
\text { pulp sheets } \\
\mathrm{DP}=890\end{array}$ & $\begin{array}{c}{[\mathrm{Emim}]} \\
\mathrm{OAc}\end{array}$ & $\begin{array}{l}\text { Dry-jet wet } \\
\text { spinning }\end{array}$ & $\begin{array}{l}\mathrm{C}=0.08 \mathrm{w} \% \\
\text { extrusion } \\
\quad \text { speed }=2.65 \cdot 10^{-3} \mathrm{~m} / \mathrm{s}\end{array}$ & $\begin{array}{l}\text { Modified } \\
\text { MWCNs } \\
\text { with CMC } \\
\text { (0.1 mass } \\
\text { fraction) }\end{array}$ & )Water & $\begin{array}{l}\text { Conductivity } \\
0.24 \mathrm{~m} / \mathrm{s}\end{array}$ & $\begin{array}{l}\text { Zhu et al. } \\
\text { (2014) }\end{array}$ \\
\hline $\begin{array}{l}\mathrm{MCC} \\
\mathrm{DP}=270\end{array}$ & {$[\mathrm{Emim}] \mathrm{Cl}$} & $\begin{array}{l}\text { Dry-jet wet } \\
\text { spinning }\end{array}$ & $\mathrm{C}=11.5 \mathrm{w} \%$ & $\begin{array}{l}\mathrm{Fe}_{3} \mathrm{O}_{4} \\
0,10,20 \text {, or } \\
\quad 30 \mathrm{w} \%\end{array}$ & Water & $\begin{array}{l}\text { Ultimate } \\
\text { Stress } 129,82,71 \text {, } \\
59 \mathrm{MPa}\end{array}$ & $\begin{array}{l}\text { Sun et al. } \\
\text { (2008) }\end{array}$ \\
\hline $\begin{array}{l}\text { (MCC) } \\
\text { powder }\end{array}$ & [Emim]OAc & $\begin{array}{l}\text { Dry-jet wet } \\
\text { spinning }\end{array}$ & $\mathrm{C}=8.25 \mathrm{w} \%$ & $\begin{array}{l}\text { Nanomag- } \\
\text { netite } \\
\text { particles } \\
(\mathrm{NM}) \\
(0 \text { to } 10 \mathrm{w} \%)\end{array}$ & Water & $\begin{array}{l}\text { Ultimate } \\
\text { Stress } 121- \\
99 \mathrm{MPa} \text {, Elonga- } \\
\text { tion }=28 \%-14 \%\end{array}$ & $\begin{array}{l}\text { Maxim et al. } \\
\text { (2012) }\end{array}$ \\
\hline $\begin{array}{l}\mathrm{MCC} \\
\mathrm{DP}=270\end{array}$ & {$[\mathrm{Emim}] \mathrm{Cl}$} & $\begin{array}{l}\text { Dry-jet wet } \\
\text { spinning }\end{array}$ & $\mathrm{C}=14 \mathrm{w} \%$ & $\begin{array}{l}\mathrm{TiO}_{2}=3.5 \\
5.0,7.5 \\
\text { w\% }\end{array}$ & Water & $\begin{array}{l}\text { Tensile strength } \\
127,112,106 \\
125 \mathrm{MPa}\end{array}$ & $\begin{array}{l}\text { Maxim et al. } \\
(2010)\end{array}$ \\
\hline $\begin{array}{l}\mathrm{MCC} \\
\mathrm{DP}=200\end{array}$ & {$[\mathrm{Amim}] \mathrm{Cl}$} & $\begin{array}{l}\text { Dry-jet wet } \\
\text { spinning }\end{array}$ & $\mathrm{C}=5,7,9 \mathrm{w} \%$ & $\begin{array}{l}\text { nano- } \\
\mathrm{SiO}_{2}=4, \\
6,8,10 \\
\text { and } 12 \\
\text { w\%) }\end{array}$ & Water & $\begin{array}{l}\text { Tensile } \\
\text { strength } \sim 56 \mathrm{MPa}\end{array}$ & $\begin{array}{l}\text { Song et al. } \\
\text { (2013) }\end{array}$ \\
\hline $\begin{array}{l}\text { Eucalyptus } \\
\text { pulp } \\
\mathrm{DP}=569\end{array}$ & {$[\mathrm{Bmim}] \mathrm{Cl}$} & $\begin{array}{l}\text { Dry-jet wet } \\
\text { spinning }\end{array}$ & $\begin{array}{l}\mathrm{C}=12 \mathrm{w} \%, \mathrm{~T}=80 \\
\quad \text { to } 120\end{array}$ & $\begin{array}{l}\text { Silver } \\
\text { particles } \\
(0.1 \mathrm{w} \%) \\
\text { \& charcoal } \\
(6 \mathrm{w} \%)\end{array}$ & Water & $\begin{array}{l}\text { Tensile strength } \\
635 \mathrm{MPa} \text { for } \\
\text { microsilver, } \\
194 \mathrm{MPa} \text { for } \\
\text { charcoal }\end{array}$ & $\begin{array}{l}\text { Wendler } \\
(2009 a, \\
2009 b)\end{array}$ \\
\hline Wood pulp & {$[\mathrm{Bmim}] \mathrm{Cl}$} & $\begin{array}{l}\text { Dry-wet } \\
\text { spinning }\end{array}$ & $\mathrm{C}=6 \mathrm{w} \%, \mathrm{~T}=100$ & $\begin{array}{l}\text { Nano } \\
\quad \text { silver }=0 \text {, } \\
0.5,1.0 \\
\text { w\% }\end{array}$ & Water & $\begin{array}{l}\text { Tensile strength } \\
\text { 16.5 MPa, Elon- } \\
\text { gation } 23.77 \% \text {, } \\
22.79 \%, 31.03 \%\end{array}$ & $\begin{array}{l}\text { Chen et al. } \\
\text { (2015b) }\end{array}$ \\
\hline $\begin{array}{l}\text { Cellulose } \\
\text { pulp sheets } \\
\mathrm{DP}=890\end{array}$ & $\begin{array}{l}{[\mathrm{Emim}]} \\
{\left[\mathrm{Et}_{2} \mathrm{PO}_{4}\right]}\end{array}$ & $\begin{array}{l}\text { Dry-jet wet } \\
\text { spinning }\end{array}$ & $\mathrm{C}=4 \mathrm{w} \%$ & $\begin{array}{l}\text { Curcumin } \\
0,1,5,10 \\
\text { w\% }\end{array}$ & Water & $\begin{array}{l}\text { Tensile strength } \\
\text { 270.7, 336.7, } \\
\text { 284.3, 223.2 } \mathrm{MPa}\end{array}$ & $\begin{array}{l}\text { Coscia et al. } \\
\text { (2018) }\end{array}$ \\
\hline
\end{tabular}

the presence of magnetite particles weakens the overall mechanical properties. In a second work, (Maxim et al. 2012) the authors prepared nanomagnetite (NM)-loaded cellulose fibers via dry-jet-wet spinning using ([Emim]OAc) as an ionic solvent. The presence of $0.75 \%$ (mass ratio) nanomagnetite in the cellulose matrix significantly improved the mechanical properties of the fibers, while the higher amount of NM, led 
Fig. 7 a SEM images of cross-sectional fracture of $\mathbf{a}_{\mathrm{i}}$ the cellulose, $\mathbf{a}_{\mathrm{ii}}$ cellulose/MWCN composite fibers and $\mathbf{a}_{\mathrm{iii}}$ TEM image of the composite fiber. MWCN (4 w \%) (Zhang et al. 2007), b Optical micrographs of MWNTs dispersion in [Emim][Ac] $\mathbf{b}_{\mathrm{i}}$ without carboxymethyl cellulose (CMC) and $\mathbf{b}_{\mathrm{ii}}$ with CMC(Zhu et al. 2014), c A TEM image of the nanocomposite fiber (Song et al. 2013), d d d Macroscopic and $\mathbf{d}$ ii microscopic presentation of composite fibres. Cellulose with a concentration of $5 \%$ curcumin (Coscia et al. 2018)
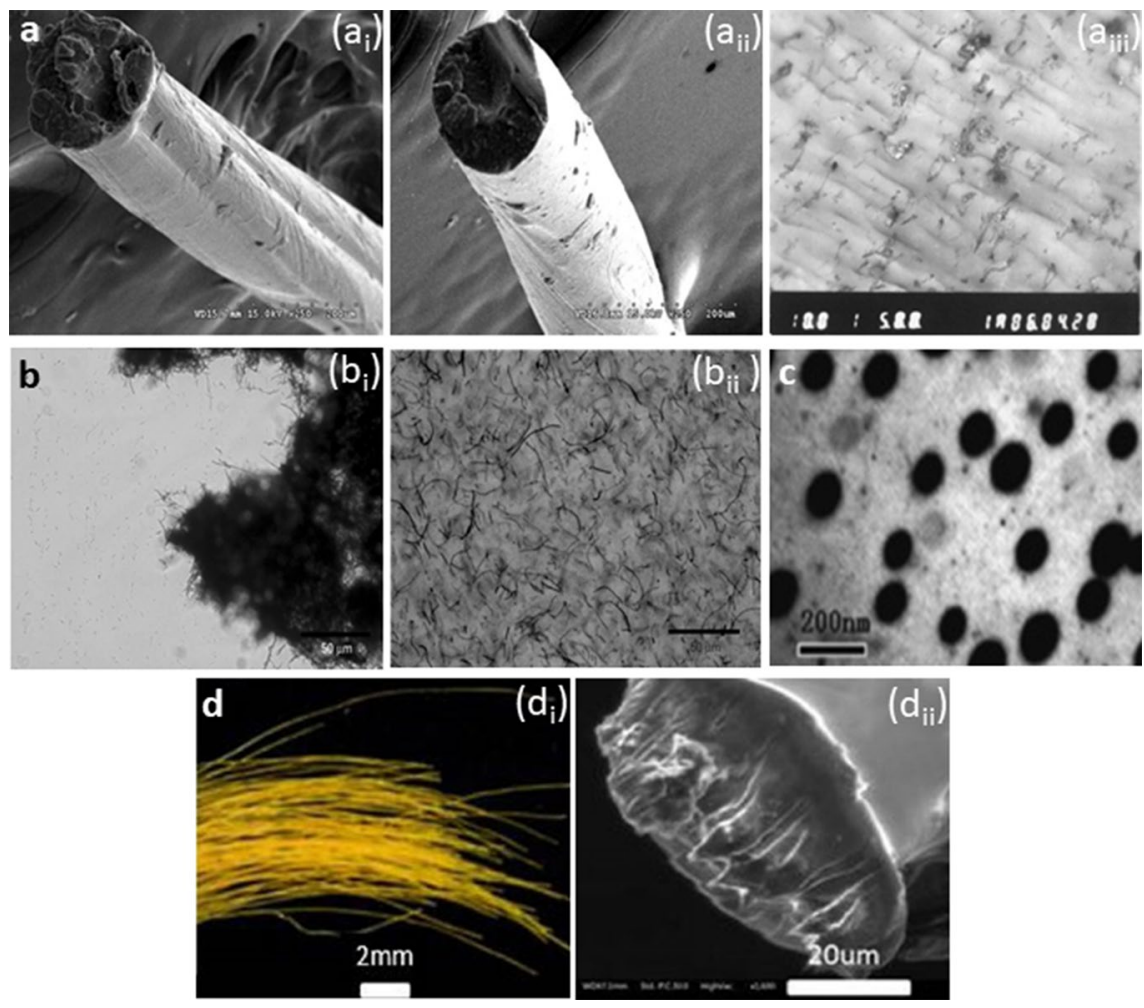

to a reduction of mechanical properties as a result of large agglomerates that create defects within fibers. The authors also incorporated $\mathrm{TiO}_{2}$ microparticles inside the fibers to improve the antibacterial and photocatalytic properties of cellulose fibers using previous procedure. Results revealed that the presence of particles (5 w\%) did not have a considerable effect on mechanical properties of fibers and particles have the tendency to outcrop the surface of the fibers that provided a large active surface area (Maxim et al. 2010). Song et al. (2013) used [Amim] $\mathrm{Cl}$ as a good solvent for cellulose and well dispersant for nano- $\mathrm{SiO}_{2}$ to produce bio-nanocomposite fiber via dry-jet-wet spinning method. Generally, the presence of nanoparticles drastically alters the viscoelastic properties of the solution. In this study, from the oscillatory shear measurements for the microcrystalline cellulose (MCC)/nano- $\mathrm{SiO}_{2} / \mathrm{AMIMCl}$ solutions (with different content of nano- $\mathrm{SiO}_{2}$ in a range of $0-12 \mathrm{w} \%$ ), it was found that the storage moduli $\left(\mathrm{G}^{\prime}\right)$ and viscosity of the solution enhanced with the increase of nano$\mathrm{SiO}_{2}$ content, and the gelatin network occurred above $10 \mathrm{w} \%$ nano- $\mathrm{SiO}_{2}$. Moreover, the shear viscosity of the solutions with nano- $\mathrm{SiO}_{2}$ was lower than that of
cellulose/IL solutions under high shear rates. At 8 w\% well-dispersed particles were observed (Fig. 7c) and tensile strength of the nanocomposite fibers had the highest values. The regenerated cellulose and nanocomposite fibers were the typical cellulose II crystalline form, which was different from the native cellulose with the dominated polymorph of Type I. The nanocomposites exhibited higher thermal stability by increasing the amount of nano- $\mathrm{SiO}_{2}$.

Recently, Coscia et al. produced bio-renewable regenerated curcumin/cellulose composites fibers via dry-jet-wet-spinning method using $[$ Emim] $]\left[\mathrm{Et}_{2} \mathrm{PO}_{4}\right]$ as the IL. Curcumin was found to be uniformly dispersed in cellulose fibers and led to formation of yellow fibers (Fig. 7d) (Coscia et al. 2018). The presence of curcumin improved mechanical properties of fibers. Such strong cellulose fiber with a pharmacologically potent drug curcumin could be applied for medicinal, cosmetic and food packaging applications.

\section{Wet spinning}

More recently, Liu and coworkers used an ecofriendly wet-spinning method (Fig. 8) to produce 
Fig. 8 Schematic of eco-friendly wet-spinning method (Liu et al. 2019)

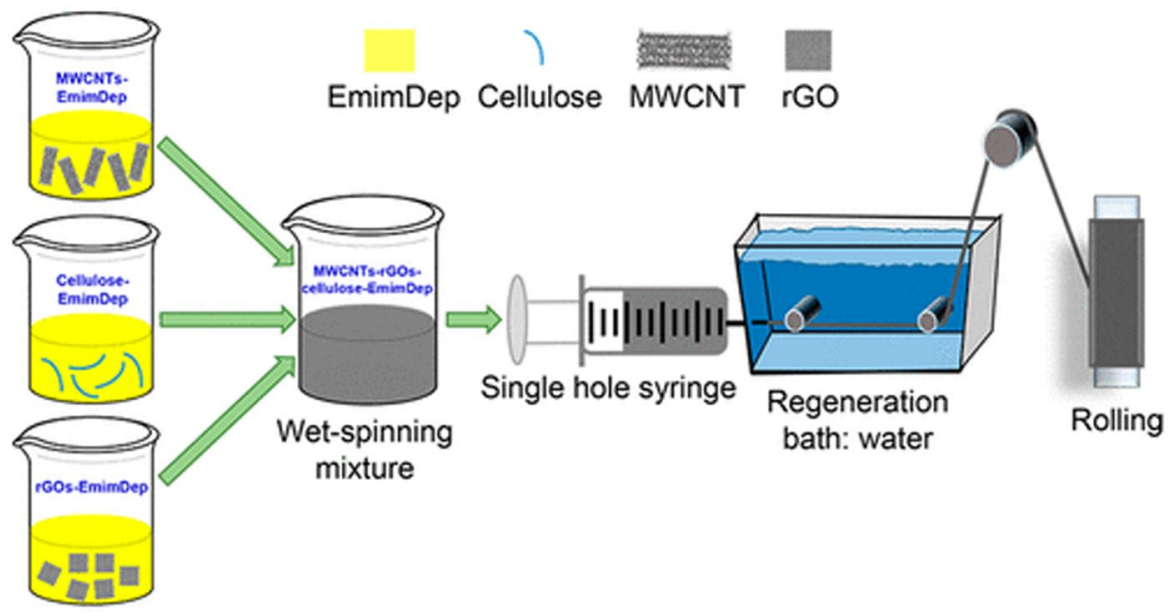

conductive MWCNTs-graphene sheets (rGOs)-cellulose fiber with a mass ratio of 2:3:1 in which 1-ethyl3-methylimidazolium diethyl phosphate [Emim] $\left[\mathrm{Et}_{2} \mathrm{PO}_{4}\right]$ was used as both green solvent and dispersant (Liu et al. 2019). Results showed that the dispersion was improved as a result of the synergy effect of CNT and rGO in comparison to each individual component. The obtained fibers showed electrical conductivity of $1195 \mathrm{~S} / \mathrm{m}$, the specific capacitance of $597 \mathrm{mF} / \mathrm{cm}^{2}$, and a specific surface area of $91 \mathrm{~m}^{2} / \mathrm{g}$.

Härdelin and Hagström dispersed carbon black (CB) and graphene nanoplatelets (GNP) in an IL ([Emim]OAc) based cellulose solution using shear mixing and produced carbon filler-loaded cellulose fibers using the wet-spinning method (Härdelin and
Hagström 2015). The presence of CB and GNP particles in the spin dope led to the formation of micropores in the fiber. Low adhesion between cellulose and filler particles in combination with the developed microporosity led to the reduction of fiber tenacity.

To improve the thermal stability and tensile strength of the MCC fibers, Luo et al. (2014) incorporated halloysite nanotubes (HNTs), a new type of clay, inside the fiber using [Amim] $\mathrm{Cl}$ as ionic liquid solvents. The results indicated that the addition of HNTs not only modified thermal and mechanical properties but also significantly improved the moisture barrier properties of the regenerated MCC fibers. Table 5 shows fiber properties from different composite cellulose fibers produced with

Table 5 Fiber properties of different composite cellulose fibers produced with wet- spinning method from different cellulose sources

\begin{tabular}{|c|c|c|c|c|c|c|c|}
\hline $\begin{array}{l}\text { Cellulose } \\
\text { source }\end{array}$ & Ionic solvent & $\begin{array}{l}\text { Solution spin- } \\
\text { ning }\end{array}$ & $\begin{array}{l}\text { Concen- } \\
\text { tration \& } \\
\text { temperature } \\
\left({ }^{\circ} \mathrm{C}\right)\end{array}$ & Additive & Spinning bath & Fiber properties & References \\
\hline Cotton pulp & $\begin{array}{l}{[\mathrm{Emim}]} \\
{\left[\mathrm{Et}_{2} \mathrm{PO}_{4}\right]}\end{array}$ & Wet-spinning & $\mathrm{C}=1 \mathrm{w} \%$ & $\begin{array}{l}\text { MWCNTs, } \\
\text { graphene } \\
\text { sheets }\end{array}$ & Water & $\begin{array}{l}\text { Tensile } \\
\text { strength } \sim 5.5 \mathrm{MPa} \text {, } \\
\text { electrical conduc- } \\
\text { tivity }=1195 \mathrm{~S} / \mathrm{m}\end{array}$ & $\begin{array}{l}\text { Liu et al. } \\
\text { (2019) }\end{array}$ \\
\hline $\begin{array}{l}\text { Pulp } \\
\text { DP }=620 \text { and } \\
1360\end{array}$ & [Emim] OAc & Wet-spinning & $\begin{array}{c}\mathrm{C}=6 \mathrm{w} \% \\
\text { extrusion } \\
\text { speed }=2 \\
\mathrm{~m} \mathrm{~min}^{-1}\end{array}$ & $\begin{array}{l}\text { Carbon black } \\
\text { (CB), } \\
\text { graphene } \\
\text { nanoplate- } \\
\text { lets (GNP) }\end{array}$ & Water $60^{\circ} \mathrm{C}$ & $\begin{array}{l}\text { Tensile strength } \\
120 \mathrm{MPa} \text { (with } \\
\mathrm{CB}), 150 \mathrm{MPa} \\
\text { (with GNP) }\end{array}$ & $\begin{array}{l}\text { Härdelin and } \\
\text { Hagström } \\
(2015)\end{array}$ \\
\hline $\begin{array}{l}\text { MCC } \\
\text { (Vivapur } \\
101) \\
\text { DP }=200\end{array}$ & {$[\mathrm{Amim}] \mathrm{Cl}$} & Wet-spinning & $\mathrm{C}=9 \mathrm{w} \%$ & $\begin{array}{l}\text { Halloysite } \\
\text { nanotubes } \\
\text { (HNTs) (0 } \\
\text { to 9) w\% }\end{array}$ & $\begin{array}{l}\text { Deionized } \\
\text { water }\end{array}$ & $\begin{array}{l}\text { Tensile strength } \\
73.8-113.8 \mathrm{MPa} \text {, } \\
\text { Elongation } \\
17.1 \%-12.0 \%\end{array}$ & $\begin{array}{l}\text { Luo et al. } \\
\text { (2014) }\end{array}$ \\
\hline
\end{tabular}


wet spinning method and from different cellulose sources. The dependence of dynamic storage modulus $\left(\mathrm{G}^{\prime}\right)$, loss modulus $\left(\mathrm{G}^{\prime \prime}\right)$ and complex viscosity $\left(\left|\eta^{*}\right|\right)$ for the 9 w\% MCC/AMIMCl/HNTs dispersions with different content of HNTs measured. For the pure $\mathrm{MCC} / \mathrm{AMIMCl}$ solutions, $\mathrm{G}^{\prime}$ was always smaller than $\mathrm{G}^{\prime \prime}$ and showed a typical liquid-like behavior. Rheological measurements showed that the dispersions had stronger shear thinning behavior and the dispersions displayed stronger birefringence with increasing HNT content.

\section{Solution-spinning of cellulose/polymer blend fibers}

Blend fibers consisting of man-made polymeric materials and natural and renewable biopolymers such as polysaccharides are well established in a multitude of applications such as textile markets. However, the physicochemical properties of natural polysaccharides like cellulose limit their processability. In this case, IL solutions may open a new window for the blend fiber production by substituting hazardous solvents for cellulose processing (Tavanaie 2013). Since ILs are able to dissolve a wide range of polymers, the production of cellulose-polymer blend fibers has received a lot of attention. However, the formation of a homogeneous solution of different polymers does not necessarily result in the formation of a homogeneous blend fiber phase separation can occur upon coagulation if polymers are not compatible. Generally, natural polymers tend to have a strong affinity to cellulose.

\section{Dry-jet-wet spinning}

In two extensive studies, 15 different polysaccharides were used to investigate their miscibility and processability with cellulose in solutions using [Emim]OAc (Wendler et al. 2010, 2011). The rheological behavior of the solutions was considered to investigate the effect of polysaccharide addition compared to pure cellulose solution. The results indicated that the blend solutions (especially, xanthan, gum tragacanth and LBG) exhibited higher viscosities and elasticity than the pure counterparts.

Polysaccharides with a structure similar to cellulose, e.g., xylan, were miscible, while high-molar and side chains containing polysaccharides such as xanthan gum formed co-continuous morphologies. Blend fibers produced with dry-jet-wet spinning represented lower physical properties compared to the unmodified fiber.

Chitin and chitosan have also shown a desirable miscibility with cellulose to produce bi-polymeric fibers and films (Fu et al. 2017). Walther et al. concluded that 1-ethyl- 3-methylimidazolium propionate ([Emim]Opr) dissolves cellulose-chitin mixtures better than dialkylimidazolium acetates or halides (Walther et al. 2016).

Cellulose/chitosan blends also show promising systems for creating new polymeric materials with improved properties. The reactivity of chitosan is more versatile than cellulose due to the presence of $\mathrm{NH}_{2}$ groups (Dutta et al. 2004). Blend cellulose/chitosan fibers produced by dry-jet-wet spinning method with higher tensile strength in comparison to regenerated cellulose fibers have been reported using the mixture of glycine hydrochloride and $\left[\mathrm{B}_{4} \mathrm{mim}\right] \mathrm{Cl}(\mathrm{Ma}$ et al. 2012).

Lehmann and co-workers have demonstrated that cellulose can be co-processed with lignin added to the cellulose solution (Lehmann et al. 2013, 2012). Some studies have used dry-jet-wet spinning to produce lignocellulosic fibers (Ma et al. 2015; Sun et al. 2011). Ma et al. (2015) produced high performance regenerated cellulosic fibers using recycled and low refined lignocellulosic materials using [DBNH]OAc as the IL (Fig. 9 a, $\mathrm{a}_{\mathrm{i}}$ ).

The relationship between the chemical composition/structure of the raw materials, hemicelluloses and two different types of lignin (isolated pure lignin and residue lignin in the native form), the viscoelastic properties of spinning dope, spinnability, fiber tensile properties and the morphology of the spun fibers have been investigated. The rheology measurement of the dopes indicated that the increasing of the
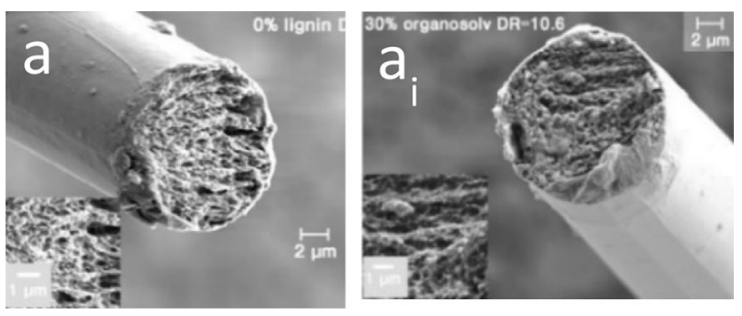

Fig. 9 SEM images of cross section of composite fibers with a, $0 \%$, ai 30\% lignin (Ma et al. 2015) 
lignin content decreased the zero shear viscosity and dynamic moduli. To compensate for the loss of the zero shear viscosity, the solutions were spun at lower temperatures. Dissolution and spinning of lignin and cellulose blends with ratios as high as 1:1 can be achieved. Recycled lignocellulosic, such as fine paper, cardboard, and newsprint were also assayed for their spinnability through the Ioncell process in [DBNH]OAc. The dope prepared from recycled fine paper showed great spinnability.

Blending of cellulose with synthetic polymers using ILs is more complicated since hydrophilic areas in the polymer should facilitate miscibility (Ingildeev et al. 2012). Both formation of a homogenous copolymer matrix and phase separation upon coagulation of a Polyacrylonitrile (PAN)/cellulose IL solution have been reported (Ingildeev et al. 2012; Zhang et al. 2019b). Fibrillated regenerated cellulose fibers have been developed via the immiscible blending of PAN and cellulose in [Bmim]Cl (Fig. 10). Since fiber spinning greatly depended on rheological properties of spinning dope, the shear viscosity $(\eta)$ as a function of the shear rate was measured. The viscosity totally decreased with increasing shear rate, which indicated non-Newtonian flow and a typical highly viscous liquid. At low shear rates (below $5 \mathrm{~s}^{-1}$ ) the $\eta$ of Cellulose/PAN blend solutions was larger than that of the Neat Cellulose. At higher shear rates (above $10 \mathrm{~s}^{-1}$ ), due to shear-thinning, a decrease of $\eta$ was observed. For dry-jet wet spinning of fibers, the spinning dopes prepared with the fixed cellulose concentration of $10 \mathrm{w} \%$ and the weight ratio of Cell/PAN 100/10 and $100 / 20$. DMSO was used to remove the PAN phase and mechanical fibrillation treatment was applied to the fibers into microfibrillated cellulose fibers. The immiscible polymer blending approach shows good potential for the production of fibrillated cellulose with controllable size via a simple and energy-saving method (Zhang et al. 2019b).

Cellulose/aromatic polysulfonamide (PSA) blended fibers were successfully produced using dry-jet wet spinning technology and $[\mathrm{Bmim}] \mathrm{Cl}$ as the ionic solvent in order to improve flame-retardant, hydrophilic and mechanical properties. Results demonstrated a strong interaction between cellulose and PSA. The hydrophilic and mechanical properties of blended fibers was enhanced with increasing the content of cellulose (Wu et al. 2017).

\section{Wet-spinning}

Mundsinger et al. (2015) prepared wet-spun cellulose fibers, containing up to $25 \mathrm{w} \%$ chitin using [Emim] $\mathrm{OPr}$ as a solvent. The rheology of the spinning dopes was investigated for different biopolymer ratios. Chitin/cellulose solutions with relatively low amount of cellulose exhibited very low zero shear viscosities compared to pure cellulose dopes. Decreasing the chitin to cellulose ratio (the total biopolymer concentration set at $8 \mathrm{w} \%$ ) caused an increase in the zero

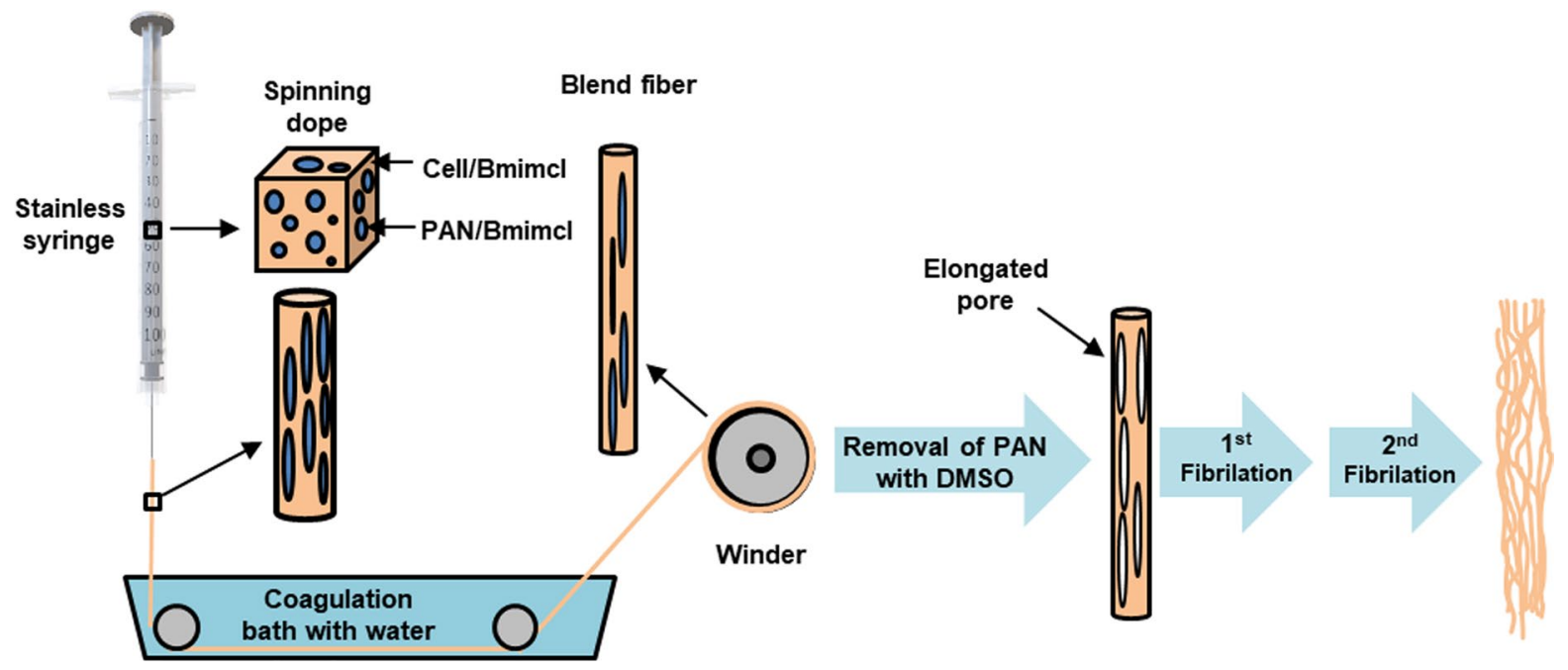

Fig. 10 Schematic illustration of the preparation of cellulose microfibrils (Zhang et al. 2019b) 
Fig. 11 SEM images of cross section and surface of $\left(\mathbf{a}, \mathbf{a}_{\mathrm{i}}\right)$ cellulose-chitin blend fiber (75:25) (Mundsinger et al. 2015), $\mathbf{b}, \mathbf{b}_{\mathrm{i}}$ cellulose fiber (De Silva et al. 2016b), c, $\mathbf{c}_{\mathrm{i}}$ cellulose/duck feather blend fiber (10:90) fibers (De Silva et al. 2016b)
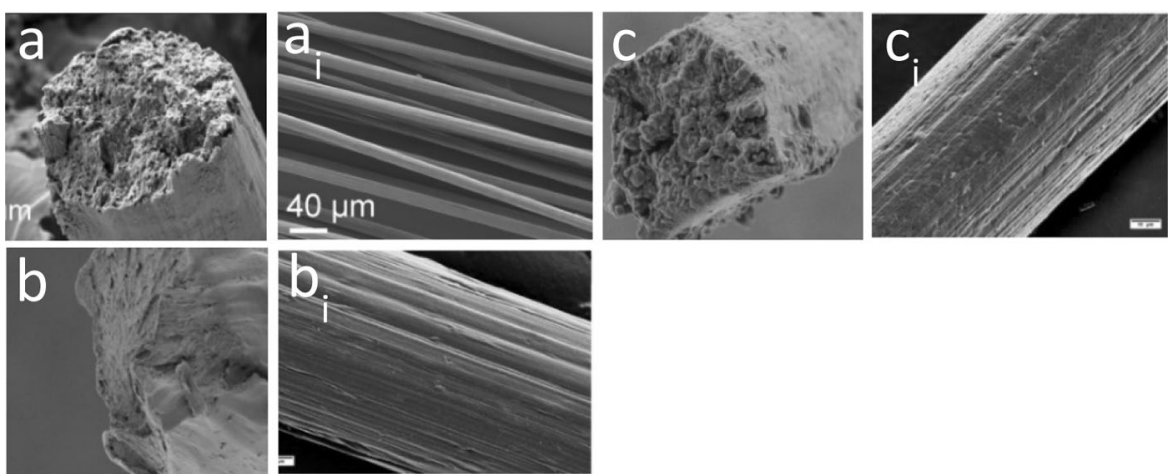

shear viscosity of the mixture. A dope containing 6 $\mathrm{w} \%$ of cellulose and $2 \mathrm{w} \%$ of chitin in [Emim]OPr displayed rheological properties that were sufficient for multifilament production. Wet-spun multifilament fibers were successfully obtained (Fig. 11a, $a_{\mathrm{i}}$ ). Silva et al. (2016b) developed composite fibers of cellulose and duck feathers (Fig. 11b, c), using [Amim]OAc as common solvent with improved mechanical properties $(+63.7 \%$ of the tensile strain) over regenerated cellulose fibers (RCF).

Other blend fibers such as cellulose/polyacrylonitrile, cellulose/polyamide (Ingildeev et al. 2012) and cellulose/polycaprolactone (Xiong et al. 2012) have been easily produced through concurrent dissolution of cellulose and synthetic polymer and subsequent wet spinning. Mutual miscibility of the two components is the most important factor which affects the mechanical properties of blend fibers. It is worth mentioning that even these promising first results; the synthesis of cellulose blends via IL solutions is still facing some challenges. Chemical derivatization and composites and blends formation of polysaccharides is limited by the low solubility and the low thermal stability of these materials. The presence of ILs with sufficient solubility of cellulose opens new windows for its functionalization and processing and can basically change the current situation. However, the advantages offered by IL for the synthesis of cellulose-based composites and blends have only been partially exploited to date (Pereira et al. 2018).

\section{Electrospinning of cellulose with ionic solvents}

Cellulose nanostructures have recently gained increased attention and found advanced applications in various fields. Nanocellulose merges the inherent features of cellulose and specific characteristics of nanoscale materials. Given that cellulose is one of the oldest polymers used in manufacture of fibers, it has been taken into consideration and proposed for production of nanofibers. Regenerated cellulose ultrafine fibers in the nanometer range due to special morphology and geometrical dimensions, possess improved properties different from conventional micro fibers, interesting for industrial applications (Bazbouz et al. 2019; Otsuka et al. 2017; Zhang et al. 2019c). Electrospinning is a simple and effective process to produce the polymeric nanofibrous materials for a wide range of applications. This method works based on the drawing of viscoelastic solution or melt under a strong electrostatic field (Foong et al. 2020; Maleki et al. 2020, 2018; Mokhena and John 2019; Udangawa et al. 2019). Fiber deposition using different collectors and by manipulating the electrical field can result in various structures in the form of randomly oriented webs or aligned bundles and yarns. Moreover, electrospinning allows modulating the characteristics and functionalities of nanofibrous structures by controlling the fiber features (morphology, diameter, crystallinity, porosity, etc.) by tuning solution properties and adjusting the process variables (Foong et al. 2020; Maleki et al. 2017; Zavgorodnya et al. 2017). The nanofibrous structures composed of electrospun cellulose fibers generally exhibit several excellent characteristics, likely very large surface area over volume ratio, high porosity with a very small pore size, mechanical reinforcement, and enhanced surface reactivity, which make them appropriate candidates for diverse technical, industrial, and biomedical applications such as functional textiles, filtration membranes, tissue engineering scaffolds, wound 
healing, drug delivery, etc. (Ahn et al. 2012a, b; Bazbouz et al. 2019; de Campos et al. 2019; Devarayan et al. 2013; Freire et al. 2011; Kang et al. 2013; Liu et al. 2017; Mokhena and John 2019; Nechyporchuk et al. 2016; Norrrahim et al. 2018; Otsuka et al. 2017; Zhang et al. 2019c; Zheng et al. 2014). In contrast to the advantages, due to the poor solubility of cellulose in volatile solvents, the electrospinning of cellulose is chalenging. The strong inter- and intra-molecular interactions of hydrogen bonding and rigid backbone structure of cellulose limit its dissolution in common solvents suitable for electrospinning. Thus, electrospinning of cellulose is challenging and specific procedures need to be considered for the fabrication cellulosic nanofibers using this method (Abdul Khalil et al. 2015b; Frey 2008; Härdelin et al. 2012; Hsieh 2018; Kargarzadeh et al. 2018; Le Corre et al. 2014; Prasanth et al. 2014; Quan et al. 2010; Xu et al. 2008; Zavgorodnya et al. 2017).

Many attempts have been devoted to achieve an effective and eco-friendly solvent for electrospinning cellulose. The different solvent systems used in wetor dry-jet-wet spinning processes, including $\mathrm{NMMO/}$ water, lithium chloride/dimethylacetamide ( $\mathrm{LiCl} /$ DMAc), $\mathrm{NaOH} /$ urea, and DMSO/triethylamine/ $\mathrm{SO}_{2}$, have also been used for the electrospinning procedure (Bhat et al. 2019; Chen et al. 2017; Thakur et al. 2017; Xu et al. 2018b; Zhang et al. 2017a, 2019b). Swatloski et al. set a milestone for cellulose processing since they first reported a procedure to dissolve cellulose in ILs (Swatloski 2002). Solubility of cellulose in ILs boosted the electrospinning procedure and ILs-based solvents have been proposed as nontoxic and nonflammable media (Bhat et al. 2019; Hou et al. 2016; Zhang et al. 2019b). However, due to its high viscosity and nonvolatile nature, electrospinning of a cellulose/ILs solution is challenging and it is not easy to control. During the electrospinning process, the solvent has to be removed completely from the fibers. Partial solvent removal can result in fiber fusion, and fiber deposits tend to collapse and agglomerate. ILs cannot evaporate completely between the electrospinning nozzle and the collector due to their low volatility. Hence, to control the morphology of the electrospun fibers, an additional process is required (Härdelin et al. 2012; Prasanth et al. 2014; Teixeira et al. 2020). A coagulation liquid medium such as alcohol or water has been proposed to remove the IL from deposited cellulose nanofibers (Udangawa et al.
2019; Ye et al. 2016; Zheng et al. 2014). Viswanathan et. al (Viswanathan et al. 2006) for the first time, conceived the electrospinning of biopolymeric fibers from room temperature ILs. Electrospun fibers from cellulose/[Bmim $] \mathrm{Cl}$ solution was deposited into an ethanol bath, which acted as coagulant for cellulose. However, due to the high viscosity of the cellulose/ $[\mathrm{Bmim}] \mathrm{Cl}$ solution and low volatility of [Bmim] $\mathrm{Cl}$, cellulose fibers produced during this procedure achieved diameters in the range of microns.

The schematic of typical electrospinning process of cellulose based on ILs is represented in Fig. 12. The setup consists of a high-voltage power supply, a syringe nozzle, and a coagulation bath collector. A syringe pump is used to provide a constant flow rate of the cellulose/IL to feed a droplet at the tip of the nozzle. The electrically-charged jet is ejected from the tip of the Taylor cone, and it is drawn towards the grounded conductive coagulation bath collector within the electrical field. The residual IL is removed from the electrospun fibers by passing through a coagulation bath. Cellulose fibers slowly solidify in the coagulation bath in which the IL is replaced by a coagulant solvent like water or alcohol. This solvent is then removed from these hydrogel fibers by either standard desiccation or freeze-drying (Bazbouz et al. 2019; Frey 2008; Mahmood et al. 2017; Zheng et al. 2014). Parallel copper wires rotating drum or a rotating cylinder partially submerged in a coagulation bath, have been also used as collectors (Härdelin et al. 2013; Iş1k et al. 2015). In addition, researchers have developed a system for melt-electrospinning or modified the process by incorporating the temperature

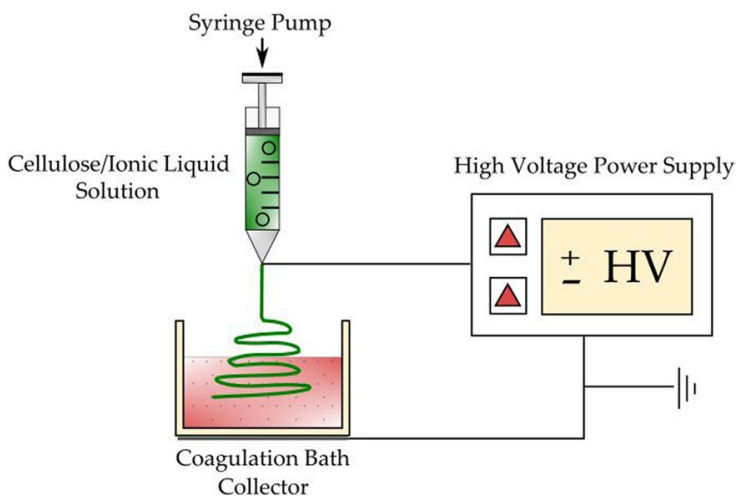

Fig. 12 Schematic illustration of the electrospinning setup used in the production of cellulose nanofibers from ILs 
control at the spinneret, at the collector, or at the coagulation bath (Liu et al. 2017; Prasanth et al. 2014; Quan et al. 2010; Xu et al. 2018b).

Many factors and variables can alter the ultimate characteristics of fibers obtained via the electrospinning of cellulose/ILs solution and thus their feasible applications. The control of the effective factors within the electrospinning procedure (e.g., solution properties, process variables, coagulant liquid features, and ambient conditions) needs to be pursued to gain cellulose nanofibers with a specific morphology, diameter, crystallinity, and surface characteristics. Several attempts to optimize the electrospinning process to fabricate cellulose nanofibers from ILs have been performed. Table 6 reviews and summarizes published works regarding the electrospinning of fibers from native cellulose dissolved in ILs.

Research attempts pursue different approaches. Several works have been performed to prevail the challenges of spinnability of cellulose/ILs solutions. Such researches have suggested to use a co-solvent beside ILs to modulate the viscosity, and surface tension of the solvent, to decrease the entanglement density of the system, and to enhance electrical conductivity, and processability of cellulose in the solvent (Ahn et al. 2012a; Freire et al. 2011; Härdelin et al. 2012; Quan et al. 2010; Xu et al. 2008). In some other experimental works, the parameters affecting the spinning process and structural morphology of cellulose/IL electrospun fibers, including the type of the cellulose (Ahn et al. 2012b; Bazbouz et al. 2019; Kang et al. 2013; Polaskova et al. 2013), solution features (concentration and viscosity, cellulose molecular weight, IL solvent system) (Ahn et al. 2012a; Freire et al. 2011; Härdelin et al. 2012; Quan et al. 2010; $\mathrm{Xu}$ et al. 2008), and coagulation parameters (coagulant liquid type, immersion time, and method to collect and solidify the fibers) (Bazbouz et al. 2019), have been investigated.

Solution conductivity has an important impact on controlling the electrospinning process and fiber properties and, in view of this, ILs as solvents have the advantage to form the ultrathin and uniform fibers due to their high conductivity. However, high viscosity and surface tension of cellulose/ILs solutions lead to non-uniform beaded fibers. Depending on the molecular weight, polymer solutions can be electrospun within a specified concentration range. An optimal solution concentration gives an adequate viscosity for the formation of continuous uniform bead free fibers (Bazbouz et al. 2019). Quan et al. (2010) reported that the diameter and morphology of the electrospun cellulose fibers were affected by the concentration of cellulose in the IL $([\mathrm{Bmim}] \mathrm{Cl})$ by influencing the viscosity of the solution. The resulting fibers electrospun from the $[\mathrm{Bmim}] \mathrm{Cl}$ solutions with different cellulose contents were observed via SEM, as shown in Fig. 13. The low cellulose concentration $(1.5 \mathrm{w} \%)$ showed the lowest viscosity and led to the formation of massive blocks with only a few cellulose fibers. When the concentration increased to $2.4 \mathrm{w} \%$, numerous fibers were formed while, as the solution concentration reached 3 and $4 \mathrm{w} \%$, the blocks disappeared, and fine fibers were achieved. However, when the concentration was raised to $5 \mathrm{w} \%$, the viscosity increased significantly and the fibers with large diameters were formed.

The temperature-controlled electrospinning has been also reported as an effective method to eliminate high viscosity and surface tension limitation of cellulose/ILs solutions by applying an enclosure with a constant temperature surrounding the nozzle. Viscosity and surface tension of the spinning solution decrease at high temperatures (Foong et al. 2020). The melt electrospinning is also another option to minimize the viscosity of spinning solutions. Xu et al. applied a laser-heated melt-set up to generate ultrafine cellulose fibers. They proposed a green and highly efficient process consisting the steps of cellulose dissolution, gel preparation, melt-electrospinning, and fiber coagulation (Xu et al. 2018b).

Another approach to reduce the viscosity and surface tension of cellulose/ILs solutions is to incorporate co-solvents. The effect of co-solvents on the electrospinning of cellulose nanofibers from ILs has been studied by several researchers (Table 6). Härdelin and coworkers performed electrospinning of cellulose pulp from ILs with three different co-solvents: dimethyl acetamide (DMAc), DMF, and DMSO (Härdelin et al. 2012). The goal was to make a relevance between the solution parameters (e.g., viscosity, surface tension, and conductivity) and spinnability in the presence of co-solvent. Results showed that pure [Emim][Ac] did not give the desired fiber formation. The DMSO-based system exhibited higher viscosity values compared to the DMAc- and DMF-based systems, and fibers were formed at a broader interval of [Emim]OAc ratios. Hence, the solution is spinnable 


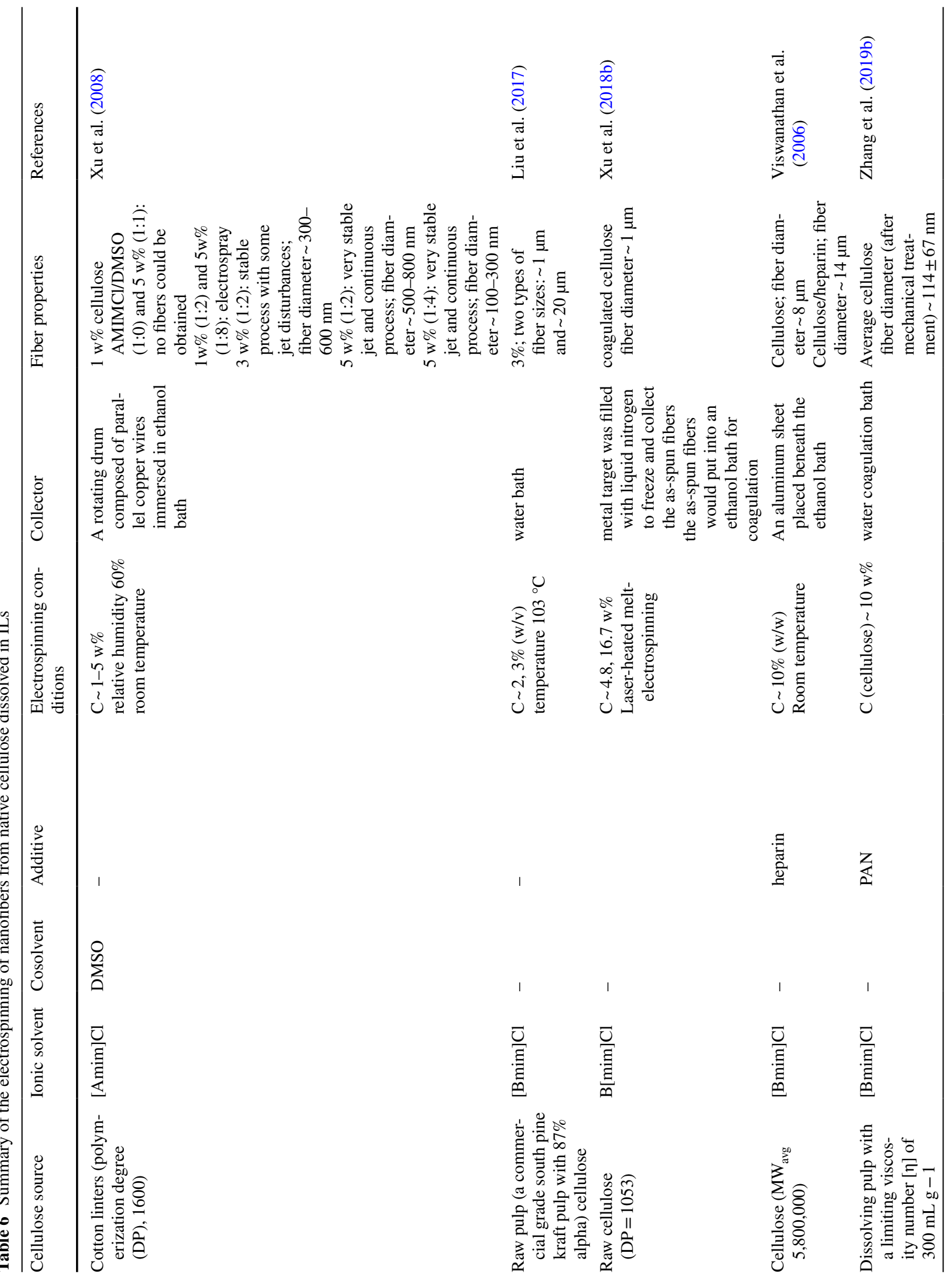




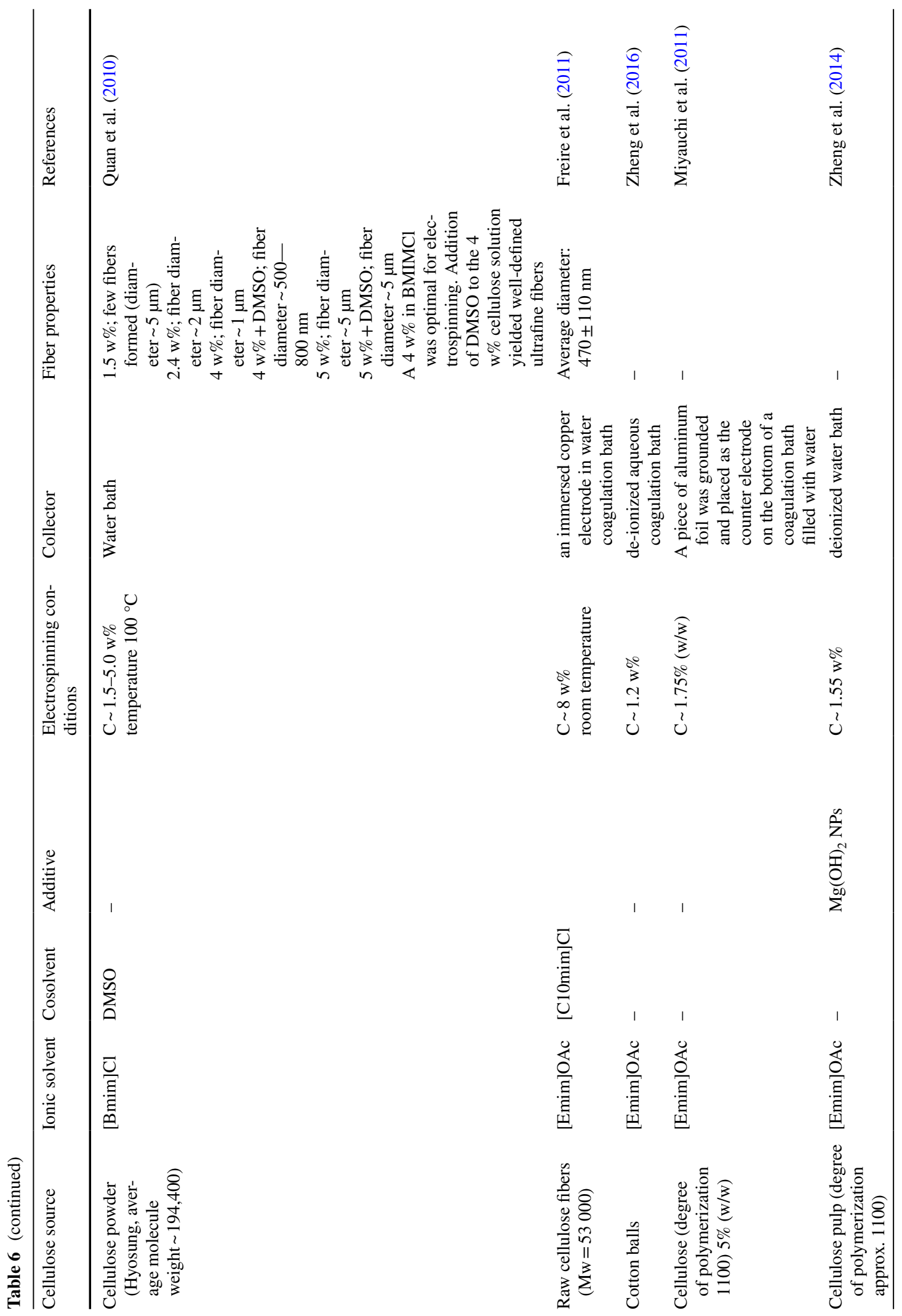




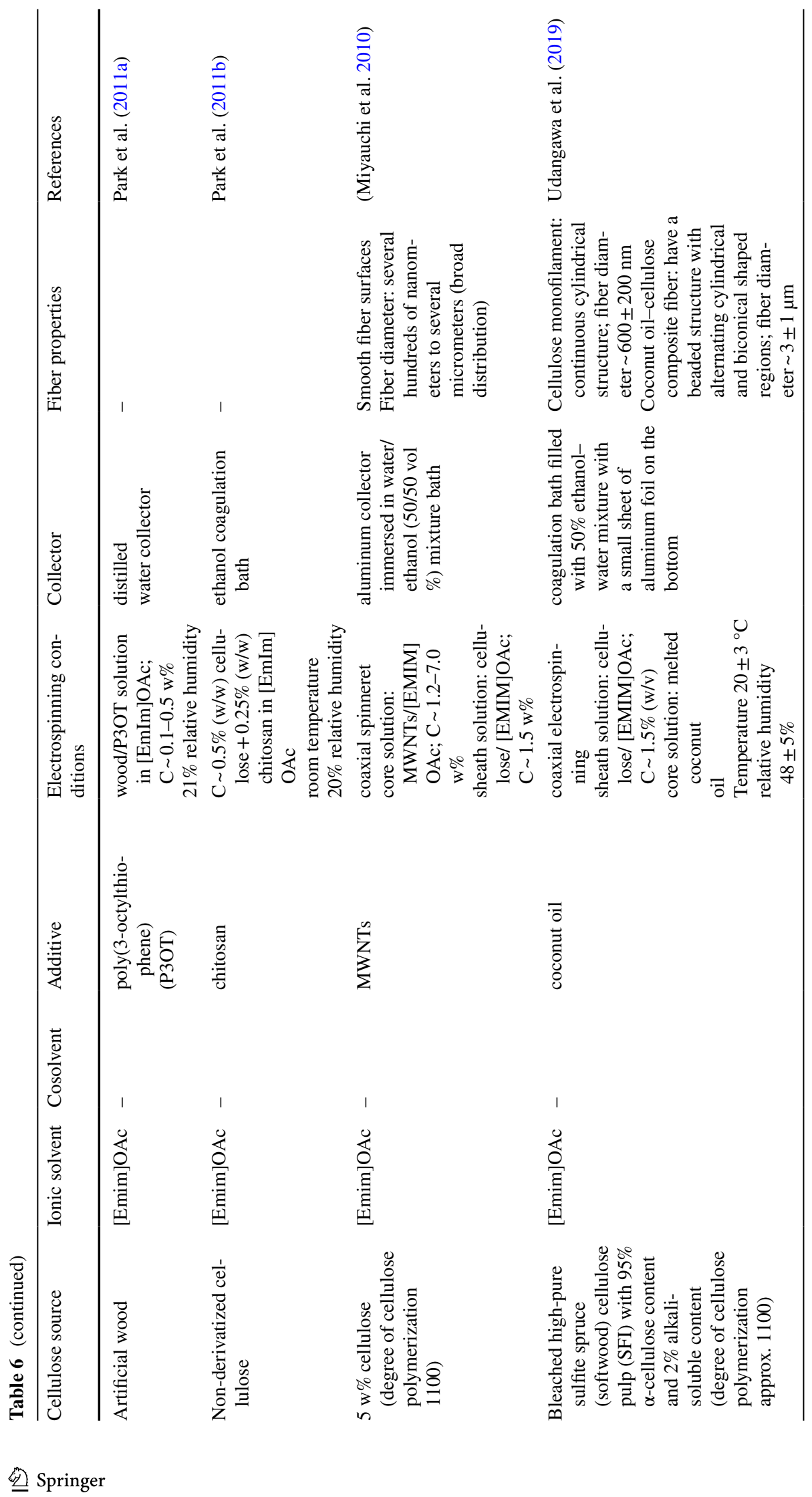




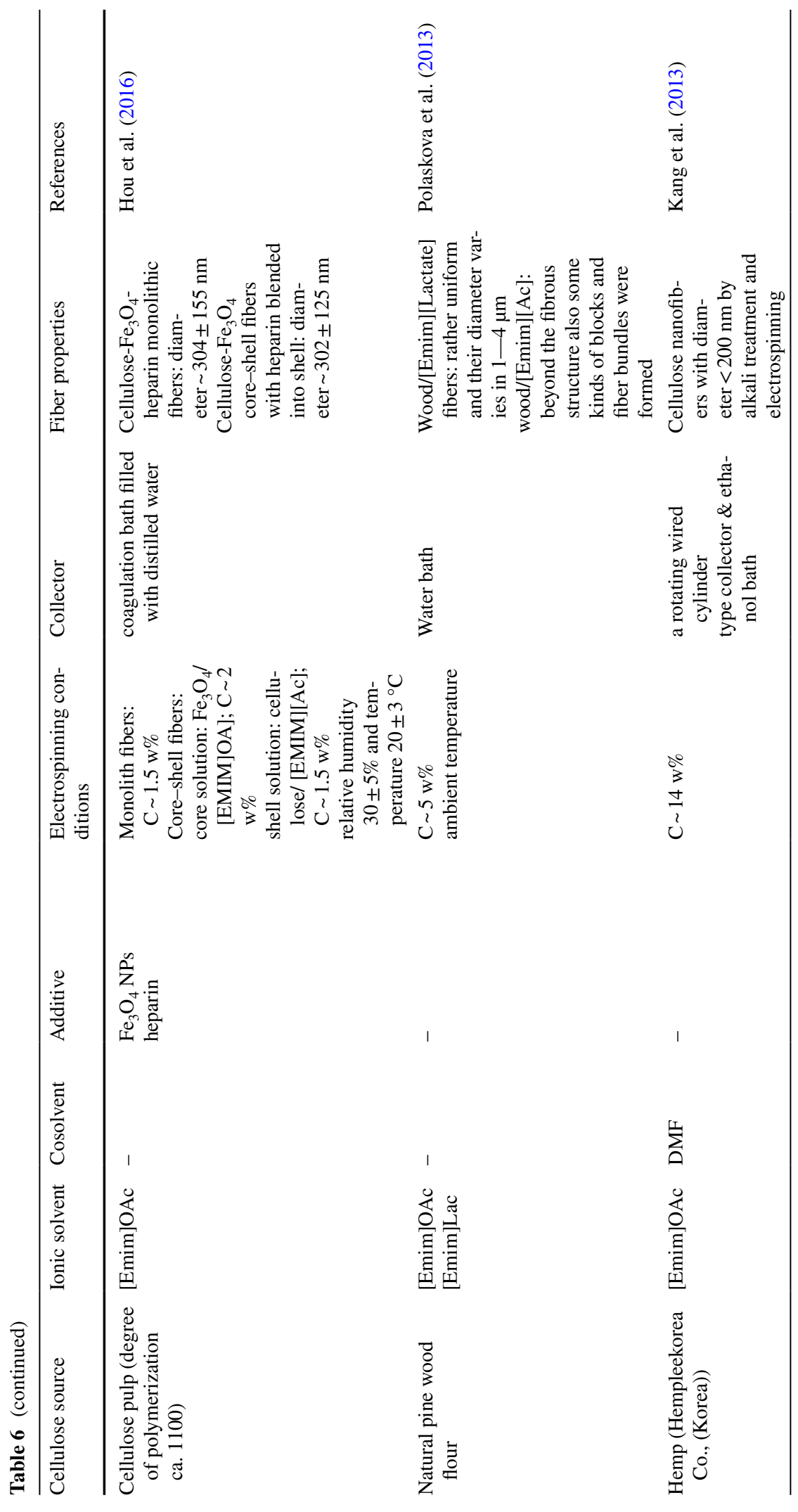




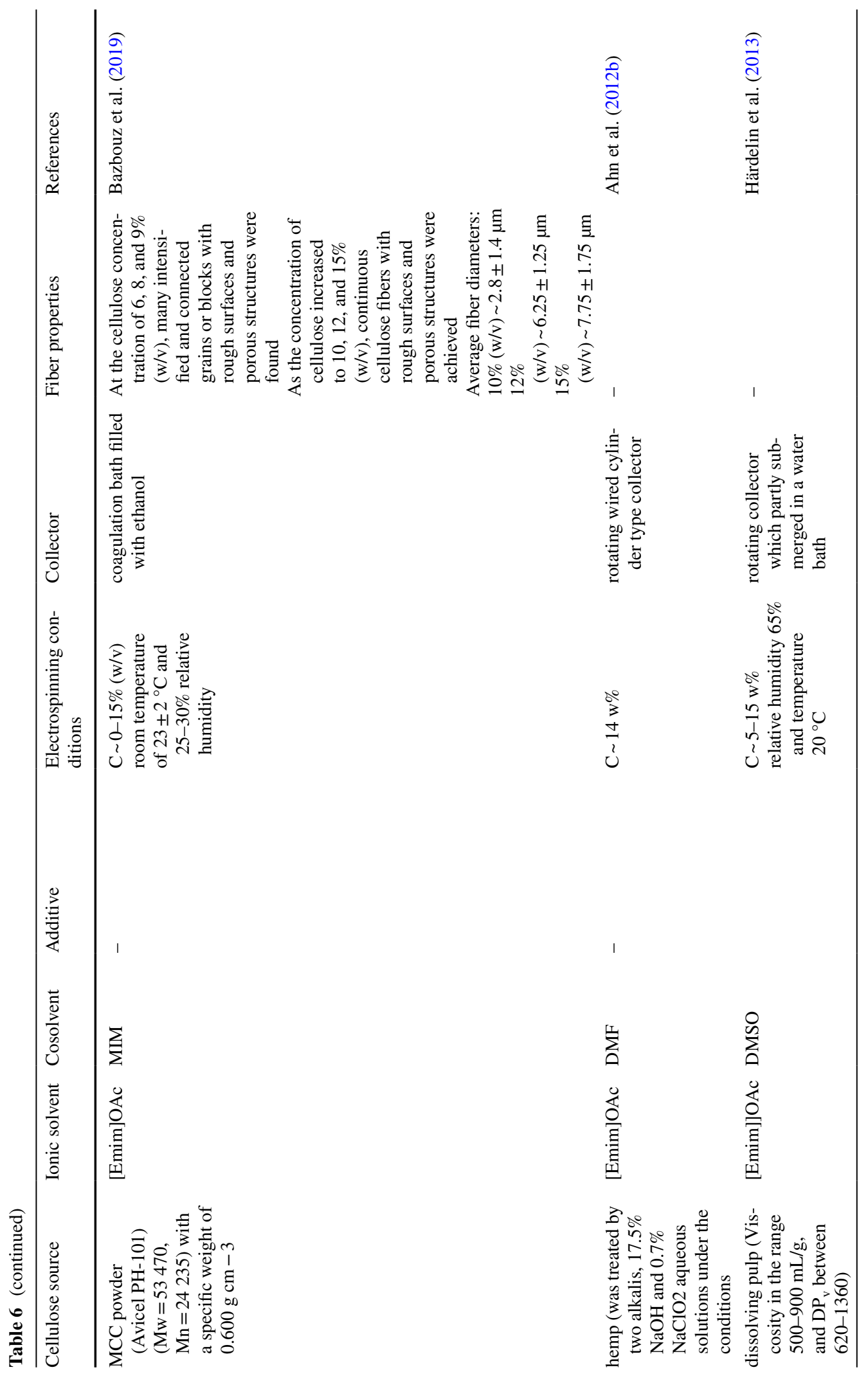




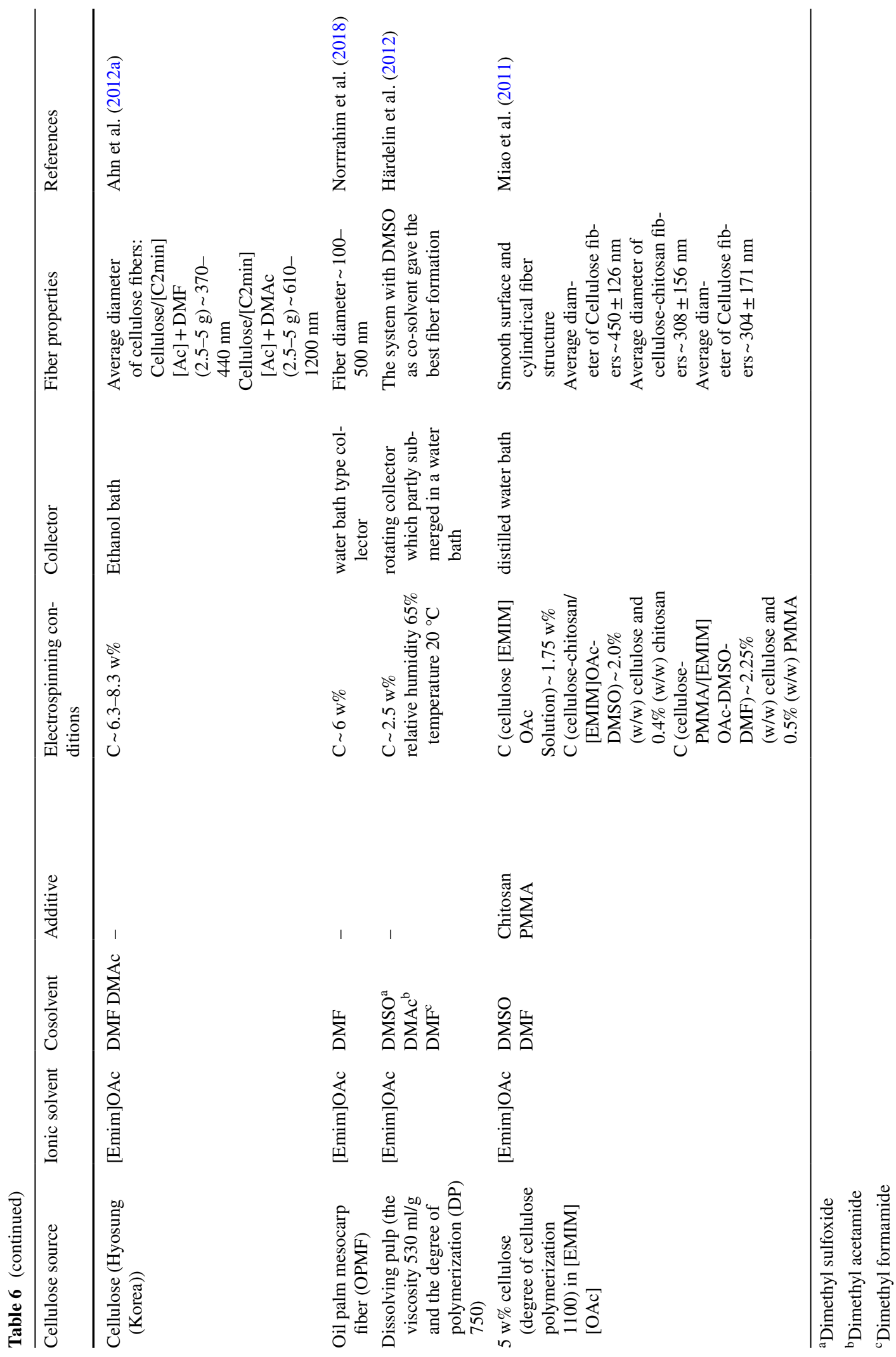




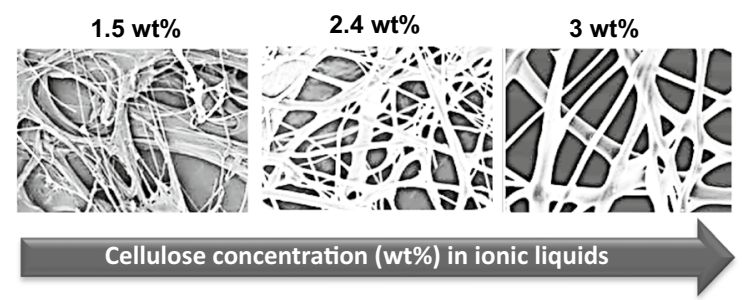

Fig. 13 Schematic of electrospun nanofibers from different cellulose concentration solutions in ILs (Quan et al. 2010)

at a lower content of [Emim]OAc than that of DMAcand DMF-based systems (Fig. 14).

The effect of blend ratio of [Amim] Cl and DMSO, as the proposed co-solvent, was investigated by $\mathrm{Xu}$ et. al. (2008). They found that the addition of DMSO to cellulose/[Amim][Cl] as co-solvent significantly decreased the surface tension, entanglement density of the network, and while the viscosity of the spinning solution improved the electrospinnability of the solution dramatically. At equal blend ratio of [Amim] Cl/DMSO, the solution was too viscous to be electrospun and no fibers were formed. By increasing the [Amim] Cl/DMSO ratio to $1: 2$ and 1:4, very stable jets were formed and continuous fibers with diameters in the ranges of 500-800 $\mathrm{nm}$ and 100-300 nm were produced, respectively (Fig. 15). At a high [Amim]Cl/ DMSO ratio of $1: 8$, instead of fiber formation, electrospray occurred.

Therefore, a balance between the parameters, such as polymer concentration, viscosity, surface tension, conductivity, and co-solvent contribution, is necessary for controlling the process to obtain uniform cellulose nanofibers with desired morphology and properties. Literature reviews have proven that
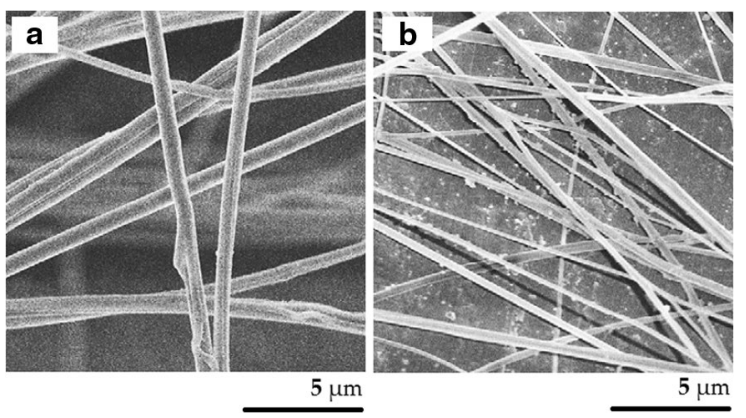

Fig. 15 SEM images of cellulose fibers electrospun at different $[\mathrm{Amim}] \mathrm{Cl} / \mathrm{DMSO}$ ratios. a 1:2; b 1:4; The electrospinning solution are prepared at $5 \mathrm{w} \%$ cellulose concentration (Xu et al. 2008)

the coagulant liquid type is also an important factor affecting the final properties of the nanofiber deposits. The effects of coagulation parameters (coagulation type and time) on the electrospun cellulose fiber structures, have been explored in several works (Bazbouz et al. 2019; Foong et al. 2020; Miyauchi et al. 2011; Quan et al. 2010). Results have shown that spinnability, morphology, and structure of fibers are mainly affected by the procedure used to collect and solidify them. It has been indicated that coagulant liquids owning to different polarities, lead to form fibers with different structural properties such as morphology, porosity, and crystallinity. When water was used as a coagulation bath, due to the relatively slow IL extraction speed of water, ribbon fiber morphology was observed. Also, in some cases, it was observed that cellulose fibers were deposited on the surface of the water bath, and piled up. Thus, wet cellulose fibers merged with each other like a film. In contrast, ethanol was observed a good solvent remove ILs from
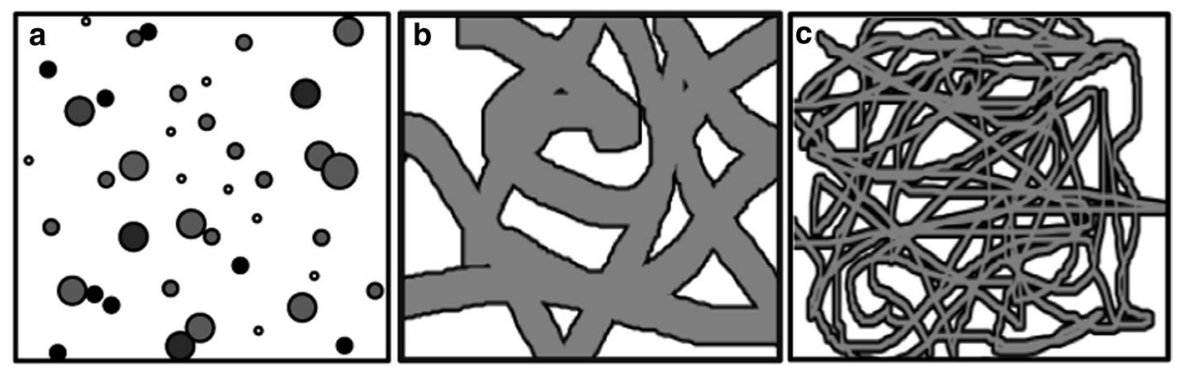

Fig. 14 Schematic of electrospun cellulose fibers a example for the state that no fiber formation (50 w\% DMF or $50 \mathrm{w} \%$ DMAc); $\mathbf{b}$ example for the state that tendencies to form fibers (pure EmimAc); c example for the fiber formation state $50 \mathrm{w} \%$ DMSO (Härdelin et al. 2012) 
cellulose fibers, more effective than water. However, ethanol is highly flammable, thus mixture of water/ ethanol can reduce the fire hazard as well as enhance the ILs kinetic removal from the fibers. Cylindrical fiber morphology was obtained in the mixture of water and ethanol $(50: 50 \mathrm{w} / \mathrm{w})$ coagulation bath. To avoid fiber agglomerations, surfactants can be added to the coagulation bath. Recirculation of coagulant, and using rotating collector for alternative immersion of fibers in a coagulation bath are other suggested routs for fiber collection and to remove the non-volatile solvent from the electrospun fibers (Foong et al. 2020; Meli et al. 2010; Xu et al. 2008).

\section{Electrospinning blend fibers}

Aiming at improving the electro-spinnability of cellulose, or exploiting synergistic effects of different polymers for giving special properties, other materials can also be blended besides cellulose to obtain hybrid nanofibrous structures with advanced functions. In general, solution blending is only possible if a common solvent between cellulose and other components of the blend be selected. Finding a common solvent for blending components during the process can be problematic. Hence, multi-jet electrospinning is another method to produce blended fibrous structures in which, the various components are electrospun independently (Le Corre et al. 2014; Zhang et al. 2019b). Among the progresses of cellulose-based hybrids prepared by electrospinning, the blending of polysaccharides, such as chitosan and heparin has gained attention for diverse applications, especially in the biomedical field. Viswanathan et al. (2006) used an electrospinning setup to produce cellulose-heparin blended fibers using ILs. Different solutions of cellulose/[Bmim] $\mathrm{Cl}$ and heparin/1-ethyl-3-methylimidazolium benzoate [Emim]Bz were separately prepared and, prior to the electrospinning, both RTIL solutions were mixed to afford a clear cellulose-heparin solution. Fibers were then collected in an ethanol coagulation bath. The electrospun blended fibers were used to design artificial vessels with excellent blood compatibility. In a report by Park et al. (2011b), chitosancellulose hybrid fibers from an IL was demonstrated for the first time. [Emim]OAc used for dissolving both cellulose and chitosan, and the blend solution was directly electrospun in the ethanol coagulation bath. The electrospun chitosan-cellulose hybrids had a potential application as antimicrobial materials for wound dressing in the biomedical field or for food coatings.

In another research work (Miao et al. 2011), cellulose-based hybrid fibers were produced by electrospinning from blend solutions of cellulose-chitosan and cellulose-PMMA in [Emim][Ac] for wound healing applications. Due to the hydrophobic nature of PMMA, DMF and DMSO were used as co-solvents. The electrospun hybrid fibers were collected into a coagulation distilled water bath to remove [Emim] OAc and to solidify the fibers. A recently published work (Zhang et al. 2019b), suggested a new procedure for the fabrication of micro-fibrillated cellulose fibers through the immiscible blending of PAN and cellulose in $[\mathrm{Bmim}] \mathrm{Cl}$. The electrospinning of PAN/ cellulose using $[\mathrm{Bmim}] \mathrm{Cl}$, followed by a removal of the PAN phase, allowed obtaining fine cellulose fibers with smaller diameters. This method made possible to control the size of the cellulose fibers and the porosity of the cellulosic matrix by changing the cellulose/PAN blend ratios. Research attempts to electrospun cellulose-based blend fibers are summarized in Table 6.

Co-axial electrospinning approach to produce coreshell fibers

Pharmaceutical and food industries are large consumers of cellulosic materials in a multitude of different applications. Hence, there has been interest in using coaxial electrospinning of core-shell type structures based on cellulosic materials to develop new types of composite nanofibrous materials with advanced functions. Coaxial electrospinning has taken advantages of two components in the core and shell layers, and it is possible to add fillers or encapsulate nanoparticles, drugs, bioactive agents, or other nanomaterials for giving special properties, i.e., antibacterial, biological, mechanical, conductivity, etc. (Miyauchi et al. 2010; Thakur et al. 2017). Different materials have been embedded in a cellulosic shell using coaxial electrospinning of IL-based solutions (Table 6). Miyauchi et al. used the coaxial spinneret for electrospinning [Emim]OAc-based solutions to incorporate MWNT in a cellulose shell to produce conductive fibrous materials (Fig. 16) (Miyauchi et al. 2010).

In a recently published work (Udangawa et al. 2019), a coaxial electrospinning setup was used to 

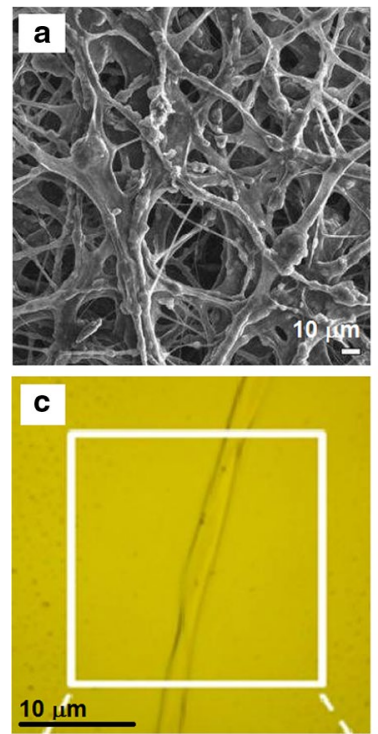

Fig. 16 SEM a and TEM b images of core-sheath of MWNTs-cellulose nanofiber, with a MWNT-cellulose $=40 / 60$ w\%, optical images of c pure cellulose fiber; d MWNT/cellulose fiber with a MWNT: cellulose ratio of 40\%: $60 \%$ (Miyauchi et al. 2010)

produce coconut oil-cellulose beaded microfibers as temperature-regulating fibrous materials. [Emim] OAc was chosen as the solvent to prepare the cellulose solution. Phase-change material coconut oil was incorporated inside the cellulosic sheath while the mixture of ethanol-water coagulation bath was used for collecting the core-shell fibers. Figure 17 shows the morphology of the electrospun fibers.

The cellulose monolithic fibers exhibited a cylindrical structure (Fig. 17a) with an average diameter of $600 \pm 200 \mathrm{~nm}$. In contrast, core (coconut oil)-shell (cellulose) fibers showed a beaded structure with intermittent cylindrical and biconical shaped zones (Fig. 17b). The core-shell structure of the coconut oil-cellulose fibers was confirmed in images (Fig. 17c).

Fig. 17 Schematic morphology of electrospun fibers; a monolithic cellulose fibers, b coconut oil-cellulose core-shell fiber, c size of coconut oil-cellulose core-shell fiber (Udangawa et al. 2019)
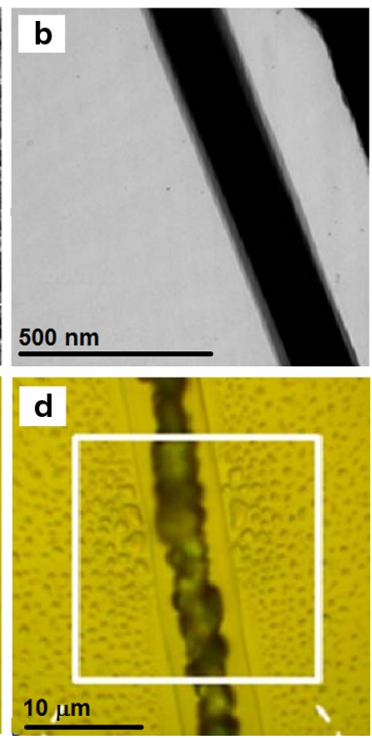

Applications of cellulose fibers

Cellulose-based materials have been recently developed for a wide range of uses in various fields and several commercial and industrial applications. A general description of the recent eco-friendly applications of cellulose fibers with a focus on biomedical uses is provided in this section. Cellulose is mostly adopted by the paper and packaging industries to replace the use of synthetic polymers derived from petrochemical resources. Cellulose composites are cost effective and non-toxic by nature, hence they can be an important component towards developing biodegradable packaging for food industry applications (Ghaderi et al. 2014; $\mathrm{Mu}$ et al. 2019; Sharma et al. 2019).

The potential application of cellulose and its biocomposites have been also largely considered in other fields such as the construction of structural composites, filtration devices, electronics, and sensors (Bethke et al. 2018; Orelma et al. 2020; Sharma et al. 2019).

Nanocellulose with high strength, nanoscale dimension, and large surface area with gas and water barrier properties is a promising material for the fabrication of high-performance membranes and filters. Owning to these properties, environmental applications have been explored, e.g., adsorption of heavy metals and dyes, removal of contaminants, and purification of industrial and drinking water systems (Salama 2019; Wang 2019).

After being extracted from natural sources, regenerated cellulose fibers can be transformed and used in a variety of shapes (e.g., filament or staple fibers, yarns, fabric, nonwovens, membranes, etc.) and applications. The cellulose fiber-based materials are showing a remarkable interest in the last years and a successive growth is expected by an increasing demand in sectors of medical and health products, technical applications, and household products. Cellulosic

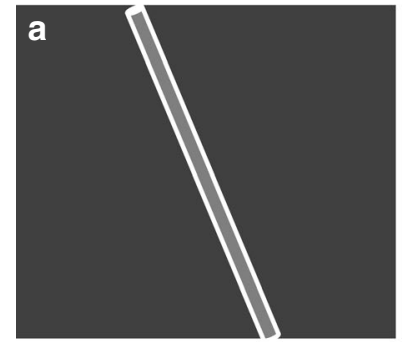

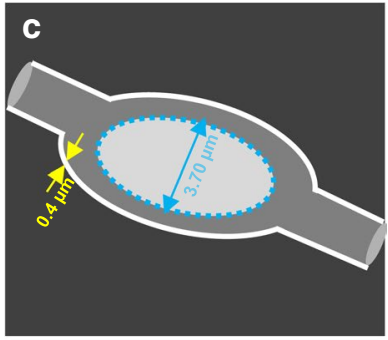


fibers possess unique properties in moisture control, thus enabling the human body to adapt properly its temperature and give a comfortable feeling when textiles are used in direct skin contact. This feature, which is advantageous for many textile and clothing applications, might explain the rapid production growth of regenerated cellulosic fibers over synthetic fibers. Staple fibers are still the market-leading bulk product for textiles and nonwovens. The good performance of the yarns spun from staple cellulosic fibers during knitting and weaving procedures confirmed the competitive quality of suitability for the production of apparels, therefore suggesting the IL-based cellulosic fibers as an alternative to viscose and Lyocell for production of fabrics and garments (Michud et al. 2016b). Dry-jet wet spinning was used to produce filaments from cellulose/IL solution. The continuous filaments were also cut to staple fibers and compared to the commercial viscose fibers. Staple fibers were converted into yarns by ring spinning technology. The application of cellulose-based fibers is widely reported in the literature. A general description of the recent eco-friendly applications of cellulose fibers with a focus on biomedical uses is provided in this section.

Renewable sources, biodegradability, biocompatibility, hydrophilicity, and low toxicity are the intrinsic features of cellulose that make it a suitable candidate for biomedical applications (Abdul Khalil et al. 2020; Teixeira et al. 2020; Thakur et al. 2017). Cellulose fiber-based materials owning to their tunable chemical, physical, and mechanical properties have been widely studied for developing biomaterials such as tissue engineering scaffolds, drug delivery systems, wound dressings, and artificial skin or artificial blood vessels (Abdul Khalil et al. 2020; Courtenay et al. 2018a, 2018b; Czaja et al. 2006).

Cellulose biocomposites are good candidates for tissue engineering scaffolds due to their suitable mechanical strength and biocompatibility (Palaninathan et al. 2018; Petersen and Gatenholm 2011; Zhijiang et al. 2019). Regenerated cellulose fibers also have been used for creating three-dimensional tissues with capillaries (Ko and Iwata 2001) and for cardiac (Entcheva et al. 2004), bone (Ao et al. 2017; Zhang et al. 2019d), muscle (Jia et al. 2013) and tooth (He et al. 2015; He et al. 2014) tissue engineering. However, when fabricating cellulose fibers, the toxicity of ILs has to be considered since residuals of ILs may end up in the body of patient. For this reason, IL-based biomaterials will be offered to the market if IL impurities do not adversely affect the health. For example, ILs with fluorine-based anions may expose toxicities on many various organisms (Zhao et al. 2007). Thus, ILs used to process biomaterials must be nontoxic, and have to possess also low melting points and low viscosities to be efficient solvents for the biopolymers. Viswanathan et al. (2006) used RTILs to produce electrospun cellulose and celluloseheparin composite fibers for constructing the artificial vessels with excellent blood compatibility.

Cellulose has been considered to condense drugloaded matrices as suitable tablets for oral usage. Despite the long history of application in tableting, there is still research about the use of cellulose as a novel drug delivery system. Nanocellulosebased materials such as hydrogels, microspheres, and fibrous membranes have been also exploited as drug carriers (Abdul Khalil et al. 2015a; Lin and Dufresne 2014; Mishra et al. 2017). Electrospinning is an impressive and beneficial method to develop cellulose-based nanofibrous drug delivery systems with high efficiency. Different types of drugs can be easily entrapped into the electrospun structures with high encapsulation efficiency, and their release behavior can be altered by controlling the morphology, diameter, porosity, and the composition by changing the process variables and type of materials. Several approaches such as post-spinning modifications, electrospinning of drug/polymer blend solution, emulsion electrospinning, and core-shell electrospinning have been proposed to incorporate drug into electrospun cellulose matrix (Liu et al. 2017; Thakur et al. 2017).

Cellulose-based fiber materials have been also proposed as skin wound dressings (Fu et al. 2013; $\mathrm{Li}$ et al. 2015a, b). These materials have high water retention capacity to provide the proper moisture at the wound site. Adequate mechanical strength, high permeability and conformability, and low toxicity are other favorable features as temporal biologic dressings. Several studies have focused on pre-clinical and clinical trials of bacterial cellulose (BC) and of nanocellulose derived from plants for wound dressing (Czaja et al. 2006; Hakkarainen et al. 2016). Preclinical tests of nanocellulose scaffolds with high porosity exhibited an accelerating healing process in rats compared to common gauzes with low porosity ( $\mathrm{Li}$ et al. 2015b). The inflammatory response was 
also less intense when wounds were covered with $\mathrm{BC}$ dressings. Owning to their efficiency, some of the BC wound dressings are already commercially available. For example, wound dressings with brands of Biofill ${ }^{\circledR}$ and Bioprocess ${ }^{\circledR}$ are currently commercially offered to treat burns and ulcers. Gengiflex ${ }^{\circledR}$ has been proposed for periodontal diseases, and XCell@ has been commercialized for chronic wound care (Czaja et al. 2006; Fontana et al. 1990). Nanofibrillar cellulose (NFC) derived from wood has been also considered as a biological dressing on burn lesions, where split-thickness skin wounds are originated after skin removal (Hakkarainen et al. 2016).

\section{Concluding remarks and future perspectives}

While scalable manufacturing is the bottleneck for technology development of many nanoscale materials, fibrillated cellulose provides an approximately unlimited resource for functional materials, since cellulose is produced daily by nearly 3 billion trees and other plants, such as bamboo and sugarcane ( $\mathrm{Li}$ et al. 2021). Over the last decades, researchers have discovered cellulose as a promising candidate for many applications, and its commercialization in a wide range of products has accelerated. This acceleration comes from consumers' increasing awareness of sustainability and renewability and global regulatory policies. Hence, great efforts have been made to manufacture and develop more efficient and applicable fiber-based cellulosic materials for diverse applications. Among different producing methods, fiber spinning including wet-, dry-, and electro-spinning have been considered as the most suitable, due to their versatile parameters and settings for achieving different fiber sizes, morphologies, and structures.

Although there have been rapid progresses and developments in manufacturing man-made cellulose fibers, some challenges still exist. Researchers have been working to achieve more sustainable and environmentally-friendly man-made cellulose fibers through the application of ILs as green solvents during different fiber spinning procedures. With reduced production costs and increased yields, ongoing growth in fibrillated cellulose production is anticipated as a sustainable material to meet global challenges.
Funding Open access funding provided by Università di Pisa within the CRUI-CARE Agreement.

\section{Declarations}

Conflicts of interest All authors declare no conflict of interests.

Open Access This article is licensed under a Creative Commons Attribution 4.0 International License, which permits use, sharing, adaptation, distribution and reproduction in any medium or format, as long as you give appropriate credit to the original author(s) and the source, provide a link to the Creative Commons licence, and indicate if changes were made. The images or other third party material in this article are included in the article's Creative Commons licence, unless indicated otherwise in a credit line to the material. If material is not included in the article's Creative Commons licence and your intended use is not permitted by statutory regulation or exceeds the permitted use, you will need to obtain permission directly from the copyright holder. To view a copy of this licence, visit http://creativecommons.org/licenses/by/4.0/.

\section{References}

Abdul Khalil H et al (2020) A review on plant cellulose nanofibre-based aerogels for biomedical applications. Polymers 12:1759

Abdul Khalil HPS, Bhat AH, Abu Bakar A, Tahir PM, Zaidul ISM, Jawaid M (2015a) Cellulosic nanocomposites from natural fibers for medical applications: a review BT. In: Pandey JK, Takagi H, Nakagaito AN, Kim H-J (eds) Handbook of polymer nanocomposites. processing, performance and application: volume $\mathrm{C}$ : polymer nanocomposites of cellulose nanoparticles, Springer, Berlin pp 475-511. Doi:https://doi.org/10.1007/978-3-642-45232$1 \_72$

Abdul Khalil HPS, Davoudpour Y, Bhat AH, Rosamah E, Tahir PM (2015b) Electrospun cellulose composite nanofibers BT. In: Pandey JK, Takagi H, Nakagaito AN, Kim H-J (Eds) Handbook of polymer nanocomposites. Processing, performance and application: volume C: polymer nanocomposites of cellulose nanoparticles, Springer, Berlin, pp 191-227. Doi:https://doi.org/10.1007/978-3-64245232-1_61

Abu-Eishah SI (2011) Ionic liquids recycling for reuse. Ionic Liq Classes Properties 10:239-272

Abushammala H, Hettegger H, Bacher M, Korntner P, Potthast A, Rosenau T, Laborie M-P (2017) On the mechanism of the unwanted acetylation of polysaccharides by 1 , 3-dialkylimidazolium acetate ionic liquids: part 2-the impact of lignin on the kinetics of cellulose acetylation. Cellulose 24:2767-2774

Adusumali RB, Reifferscheid M, Weber H, Roeder T, Sixta H, Gindl W (2006) Mechanical properties of regenerated cellulose fibers for composites. In: Macromolecular symposia, vol 244. Wiley Online Library, pp 119-125. https://doi.org/10.1002/masy.200651211 
Ahn Y, Hu D-H, Hong JH, Lee SH, Kim HJ, Kim H (2012a) Effect of co-solvent on the spinnability and properties of electrospun cellulose nanofiber. Carbohydr Polym 89:340-345. https://doi.org/10.1016/j.carbpol.2012.03. 006

Ahn Y, Lee SH, Kim HJ, Yang Y-H, Hong JH, Kim Y-H, Kim $\mathrm{H}$ (2012b) Electrospinning of lignocellulosic biomass using ionic liquid. Carbohyd Polym 88:395-398. https:// doi.org/10.1016/j.carbpol.2011.12.016

Ahn Y, Kang Y, Park B, Ku MK, Lee SH, Kim H (2014) Influence of lignin on rheological behaviors and electrospinning of polysaccharide solution. J Appl Polym Sci. https://doi.org/10.1002/app.40031

Ahn Y, Song Y, Kwak S-Y, Kim H (2016) Highly ordered cellulose II crystalline regenerated from cellulose hydrolyzed by 1-butyl-3-methylimidazolium chloride. Carbohydr Polym 137:321-327

Anderson JL, Dixon JK, Brennecke JF (2007) Solubility of $\mathrm{CO} 2, \mathrm{CH} 4, \mathrm{C} 2 \mathrm{H} 6, \mathrm{C} 2 \mathrm{H} 4, \mathrm{O} 2$, and $\mathrm{N} 2$ in 1-Hexyl3-methylpyridinium Bis (trifluoromethylsulfonyl) imide: comparison to other ionic liquids. Acc Chem Res 40:1208-1216

Ao C, Niu Y, Zhang X, He X, Zhang W, Lu C (2017) Fabrication and characterization of electrospun cellulose/nanohydroxyapatite nanofibers for bone tissue engineering. Int J Biol Macromol 97:568-573

Arno Parviainen AWTK, Mutikainen I, Hummel M, Selg C, Hauru LKJ, Sixta H, Kilpelinen I (2013) Predicting cellulose solvating capabilities of acid-base conjugate ionic liquids. Chemsuschem 6:2161-2169

Asim AM, Uroos M, Naz S, Sultan M, Griffin G, Muhammad N, Khan AS (2019) Acidic ionic liquids: promising and cost-effective solvents for processing of lignocellulosic biomass. J Mol Liq 287:110943

Barthel S, Heinze T (2006) Acylation and carbanilation of cellulose in ionic liquids. Green Chem 8:301-306

Baur J, Silverman E (2007) Challenges and opportunities in multifunctional nanocomposite structures for aerospace applications. MRS Bull 32:328-334

Bazbouz MB, Taylor M, Baker D, Ries ME, Goswami P (2019) Dry-jet wet electrospinning of native cellulose microfibers with macroporous structures from ionic liquids. J Appl Polym Sci 136:47153-47153. https://doi.org/10. 1002/app.47153

Becherini S, Mezzetta A, Chiappe C, Guazzelli L (2019) Levulinate amidinium protic ionic liquids (PILs) as suitable media for the dissolution and levulination of cellulose. New J Chem 43:4554-4561

Bentivoglio G, Röder T, Fasching M, Buchberger M, Schottenberger H, Sixta H (2006) Cellulose processing with chloride-based ionic liquids. Lenzinger Ber 86:154-161

Berga L et al (2020) Cellulose dissolution and regeneration using a non-aqueous, non-stoichiometric protic ionic liquid system. Cellulose 27:9593-9603

Bethke K et al (2018) Functionalized cellulose for water purification, antimicrobial applications, and sensors. Adv Funct Mater 28:1800409

Bhat AH, Khan I, Usmani MA, Umapathi R, Al-Kindy SMZ (2019) Cellulose an ageless renewable green nanomaterial for medical applications: an overview of ionic liquids in extraction, separation and dissolution of cellulose. Int
J Biol Macromol 129:750-777. https://doi.org/10.1016/j. ijbiomac.2018.12.190

Bodachivskyi I, Page CJ, Kuzhiumparambil U, Hinkley SF, Sims IM, Williams DBG (2020) Dissolution of cellulose: are ionic liquids innocent or noninnocent solvents? ACS Sustain Chem \& Eng 8:10142-10150

Branco LC, Carrera G, Aires-de-Sousa J, Martin IL, Frade R, Afonso CA (2011) Physico-chemical properties of taskspecific ionic liquids. ionic liquids: theory, properties, new approaches; Kokorin A (Ed): pp. 61-94

Brinchi L, Cotana F, Fortunati E, Kenny JM (2013) Production of nanocrystalline cellulose from lignocellulosic biomass: technology and applications. Carbohydr Polym 94:154-169. https://doi.org/10.1016/j.carbpol.2013.01. 033

Burchard W, Habermann N, Klüfers P, Seger B, Wilhelm U (1994) Cellulose in Schweizer's reagent: a stable, polymeric metal complex with high chain stiffness. Angew Chem Int Ed Engl 33:884-887

Cai T, Zhang H, Guo Q, Shao H, Hu X (2010) Structure and properties of cellulose fibers from ionic liquids. J Appl Polym Sci 115:1047-1053

Cai T, Yang G, Zhang H, Shao H, Hu X (2012) A new process for dissolution of cellulose in ionic liquids. Polym Eng Sci 52:1708-1714

Chen J, Guan Y, Wang K, Zhang X, Xu F, Sun R (2015a) Combined effects of raw materials and solvent systems on the preparation and properties of regenerated cellulose fibers. Carbohydr Polym 128:147-153

Chen JY, Sun L, Jiang W, Lynch VM (2015b) Antimicrobial regenerated cellulose/nano-silver fiber without leaching. J Bioact Compat Polym 30:17-33

Chen H, Chen J, Teng N, Na H, Zhu J (2017) Controlling the status of corn cellulose solutions by ethanol to define fiber morphology during electrospinning. Cellulose 24:863-870. https://doi.org/10.1007/ s10570-016-1127-3

Cheng G, Varanasi P, Arora R, Stavila V, Simmons BA, Kent MS, Singh S (2012) Impact of ionic liquid pretreatment conditions on cellulose crystalline structure using 1-ethyl-3-methylimidazolium acetate. J Phys Chem B 116:10049-10054

Ciacco GT, Liebert TF, Frollini E, Heinze TJ (2003) Application of the solvent dimethyl sulfoxide/tetrabutylammonium fluoride trihydrate as reaction medium for the homogeneous acylation of Sisal cellulose. Cellulose 10:125-132

Clarke CJ, Tu W-C, Levers O, Brohl A, Hallett JP (2018) Green and sustainable solvents in chemical processes. Chem Rev 118:747-800

Clemons C (2016) Nanocellulose in spun continuous fibers: a review and future outlook. J Renew Mater 4:327-339

Clough MT (2017) Organic electrolyte solutions as versatile media for the dissolution and regeneration of cellulose. Green Chem 19:4754-4768

Clough MT, Geyer K, Hunt PA, Son S, Vagt U, Welton T (2015) Ionic liquids: not always innocent solvents for cellulose. Green Chem 17:231-243

Corre DL, Tucker N, Staiger M (2014) Electrospun cellulosic fiber-reinforced composite materials. In: Natural fiber 
composites: materials, processes and applications. pp. 115-158. https://doi.org/10.1533/9780857099228.1.115

Coscia MG, Bhardwaj J, Singh N, Santonicola MG, Richardson R, Thakur VK, Rahatekar S (2018) Manufacturing \& characterization of regenerated cellulose/curcumin based sustainable composites fibers spun from environmentally benign solvents. Ind Crops Prod 111:536-543

Courtenay J, Sharma R, Scott J (2018a) Recent advances in modified cellulose for tissue culture applications. Molecules 23:654

Courtenay JC, Deneke C, Lanzoni EM, Costa CA, Bae Y, Scott JL, Sharma RI (2018b) Modulating cell response on cellulose surfaces; tunable attachment and scaffold mechanics. Cellulose 25:925-940

Cross C, Bevan E, Beadle C (1892) Improvements in dissolving cellulose and allied compounds. Br Patent 8:700

Czaja W, Krystynowicz A, Bielecki S, Brown RM Jr (2006) Microbial cellulose-the natural power to heal wounds. Biomaterials 27:145-151

de Campos A, Corrêa AC, Claro PIC, de Morais TE, Marconcini JM (2019) Processing, characterization and application of micro and nanocellulose based environmentally friendly polymer composites BT. In: Inamuddin TS, Kumar Mishra R, Asiri AM (eds) Sustainable polymer composites and nanocomposites. Springer International Publishing, Cham

De Silva R, Vongsanga K, Wang X, Byrne N (2016a) Understanding key wet spinning parameters in an ionic liquid spun regenerated cellulosic fibre. Cellulose 23:2741-2751

De Silva R, Wang X, Byrne N (2016b) Development of a novel cellulose/duck feather composite fibre regenerated in ionic liquid. Carbohyd Polym 153:115-123

Devarayan K, Hanaoka H, Hachisu M, Araki J, Ohguchi M, Behera BK, Ohkawa K (2013) Direct electrospinning of cellulose-chitosan composite nanofiber. Macromol Mater Eng 298:1059-1064. https://doi.org/10.1002/ mame.201200337

Druel L, Niemeyer P, Milow B, Budtova T (2018) Rheology of cellulose-[DBNH][CO $2 \mathrm{Et}]$ solutions and shaping into aerogel beads. Green Chem 20:3993-4002

Dutta PK, Dutta J, Tripathi V (2004) Chitin and chitosan: chemistry, properties, and applications. J Sci Ind Res 63:20-31. https://doi.org/10.1016/j.foodhyd.2010.08. 008

Ebner G, Schiehser S, Potthast A, Rosenau T (2008) Side reaction of cellulose with common 1-alkyl-3-methylimidazolium-based ionic liquids. Tetrahedron Lett 49:7322-7324

El Seoud OA, Kostag M, Jedvert K, Malek NI (2020) Cellulose regeneration and chemical recycling: closing the "cellulose gap" using environmentally benign solvents. Macromol Mater Eng 305:1900832

Entcheva E, Bien H, Yin L, Chung C-Y, Farrell M, Kostov Y (2004) Functional cardiac cell constructs on cellulosebased scaffolding. Biomaterials 25:5753-5762

Feng L, Chen Z-1 (2008) Research progress on dissolution and functional modification of cellulose in ionic liquids. $\mathrm{J}$ Mol Liq 142:1-5

Ferreira DC et al (2019) Binary mixtures of ionic liquidsDMSO as solvents for the dissolution and derivatization of cellulose: effects of alkyl and alkoxy side chains. Carbohyd Polym 212:206-214

Figueiredo AR, Vilela C, Neto CP, Silvestre AJ, Freire CS (2015) Bacterial cellulose-based nanocomposites: roadmap for innovative materials. In: Thakur VK (ed) Nanocellulose polymer composites. Scrivener Publishing LLC, Beverly

Fink H-P, Weigel P, Purz H, Ganster J (2001) Structure formation of regenerated cellulose materials from NMMOsolutions. Prog Polym Sci 26:1473-1524

Fontana $\mathbf{J}$ et al (1990) Acetobacter cellulose pellicle as a temporary skin substitute. Appl Biochem Biotechnol 24:253-264

Foong CY, Wirzal MDH, Bustam MA (2020) A review on nanofibers membrane with amino-based ionic liquid for heavy metal removal. J Mol Liq 297:111793-111793. https://doi.org/10.1016/j.molliq.2019.111793

Forsyth SA, Pringle JM, MacFarlane DR (2004) Ionic liquids-an overview. Aust J Chem 57:113-119

Freire MG, Teles ARR, Ferreira RA, Carlos LD, Lopes-daSilva JA, Coutinho JA (2011) Electrospun nanosized cellulose fibers using ionic liquids at room temperature. Green Chem 13:3173-3180

Frey MW (2008) Electrospinning cellulose and cellulose derivatives. Polym Rev 48:378-391. https://doi.org/10.1080/ 15583720802022281

Fu L, Zhou P, Zhang S, Yang G (2013) Evaluation of bacterial nanocellulose-based uniform wound dressing for large area skin transplantation. Mater Sci Eng, C 33:2995-3000

Fu R, Ji X, Ren Y, Wang G, Cheng B (2017) Antibacterial blend films of cellulose and chitosan prepared from binary ionic liquid system. Fibers Polym 18:852-858

Fukaya Y, Sugimoto A, Ohno H (2006) Superior solubility of polysaccharides in low viscosity, polar, and halogenfree 1, 3-dialkylimidazolium formates. Biomacromol 7:3295-3297

Fukaya Y, Hayashi K, Wada M, Ohno H (2008) Cellulose dissolution with polar ionic liquids under mild conditions: required factors for anions. Green Chem 10:44-46

Ganster J, Fink H-P (2006) Novel cellulose fibre reinforced thermoplastic materials. Cellulose 13:271-280

Gazit OM, Katz A (2012) Dialkylimidazolium ionic liquids hydrolyze cellulose under mild conditions. Chemsuschem 5:1542-1548

Ghaderi M, Mousavi M, Yousefi H, Labbafi M (2014) Allcellulose nanocomposite film made from bagasse cellulose nanofibers for food packaging application. Carbohyd Polym 104:59-65

Gindl W, Reifferscheid M, Adusumalli R-B, Weber H, Röder T, Sixta H, Schöberl T (2008) Anisotropy of the modulus of elasticity in regenerated cellulose fibres related to molecular orientation. Polymer 49:792-799

Goujon N, Wang X, Rajkowa R, Byrne N (2012) Regenerated silk fibroin using protic ionic liquids solvents: towards an all-ionic-liquid process for producing silk with tunable properties. Chem Commun 48:1278-1280

Graenacher C (1934) Cellulose solution, patent numbe: US1943176A

Gupta MK, Khokhar SK, Phillips DM, Sowards LA, Drummy LF, Kadakia MP, Naik RR (2007) Patterned silk films 
cast from ionic liquid solubilized fibroin as scaffolds for cell growth. Langmuir 23:1315-1319

Hakkarainen T et al (2016) Nanofibrillar cellulose wound dressing in skin graft donor site treatment. J Control Release 244:292-301

Hanabusa H, Izgorodina EI, Suzuki S, Takeoka Y, Rikukawa M, Yoshizawa-Fujita M (2018) Cellulose-dissolving protic ionic liquids as low cost catalysts for direct transesterification reactions of cellulose. Green Chem 20:1412-1422

Härdelin L, Hagström B (2015) Wet spun fibers from solutions of cellulose in an ionic liquid with suspended carbon nanoparticles. J Appl Polym Sci. https://doi.org/10.1002/ app. 41417

Härdelin L, Thunberg J, Perzon E, Westman G, Walkenström P, Gatenholm P (2012) Electrospinning of cellulose nanofibers from ionic liquids: the effect of different cosolvents. J Appl Polym Sci 125:1901-1909

Härdelin L, Perzon E, Hagström B, Walkenström P, Gatenholm $P$ (2013) Influence of molecular weight and rheological behavior on electrospinning cellulose nanofibers from ionic liquids. J Appl Polym Sci 130:2303-2310. https:// doi.org/10.1002/app.39449

Hauru LK, Hummel M, Michud A, Sixta H (2014) Dry jet-wet spinning of strong cellulose filaments from ionic liquid solution. Cellulose 21:4471-4481

Haward SJ, Sharma V, Butts CP, McKinley GH, Rahatekar SS (2012) Shear and extensional rheology of cellulose/ ionic liquid solutions. Biomacromol 13:1688-1699

Hayes R, Warr GG, Atkin R (2015) Structure and nanostructure in ionic liquids. Chem Rev 115:6357-6426

He X et al (2014) Uniaxially aligned electrospun all-cellulose nanocomposite nanofibers reinforced with cellulose nanocrystals: scaffold for tissue engineering. Biomacromol 15:618-627. https://doi.org/10.1021/bm401656a

He X, Cheng L, Zhang X, Xiao Q, Zhang W, Lu C (2015) Tissue engineering scaffolds electrospun from cotton cellulose. Carbohydr Polym 115:485-493

Heinze T, Schwikal K, Barthel S (2005) Ionic liquids as reaction medium in cellulose functionalization. Macromol Biosci 5:520-525

Hemanutz (2013) New supermicro fibers based on cellulose and cellulose-2.5-acetate. Chem Fib Int vol. 63: pp. 84-86

Hermanutz F, Vocht MP, Panzier N, Buchmeiser MR (2019) Processing of cellulose using ionic liquids. Macromol Mater Eng 304:1800450

Hermanutz F, Gähr F, Uerdingen E, Meister F, Kosan B (2008) New developments in dissolving and processing of cellulose in ionic liquids. Macromol symp 262(1):23-27. https://doi.org/10.1002/masy.200850203

Hideki Hanabusa YT, Rikukawa M, Yoshizawa-Fujita M (2019) Effect of alkyl chain length in anions on the physicochemical properties of cellulose-dissolving protic ionic liquids. Aust J Chem 72:55-60

Holding AJ, Heikkilä M, Kilpeläinen I, King AW (2014) Amphiphilic and phase-separable ionic liquids for biomass processing. Chemsuschem 7:1422-1434

Holding AJ, Parviainen A, Kilpeläinen I, Soto A, King AW, Rodríguez H (2017) Efficiency of hydrophobic phosphonium ionic liquids and DMSO as recyclable cellulose dissolution and regeneration media. RSC Adv 7:17451-17461

Hong JH, Ku MK, Ahn Y, Kim HJ, Kim H (2013) Air-gap spinning of cellulose/ionic liquid solution and its characterization. Fibers Polym 14:2015-2019

Hou L, Udangawa WMRN, Pochiraju A, Dong W, Zheng Y, Linhardt RJ, Simmons TJ (2016) Synthesis of heparin-immobilized, magnetically addressable cellulose nanofibers for biomedical applications. ACS Biomater Sci Eng 2:1905-1913. https://doi.org/10.1021/acsbi omaterials.6b00273

Hsieh Y-L (2018) Cellulose nanofibers: electrospinning and nanocellulose self-assemblies. Adv Green Composit. https://doi.org/10.1002/9781119323327.ch4

Huang Y-B, Xin P-P, Li J-X, Shao Y-Y, Huang C-B, Pan H (2016) Room-temperature dissolution and mechanistic investigation of cellulose in a tetra-butylammonium acetate/dimethyl sulfoxide system. ACS Sustain Chem \& Eng 4:2286-2294

Idris A, Vijayaraghavan R, Rana UA, Fredericks D, Patti AF, Macfarlane DR (2013) Dissolution of feather keratin in ionic liquids. Green Chem 15:525-534

Ingildeev $\mathrm{D}$, Hermanutz $\mathrm{F}$, Bredereck $\mathrm{K}$, Effenberger $\mathrm{F}$ (2012) Novel cellulose/polymer blend fibers obtained using ionic liquids. Macromol Mater Eng 297:585-594

Ingildeev D, Effenberger F, Bredereck K, Hermanutz F (2013) Comparison of direct solvents for regenerated cellulosic fibers via the lyocell process and by means of ionic liquids. J Appl Polym Sci 128:4141-4150

Isik M, Sardon H, Mecerreyes D (2014) Ionic liquids and cellulose: dissolution, chemical modification and preparation of new cellulosic materials. Int J Mol Sci 15:11922-11940

Işık M, Sardon H, Mecerreyes D (2015) Ionic liquid and cellulose technologies: dissolution, modification and composite preparation BT. In: Mecerreyes D (ed) Applications of ionic liquids in polymer science and technology. Springer, Berlin

Isogai A, Saito T, Fukuzumi H (2011) TEMPO-oxidized cellulose nanofibers. Nanoscale 3:71-85

Izgorodina EI, Forsyth M, MacFarlane DR (2007) Towards a better understanding of delocalized charge in ionic liquid anions. Aust J Chem 60:15-20

Jia B et al (2013) Effect of microcrystal cellulose and cellulose whisker on biocompatibility of cellulose-based electrospun scaffolds. Cellulose 20:1911-1923

Jiang W, Sun L, Hao A, Yan Chen J (2011) Regenerated cellulose fibers from waste bagasse using ionic liquid. Text Res J 81:1949-1958

Jiang $G$ et al (2012) Analysis of regenerated cellulose fibers with ionic liquids as a solvent as spinning speed is increased. Cellulose 19:1075-1083

Kagimoto J, Fukumoto K, Ohno H (2006) Effect of tetrabutylphosphonium cation on the physico-chemical properties of amino-acid ionic liquids. Chem Commun. https://doi. org/10.1039/b600771f

Kang Y, Ahn Y, Lee SH, Hong JH, Ku MK, Kim H (2013) Lignocellulosic nanofiber prepared by alkali treatment and electrospinning using ionic liquid. Fibers Polym 14:530-536 
Kargarzadeh $\mathrm{H}$ et al (2018) Advances in cellulose nanomaterials. Cellulose 25:2151-2189. https://doi.org/10.1007/ s10570-018-1723-5

Keaveney ST, Haines RS, Harper JB (2017) Ionic liquid solvents: the importance of microscopic interactions in predicting organic reaction outcomes. Pure Appl Chem 89:745-757

Kim S-j, Jang J (2013) Effect of degree of polymerization on the mechanical properties of regenerated cellulose fibers using synthesized 1-allyl-3-methylimidazolium chloride. Fibers Polym 14:909-914

King AW, Asikkala J, Mutikainen I, Järvi P, Kilpeläinen I (2011) Distillable acid-base conjugate ionic liquids for cellulose dissolution and processing. Angew Chem Int Ed 50:6301-6305

Klemm D, Heublein B, Fink H-P, Bohn A (2005) Cellulose: Fascinating biopolymer and sustainable raw material. Angew Chem Int Ed 44:3358-3393. https://doi.org/10. 1002/anie. 200460587

Ko IK, Iwata H (2001) An approach to constructing threedimensional tissue. Ann N Y Acad Sci 944:443-455

Köhler S, Liebert T, Schöbitz M, Schaller J, Meister F, Günther W, Heinze T (2007) Interactions of Ionic liquids with Polysaccharides 1 . unexpected acetylation of cellulose with 1-Ethyl-3-methylimidazolium acetate. Macromol Rapid Commun 28:2311-2317

Kosan B, Michels C, Meister F (2008) Dissolution and forming of cellulose with ionic liquids. Cellulose 15:59-66

Kosan B, Dorn S, Meister F, Heinze T (2010) Preparation and subsequent shaping of cellulose acetates using ionic liquids. Macromol Mater Eng 295:676-681

Kosmulski M, Gustafsson J, Rosenholm JB (2004) Thermal stability of low temperature ionic liquids revisited. Thermochim Acta 412:47-53

Kostag M, Jedvert K, Achtel C, Heinze T, El Seoud OA (2018) Recent advances in solvents for the dissolution, shaping and derivatization of cellulose: quaternary ammonium electrolytes and their solutions in water and molecular solvents. Molecules 23:511

Laus G, Bentivoglio G, Schottenberger H, Kahlenberg V, Kopacka H, Röder T, Sixta H (2005) Ionic liquids: current developments, potential and drawbacks for industrial applications. Lenzing Ber 84:71-85

Lee YJ, Lee SJ, Jeong SW, Kim H-c, Oh TH, Lee SG (2019) Structure and mechanical properties of regenerated cellulose fibers wet-spun from ionic liquid/cosolvent systems. Fibers Polym 20:501-511

Lehmann A, Ebeling H, Fink H (2012) Method for economical production of lignin-containing precursor fibers for use in further production of carbon fibers. Patent WO2012156441A1

Lehmann A, Bohrisch J, Protz R, Fink H (2013) Method for preparing lignocellulose spinning solution and spin regenerated fibers from it without any initial preatreatments. Patent WO2013144082A1

Li X, Li N, Xu J, Duan X, Sun Y, Zhao Q (2014) Cellulose fibers from cellulose/1-ethyl-3-methylimidazolium acetate solution by wet spinning with increasing spinning speeds. J Appl Polym Sci. https://doi.org/10.1002/app. 40225
Li Y, Jiang H, Zheng W, Gong N, Chen L, Jiang X, Yang G (2015a) Bacterial cellulose-hyaluronan nanocomposite biomaterials as wound dressings for severe skin injury repair. J Mater Chem B 3:3498-3507

Li Y et al (2015b) Evaluation of the effect of the structure of bacterial cellulose on full thickness skin wound repair on a microfluidic chip. Biomacromol 16:780-789

Li Y, Wang J, Liu X, Zhang S (2018) Towards a molecular understanding of cellulose dissolution in ionic liquids: anion/cation effect, synergistic mechanism and physicochemical aspects. Chem Sci 9:4027-4043. https://doi. org/10.1039/c7sc05392d

Li T et al (2021) Developing fibrillated cellulose as a sustainable technological material. Nature 590:47-56

Liebert T, Heinze T (2008) Interaction of ionic liquids with polysaccharides. 5. Solvents and reaction media for the modification of cellulose. BioResources 3:576-601

Lin N, Dufresne A (2014) Nanocellulose in biomedicine: current status and future prospect. Eur Polymer J 59:302-325

Lindman B, Karlström G, Stigsson L (2010) On the mechanism of dissolution of cellulose. J Mol Liq 156:76-81

Lindman B, Medronho B, Alves L, Costa C, Edlund H, Norgren M (2017) The relevance of structural features of cellulose and its interactions to dissolution, regeneration, gelation and plasticization phenomena. Phys Chem Chem Phys 19:23704-23718. https://doi.org/10.1039/ c7cp02409f

Ling Z, Chen S, Zhang X, Takabe K, Xu F (2017) Unraveling variations of crystalline cellulose induced by ionic liquid and their effects on enzymatic hydrolysis. Sci Rep 7:1-11

Liu Y, Nguyen A, Allen A, Zoldan J, Huang Y, Chen JY (2017) Regenerated cellulose micro-nano fiber matrices for transdermal drug release. Mater Sci Eng C 74:485-492

Liu Y et al (2019) Preparation of MWCNTs-graphene-cellulose fiber with ionic liquids. Acs Sustain Chem \& Eng 7(24):20013-20021

Lu B, Xu A, Wang J (2014) Cation does matter: how cationic structure affects the dissolution of cellulose in ionic liquids. Green Chem 16:1326-1335

Lundahl MJ, Klar V, Wang L, Ago M, Rojas OJ (2016) Spinning of cellulose nanofibrils into filaments: a review. Ind Eng Chem Res 56:8-19

Luo Z, Wang A, Wang C, Qin W, Zhao N, Song H, Gao J (2014) Liquid crystalline phase behavior and fiber spinning of cellulose/ionic liquid/halloysite nanotubes dispersions. J Mater Chem A 2:7327-7336

Luo M, West H, Neogi AN (2008) Method for processing cellulose in ionic liquids and fibers therefrom. Google Patents,

Ma B, Zhang M, He C, Sun J (2012) New binary ionic liquid system for the preparation of chitosan/cellulose composite fibers. Carbohyd Polym 88:347-351

Ma Y et al (2015) High-strength composite fibers from cellulose-lignin blends regenerated from ionic liquid solution. Chemsuschem 8:4030-4039

Ma Y, Hummel M, Määttänen M, Särkilahti A, Harlin A, Sixta $\mathrm{H}$ (2016) Upcycling of waste paper and cardboard to textiles. Green Chem 18:858-866

Mahmood H, Moniruzzaman M, Yusup S, Welton T (2017) Ionic liquids assisted processing of renewable resources 
for the fabrication of biodegradable composite materials. Green Chem 19:2051-2075

Maleki H, Gharehaghaji AA, Dijkstra PJ (2017) Electrospinning of continuous poly (L-lactide) yarns: effect of twist on the morphology, thermal properties and mechanical behavior. J Mech Behav Biomed Mater 71:231-237. https://doi.org/10.1016/j.jmbbm.2017.03.031

Maleki H, Semnani Rahbar R, Saadatmand MM, Barani H (2018) Physical and morphological characterisation of poly(L-lactide) acid-based electrospun fibrous structures: tunning solution properties. Plast Rubber Compos 47:438-446. https://doi.org/10.1080/14658011.2018. 1532672

Maleki H, Mathur S, Klein A (2020) Antibacterial Ag containing core-shell polyvinyl alcohol-poly (lactic acid) nanofibers for biomedical applications. Polym Eng Sci. https://doi.org/10.1002/pen.25375

Männer J, Ivanoff D, Morley RJ, Jary S (2011) TENCEL-new cellulose fibers for carpets. Lenzing Ber 89:60-71

Maton C, De Vos N, Stevens CV (2013) Ionic liquid thermal stabilities: decomposition mechanisms and analysis tools. Chem Soc Rev 42:5963-5977

Maxim ML, Sun N, Wang H, Sterner JR, Haque A, Rogers RD (2012) Reinforced magnetic cellulose fiber from ionic liquid solution. Nanomater Energy 1:225-236

Maxim ML et al. (2010) Properties of cellulose/TiO2 fibers processed from ionic liquids. In: Liebert $\mathrm{T}$ (eds) Cellulose solvents: for analysis, shaping, and chemical modification, ACS Symposium Series. American Chemical Society, Washington, DC, pp 261-274. https://doi.org/ 10.1021/bk-2010-1033.ch014

McCormick CL, Callais PA, Hutchinson BH Jr (1985) Solution studies of cellulose in lithium chloride and N, N-dimethylacetamide. Macromolecules 18:2394-2401

Medronho B, Lindman B (2015) Brief overview on cellulose dissolution/regeneration interactions and mechanisms. Adv Coll Interface Sci 222:502-508

Medronho B, Romano A, Miguel MG, Stigsson L, Lindman B (2012) Rationalizing cellulose (in) solubility: reviewing basic physicochemical aspects and role of hydrophobic interactions. Cellulose 19:581-587

Meksi N, Moussa A (2017) A review of progress in the ecological application of ionic liquids in textile processes. $\mathbf{J}$ Clean Prod 161:105-126

Meli L, Miao J, Dordick JS, Linhardt RJ (2010) Electrospinning from room temperature ionic liquids for biopolymer fiber formation. Green Chem 12:1883-1892. https://doi. org/10.1039/c0gc00283f

Mezzetta A, Becherini S, Pretti C, Monni G, Casu V, Chiappe C, Guazzelli L (2019a) Insights into the levulinatebased ionic liquid class: synthesis, cellulose dissolution evaluation and ecotoxicity assessment. New J Chem 43:13010-13019

Mezzetta A, Łuczak J, Woch J, Chiappe C, Nowicki J, Guazzelli L (2019b) Surface active fatty acid ILs: influence of the hydrophobic tail and/or the imidazolium hydroxyl functionalization on aggregates formation. J Mol Liq 289:111155

Miao J, Pangule RC, Paskaleva EE, Hwang EE, Kane RS, Linhardt RJ, Dordick JS (2011) Lysostaphin-functionalized cellulose fibers with antistaphylococcal activity for wound healing applications. Biomaterials 32:9557-9567. https://doi.org/10.1016/j.biomaterials.2011.08.080

Michud A, Hummel M, Haward S, Sixta H (2015a) Monitoring of cellulose depolymerization in 1-ethyl-3-methylimidazolium acetate by shear and elongational rheology. Carbohydr Polym 117:355-363

Michud A, Hummel M, Sixta H (2015b) Influence of molar mass distribution on the final properties of fibers regenerated from cellulose dissolved in ionic liquid by dry-jet wet spinning. Polymer 75:1-9

Michud A, Hummel M, Sixta H (2016a) Influence of process parameters on the structure formation of man-made cellulosic fibers from ionic liquid solution. J Appl Polym Sci. https://doi.org/10.1002/app.43718

Michud A et al (2016b) Ioncell-F: ionic liquid-based cellulosic textile fibers as an alternative to viscose and Lyocell. Text Res J 86:543-552

Mishra D, Shanker K, Khare P (2017) Recent advances in green sustainable nanocellulosic fiber: an overview BT. In: Singh R, Kumar S (eds) Green technologies and environmental sustainability. Springer International Publishing, Cham

Miyauchi M, Miao J, Simmons TJ, Lee J-W, Doherty TV, Dordick JS, Linhardt RJ (2010) Conductive cable fibers with insulating surface prepared by coaxial electrospinning of multiwalled nanotubes and cellulose. Biomacromol 11:2440-2445. https://doi.org/10.1021/bm1006129

Miyauchi M, Miao J, Simmons TJ, Dordick JS, Linhardt RJ (2011) Flexible electrospun cellulose fibers as an affinity packing material for the separation of bovine serum albumin. J Chromatogr Sep Tech 2:110-110

Mokhena TC, John MJ (2019) Cellulose nanomaterials: new generation materials for solving global issues. Cellulose. https://doi.org/10.1007/s10570-019-02889-w

Moon RJ, Martini A, Nairn J, Simonsen J, Youngblood J (2011) Cellulose nanomaterials review: structure, properties and nanocomposites. Chem Soc Rev 40:3941-3994

Morais ES, Lopes AM, Freire MG, Freire CS, Coutinho JA, Silvestre AJ (2020) Use of ionic liquids and deep eutectic solvents in polysaccharides dissolution and extraction processes towards sustainable biomass valorization. Molecules 25:3652

Mu R et al (2019) Recent trends and applications of cellulose nanocrystals in food industry. Trends Food Sci Technol 93:136-144

Mundsinger K, Müller A, Beyer R, Hermanutz F, Buchmeiser MR (2015) Multifilament cellulose/chitin blend yarn spun from ionic liquids. Carbohyd Polym 131:34-40

Nechyporchuk O, Belgacem MN, Bras J (2016) Production of cellulose nanofibrils: a review of recent advances. Ind Crops Prod 93:2-25. https://doi.org/10.1016/j.indcrop. 2016.02.016

Nishiyama Y, Langan P, Chanzy H (2002) Crystal structure and hydrogen-bonding system in cellulose I $\beta$ from synchrotron X-ray and neutron fiber diffraction. J Am Chem Soc 124:9074-9082

Norrrahim MNF et al (2018) Superheated steam pretreatment of cellulose affects its electrospinnability for microfibrillated cellulose production. Cellulose 25:3853-3859. https://doi.org/10.1007/s10570-018-1859-3 
Ohno H, Kameda M, Fukumoto K, Ogihara W, Yoshizawa M (2004) Novel ionic liquids composed of only heterocycles. ECS Proc Vol 2004:346-352

Olga Kuzmina JB, Vincent SR, Wanasekara ND, Kalossaka LM, Griffith J, Potthast A, Rahatekar S, Eichhorn SJ, Welton T (2017) Superbase ionic liquids for effective cellulose processing from dissolution to carbonization. Green Chem 19:5949-5957

Olsson C, Westman G (2013) Wet spinning of cellulose from ionic liquid solutions-viscometry and mechanical performance. J Appl Polym Sci 127:4542-4548

Olsson C, Hedlund A, Idström A, Westman G (2014) Effect of methylimidazole on cellulose/ionic liquid solutions and regenerated material therefrom. J Mater Sci 49:3423-3433

Orelma H, Hokkanen A, Leppänen I, Kammiovirta K, Kapulainen M, Harlin A (2020) Optical cellulose fiber made from regenerated cellulose and cellulose acetate for water sensor applications. Cellulose 27:1543-1553

Otsuka I, Njinang CN, Borsali R (2017) Simple fabrication of cellulose nanofibers via electrospinning of dissolving pulp and tunicate. Cellulose 24:3281-3288. https://doi. org/10.1007/s10570-017-1360-4

Palaninathan V et al (2018) Bioactive bacterial cellulose sulfate electrospun nanofibers for tissue engineering applications. J Tissue Eng Regen Med 12:1634-1645

Park T-J, Jung YJ, Park H, Choi S-W, Kim E, Lee SH, Kim JH (2011a) Photoluminescent synthetic wood fibers from an ionic liquid via electrospinning. Macromol Res 19:317321. https://doi.org/10.1007/s13233-011-0416-9

Park TJ et al (2011b) Native chitosan/cellulose composite fibers from an ionic liquid via electrospinning. Macromol Res 19:213-215. https://doi.org/10.1007/s13233-011-0315-0

Pereira RF et al (2018) Ionic liquids for the synthesis and design of hybrid biomaterials and interfaces. In: Delville $\mathrm{M}-\mathrm{H}$, Taubert A (eds) Hybrid organic-inorganic interfaces: towards advanced functional materials. Wiley, Weinheim, pp. 581-636. https://doi.org/10.1002/97835 27807130.ch13

Petersen N, Gatenholm P (2011) Bacterial cellulose-based materials and medical devices: current state and perspectives. Appl Microbiol Biotechnol 91:1277

Pham TPT, Cho C-W, Yun Y-S (2010) Environmental fate and toxicity of ionic liquids: a review. Water Res 44:352-372

Pinkert A, Marsh KN, Pang S, Staiger MP (2009) Ionic liquids and their interaction with cellulose. Chem Rev 109:6712-6728

Polaskova M et al (2013) Preparation of microfibers from wood/ionic liquid solutions. Carbohydr Polym 92:214217. https://doi.org/10.1016/j.carbpol.2012.08.089

Prasanth R, Nageswaran S, Thakur VK, Ahn J-H (2014) Electrospinning of cellulose: Process and applications. In: Thakur VK (ed) Nanocellulose polymer nanocomposites: fundamentals and applications. John Wiley \& Sons Inc, Hoboken

Pu Y, Jiang N, Ragauskas AJ (2007) Ionic liquid as a green solvent for lignin. J Wood Chem Technol 27:23-33

Quan S-L, Kang S-G, Chin I-J (2010) Characterization of cellulose fibers electrospun using ionic liquid. Cellulose 17:223-230
Rabideau BD et al (2020) Tuning the melting point of selected ionic liquids through adjustment of the cation's dipole moment. Phys Chem Chem Phys 22(21):12301-123011

Rahatekar S et al (2009a) Processing of natural fibers nanocomposites using ionic liquids. ECS Trans 16:119-127

Rahatekar SS et al (2009b) Solution spinning of cellulose carbon nanotube composites using room temperature ionic liquids. Polymer 50:4577-4583

Rinaldi R (2011) Instantaneous dissolution of cellulose in organic electrolyte solutions. Chem Commun 47:511-513

Röder T, Moosbauer J, Kliba G, Schlader S, Zuckerstätter G, Sixta H (2009) Comparative characterisation of man-made regenerated cellulose fibres. Lenzing Ber 87:98-105

Rosenau T, Potthast A, Kosma P, Chen C-L, Gratzl JS (1999) Autocatalytic decomposition of N-methylmorpholine $\mathrm{N}$-oxide induced by Mannich intermediates. J Org Chem 64:2166-2167

Rosenau T, Potthast A, Sixta H, Kosma P (2001) The chemistry of side reactions and byproduct formation in the system NMMO/cellulose (Lyocell process). Prog Polym Sci 26:1763-1837

Rosenau T, Potthast A, Adorjan I, Hofinger A, Sixta H, Firgo H, Kosma P (2002) Cellulose solutions in N-methylmorpholine-N-oxide (NMMO)-degradation processes and stabilizers. Cellulose 9:283-291

Rosenau T, Potthast A, Hell J (2018) Cellulose science and technology: chemistry, analysis, and applications. John Wiley \& Sons, Hoboken

Ruan D, Zhang L, Mao Y, Zeng M, Li X (2004a) Microporous membranes prepared from cellulose in $\mathrm{NaOH} /$ thiourea aqueous solution. J Membr Sci 241:265-274

Ruan D, Zhang L, Zhang Z, Xia X (2004b) Structure and properties of regenerated cellulose/tourmaline nanocrystal composite films. J Polym Sci Part b Polym Phys 42:367-373

Salama A (2019) Cellulose/calcium phosphate hybrids: New materials for biomedical and environmental applications. Int J Biol Macromol 127:606-617

Salem DR (2018) Structure formation in polymeric fibers. Carl Hanser Verlag GmbH Co KG, Munich

Schlufter K, Schmauder HP, Dorn S, Heinze T (2006) Efficient homogeneous chemical modification of bacterial cellulose in the ionic liquid 1-N-butyl-3-methylimidazolium chloride. Macromol Rapid Commun 27:1670-1676

Shamshina JL (2019) Chitin in ionic liquids: historical insights into the polymer's dissolution and isolation a review. Green Chem 21:3974-3993

Shamshina JL, Berton P (2020) Use of ionic liquids in chitin biorefinery: a systematic review. Front Bioeng Biotechnol. https://doi.org/10.3389/fbioe.2020.00011

Shamshina JL, Qin Y, Belmore K, Daly DT, Rogers RD (2021) Switchable carbamate coagulants to improve recycling ionic liquid from biomass solutions. Green Chem Eng 2(4):384-391

Sharma A, Thakur M, Bhattacharya M, Mandal T, Goswami S (2019) Commercial application of cellulose nano-composites-a review. Biotechnol Rep 21:e00316 
Singh SK, Savoy AW (2020) Ionic liquids synthesis and applications: an overview. J Mol Liq 297:112038

Sixta $\mathrm{H}$ et al (2015) Ioncell-F: a high-strength regenerated cellulose fibre. Nord Pulp Pap Res J 30:43-57

Song H, Zhang J, Niu Y, Wang Z (2010) Phase transition and rheological behaviors of concentrated cellulose/ionic liquid solutions. J Phys Chem B 114:6006-6013

Song H, Niu Y, Wang Z, Zhang J (2011) Liquid crystalline phase and gel-sol transitions for concentrated microcrystalline cellulose (MCC)/1-Ethyl-3-methylimidazolium acetate (EMIMAc) solutions. Biomacromol 12:1087-1096

Song H-Z, Luo Z-Q, Wang C-Z, Hao X-F, Gao J-G (2013) Preparation and characterization of bionanocomposite fiber based on cellulose and nano-SiO2 using ionic liquid. Carbohydr Polym 98:161-167

Stibal W, Schwarz R, Kemp U, Bender K, Weger F, Stein M (2000) Fibers, 3. General production technology. Ullmann's Encyclopedia Ind Chem

Sun N et al (2008) Magnetite-embedded cellulose fibers prepared from ionic liquid. J Mater Chem 18:283-290

Sun N, Li W, Stoner B, Jiang X, Lu X, Rogers RD (2011) Composite fibers spun directly from solutions of raw lignocellulosic biomass dissolved in ionic liquids. Green Chem 13:1158-1161

Sun H, Miao J, Yu Y, Zhang L (2015a) Dissolution of cellulose with a novel solvent and formation of regenerated cellulose fiber. Appl Phys A 119:539-546

Sun L, Chen JY, Jiang W, Lynch V (2015b) Crystalline characteristics of cellulose fiber and film regenerated from ionic liquid solution. Carbohydr Polym 118:150-155

Sun J et al (2017) Efficient dehydration and recovery of ionic liquid after lignocellulosic processing using pervaporation. Biotechnol Biofuels 10:1-14

Swatloski RP, Spear SK, Holbrey JD, Rogers RD (2002) Dissolution ofcellulose with ionic liquids. J Am Chem Soc 124:4974-4975

Swatloski RP, Rogers RD, Holbrey JD (2004) Dissolution and processing of cellulose using ionic liquids. Google Patents,

Tavanaie MA (2013) Ionic liquids as new solvents for textile fiber formation and modification. Chem Eng Technol 36:1823-1837

Teixeira MA, Paiva MC, Amorim MTP (2020) Electrospun nanocomposites containing cellulose and its derivatives modified with specialized biomolecules for an enhanced wound healing. Nanomaterials 10:557-557

Thakur VK, Thakur MK, Kessler MR (2017) Handbook of composites from renewable materials, nanocomposites: science and fundamentals, vol 7. John Wiley \& Sons, Hoboken

Tu W-C, Weigand L, Hummel M, Sixta H, Brandt-Talbot A, Hallett JP (2020) Characterisation of cellulose pulps isolated from Miscanthus using a low-cost acidic ionic liquid. Cellulose 27(8):4745-4761

Udangawa WMRN, Willard CF, Mancinelli C, Chapman C, Linhardt RJ, Simmons TJ (2019) Coconut oil-cellulose beaded microfibers by coaxial electrospinning: an ecomodel system to study thermoregulation of confined phase change materials. Cellulose 26:1855-1868. https://doi.org/10.1007/s10570-018-2151-2
Vinogradova YS, Chen JY (2016) Micron-and nano-cellulose fiber regenerated from ionic liquids. J Text Inst 107:472-476

Viswanathan G, Murugesan S, Pushparaj V, Nalamasu O, Ajayan PM, Linhardt RJ (2006) Preparation of biopolymer fibers by electrospinning from room temperature ionic liquids. Biomacromol 7:415-418

Vitz J, Erdmenger T, Haensch C, Schubert US (2009) Extended dissolution studies of cellulose in imidazolium based ionic liquids. Green Chem 11:417-424

Walther P, Ota A, Müller A, Hermanutz F, Gähr F, Buchmeiser MR (2016) Chitin foils and coatings prepared from ionic liquids. Macromol Mater Eng 301:1337-1344

Wang D (2019) A critical review of cellulose-based nanomaterials for water purification in industrial processes. Cellulose 26:687-701

Wang B, Sain M, Oksman K (2007) Study of structural morphology of hemp fiber from the micro to the nanoscale. Appl Compos Mater 14:89

Wang H, Gurau G, Rogers RD (2012) Ionic liquid processing of cellulose. Chem Soc Rev 41:1519-1537

Wang B, Qin L, Mu T, Xue Z, Gao G (2017) Are ionic liquids chemically stable? Chem Rev 117:7113-7131

Welton T (2018) Ionic liquids: a brief history. Biophys Rev 10:691-706

Wendler F, Kosan B, Krieg M, Meister F (2009b) Cellulosic shapes from ionic liquids modified by activated charcoals and nanosilver particles. Lenzing Ber 87:106-116

Wendler F et al (2010) Polysaccharide blend fibres formed from $\mathrm{NaOH}, \mathrm{N}$-methylmorpholine-N-oxide and 1-ethyl3-methylimidazolium acetate. Fibres Text Eastern Eur 18:21-30

Wendler F et al (2011) Morphology of polysaccharide blend fibers shaped from $\mathrm{NaOH}, \mathrm{N}$-methylmorpholine- $\mathrm{N}$-oxide and 1-ethyl-3-methylimidazolium acetate. Cellulose 18:1165

Wendler F, Kosan B, Krieg M, Meister F (2009a) Possibilities for the physical modification of cellulose shapes using ionic liquids. In: Macromolecular symposia, vol 1. Wiley Online Library, pp 112-122

Woodings C (2001) Regenerated cellulose fibres. Elsevier

Wu Y, Sasaki T, Irie S, Sakurai K (2008) A novel biomassionic liquid platform for the utilization of native chitin. Polymer 49:2321-2327

Wu K, Yao Y, Yu J, Chen S, Wang X, Zhang Y, Wang H (2017) Cellulose/aromatic polysulfonamide blended fibers with improved properties. Cellulose 24:3377-3386

Xie H, Li S, Zhang S (2005a) Ionic liquids as novel solvents for the dissolution and blending of wool keratin fibers. Green Chem 7:606-608

Xie X-L, Mai Y-W, Zhou X-P (2005b) Dispersion and alignment of carbon nanotubes in polymer matrix: a review. Mater Sci Eng R Rep 49:89-112

Xie H, Zhang S, Li S (2006) Chitin and chitosan dissolved in ionic liquids as reversible sorbents of $\mathrm{CO} 2$. Green Chem $8: 630-633$

Xiong R, Hameed N, Guo Q (2012) Cellulose/polycaprolactone blends regenerated from ionic liquid 1-butyl-3-methylimidazolium chloride. Carbohydr Polym 90:575-582 
Xu S, Zhang J, He A, Li J, Zhang H, Han CC (2008) Electrospinning of native cellulose from nonvolatile solvent system. Polymer 49:2911-2917

Xu A, Wang J, Wang H (2010) Effects of anionic structure and lithium salts addition on the dissolution of cellulose in 1-butyl-3-methylimidazolium-based ionic liquid solvent systems. Green Chem 12:268-275

Xu A, Chen L, Wang J (2018a) Functionalized imidazalium carboxylates for enhancing practical applicability in cellulose processing. Macromolecules 51:4158-4166

Xu H, Bronner T, Yamamoto M, Yamane H (2018b) Regeneration of cellulose dissolved in ionic liquid using laserheated melt-electrospinning. Carbohydr Polym 201:182188. https://doi.org/10.1016/j.carbpol.2018.08.062

Xue H, Verma R, Jeanne MS (2006) Review of ionic liquids with fluorine-containing anions. J Fluor Chem 127:159-176

Ye W, Li X, Zhu H, Wang X, Wang S, Wang H, Sun R (2016) Green fabrication of cellulose/graphene composite in ionic liquid and its electrochemical and photothermal properties. Chem Eng J 299:45-55. https://doi.org/10. 1016/j.cej.2016.04.030

Zavgorodnya O, Shamshina JL, Bonner JR, Rogers RD (2017) Electrospinning biopolymers from ionic liquids requires control of different solution properties than volatile organic solvents. Acs Sustain Chem \& Eng 5:5512-5519. https://doi.org/10.1021/acssuschemeng.7b00863

Zavrel M, Bross D, Funke M, Büchs J, Spiess AC (2009) Highthroughput screening for ionic liquids dissolving (ligno-) cellulose. Biores Technol 100:2580-2587

Zhang H, Wu J, Zhang J, He J (2005) 1-Allyl-3-methylimidazolium chloride room temperature ionic liquid: a new and powerful nonderivatizing solvent for cellulose. Macromolecules 38:8272-8277

Zhang H, Wang Z, Zhang Z, Wu J, Zhang J, He J (2007) Regenerated-cellulose/multiwalled-carbon-nanotube composite fibers with enhanced mechanical properties prepared with the ionic liquid 1-allyl-3-methylimidazolium chloride. Adv Mater 19:698-704

Zhang J, Xu L, Yu J, Wu J, Zhang X, He J, Zhang J (2016) Understanding cellulose dissolution: effect of the cation and anion structure of ionic liquids on the solubility of cellulose. SCIENCE CHINA Chem 59:1421-1429

Zhang J, Wu J, Yu J, Zhang X, He J, Zhang J (2017a) Application of ionic liquids for dissolving cellulose and fabricating cellulose-based materials: state of the art and future trends. Materials Chemistry Frontiers 1:1273-1290

Zhang Z, Nie Y, Zhang Q, Liu X, Tu W, Zhang X, Zhang S (2017b) Quantitative change in disulfide bonds and microstructure variation of regenerated wool keratin from various ionic liquids. ACS Sustainable Chemistry \& Engineering 5:2614-2622

Zhang S et al (2018) Regenerated cellulose by the lyocell process, a brief review of the process and properties. BioResources 13:4577-4592

Zhang J, Yamagishi N, Gotoh Y (2019b) Facilitated fibrillation of regenerated cellulose fibers by immiscible polymer blending using an ionic liquid. Cellulose 26:889-902
Zhang X et al (2019d) Aligned electrospun cellulose scaffolds coated with rhBMP-2 for both in vitro and in vivo bone tissue engineering. Carbohyd Polym 213:27-38

Zhang J, Kitayama H, Gotoh Y, Potthast A, Rosenau T (2019a) Non-woven fabrics of fine regenerated cellulose fibers prepared from ionic-liquid solution via wet type solution blow spinning. Carbohydrate polymers 226:115258

Zhang K, Barhoum A, Xiaoqing C, Li H, Samyn P (2019c) Cellulose Nanofibers: Fabrication and Surface Functionalization Techniques BT - Handbook of Nanofibers. In: Barhoum A, Bechelany M, Makhlouf ASH (eds). Springer International Publishing, Cham, pp 409-449. doi:https://doi.org/10.1007/978-3-319-53655-2_58

Zhao H, Baker GA, Song Z, Olubajo O, Crittle T, Peters D (2008) Designing enzyme-compatible ionic liquids that can dissolve carbohydrates. Green Chem 10:696-705

Zhao D, Liao Y, Zhang Z (2007) Toxicity of ionic liquids. Clean-soil, air, water 35:42-48

Zheng Y, Miao J, Maeda N, Frey D, Linhardt RJ, Simmons TJ (2014) Uniform nanoparticle coating of cellulose fibers during wet electrospinning. J Mater Chem A 2:1502915034. https://doi.org/10.1039/c4ta03221g

Zheng S, Nie Y, Zhang S, Zhang X, Wang L (2015) Highly efficient dissolution of wool keratin by dimethylphosphate ionic liquids. ACS Sustain Chem \& Eng 3:2925-2932

Zheng Y, Cai C, Zhang F, Monty J, Linhardt RJ, Simmons TJ (2016) Can natural fibers be a silver bullet? Antibacterial cellulose fibers through the covalent bonding of silver nanoparticles to electrospun fibers. Nanotechnology 27:55102-55102. https://doi.org/10.1088/0957-4484/ 27/5/055102

Zheng B, Harris C, Bhatia SR, Thomas MF (2019) Dissolution capacity and rheology of cellulose in ionic liquids composed of imidazolium cation and phosphate anions. Polym Adv Technol 30:1751-1758

Zhijiang C, Ping X, Shiqi H, Cong Z (2019) Soy protein nanoparticles modified bacterial cellulose electrospun nanofiber membrane scaffold by ultrasound-induced selfassembly technique: characterization and cytocompatibility. Cellulose 26:6133-6150

Zhu S et al (2006) Dissolution of cellulose with ionic liquids and its application: a mini-review. Green Chem $8: 325-327$

Zhu C, Chen J, Koziol K, Gilman J, Trulove P, Rahatekar S (2014) Effect of fibre spinning conditions on the electrical properties of cellulose and carbon nanotube composite fibres spun using ionic liquid as a benign solvent. Express Polym Lett 8(3):154-164

Zhu $\mathrm{C}$ et al (2016) High modulus regenerated cellulose fibers spun from a low molecular weight microcrystalline cellulose solution. Acs Sustain Chem \& Eng 4:4545-4553

Zhu C, Koutsomitopoulou AF, Eichhorn SJ, van Duijneveldt JS, Richardson RM, Nigmatullin R, Potter KD (2018) High stiffness cellulose fibers from low molecular weight microcrystalline cellulose solutions using DMSO as Co-solvent with ionic liquid. Macromol Mater Eng 303:1800029 
Zugenmaier P (2009) Contribution to the historical development of macromolecular chemistry-exemplified on cellulose. Cellul Chem Technol 43:351

Zweckmair T, Hettegger H, Abushammala H, Bacher M, Potthast A, Laborie M-P, Rosenau T (2015) On the mechanism of the unwanted acetylation of polysaccharides by 1, 3-dialkylimidazolium acetate ionic liquids: Part
1-Analysis, acetylating agent, influence of water, and mechanistic considerations. Cellulose 22:3583-3596

Publisher's Note Springer Nature remains neutral with regard to jurisdictional claims in published maps and institutional affiliations. 